\title{
Reversible protein acetylation in the regulation of mammalian hibernation
}

\author{
By \\ Andrew N. Rouble \\ BSc. Carleton University, 2012
}

A Thesis Submitted to the Faculty of Graduate Studies and Research in partial fulfillment of the requirements for the degree of

Master of Science

Department of Biology

Carleton University

Ottawa, Ontario, Canada

(C) 2014

Andrew N. Rouble 
The undersigned hereby recommend to the Faculty of Graduate Studies and Research acceptance of this thesis

\title{
Reversible protein acetylation in the regulation of mammalian hibernation
}

\author{
submitted by \\ Andrew N Rouble \\ in partial fulfillment of the requirements for the degree of Master of Science \\ Chair, Department of Biology \\ Thesis Supervisor \\ Carleton University
}




\begin{abstract}
$\underline{\text { Abstract }}$
To survive the winter, many small mammals use hibernation. Employing a remarkable strategy of metabolic rate depression these animals accrue profound energy savings by remaining in a torpid state over most of the winter. Global metabolic suppression is mediated by intricate molecular mechanisms, including the post-translational modification of cellular proteins. One such modification - reversible protein acetylation is an important regulator of metabolism, but little is known about its relevance to hibernation. This thesis provides an initial characterization of possible functions of reversible protein acetylation, and several enzymes that mediate the process (protein lysine acetyltransferases (KATs) and deacetylases (SIRTs)), in the context of a rodent model of mammalian hibernation, the thirteen-lined ground squirrel, Ictidomys tridecemlineatus. Notably, SIRT and KAT protein expression and activities increased in skeletal muscle and brown adipose tissue, respectively, during torpor, in correlation with fluctuations in downstream target acetylation. Such changes identify roles for protein acetylation during hibernation.
\end{abstract}




\section{Acknowledgements}

I would like to first thank Dr. Ken Storey (surprising, right?) for his mentorship and imparted wisdom over the past 5 years. Not only have you helped me on my journey to become a better scientist, but you have also helped me grow as a rational-thinking human being. Your lessons in common sense and logic have taught me much about myself, and will forever aid me along whatever path I decide to pursue in life. Never has someone called me an idiot more frequently - and never have I appreciated it more.

My thanks also go out to Jan Storey for her indispensable help revising this glorifiedpaper-weight of a thesis, in addition to every other scientific document I have ever written. Your helpful comments and wisdom have made me a better writer and editor. Not to mention, your extensive revisions have given me the most valuable skill a writer can have - a professional proficiency with Microsoft Word's "Track Changes" function (because there have been oh-so-many changes to track...).

I must also thank my mentor and colleague Shannon N Tessier. Your experience, guidance, and caring nature have helped me along my scientific journey more than you could know. Also, you know, we rock at writing papers together. Remember that when you become rich and famous.

Finally, I would like to thank my fellow fools at Sock ' $n$ ' Buskin Theatre Company (Carleton University's student-run theatre company). Even though you will never read this, your spirit is contained within these pages. While writing this kindling, you helped keep me sane, and ensured that I maintained a balanced perspective of life. Most importantly, you constantly reminded me of Shakespeare's wise words which every scientist should remember:

"The fool doth think he is wise, but the wise man knows himself to be a fool". 


\section{Table of Contents}

Title Page

Abstract

Acknowledgements

Table of Contents

List of Abbreviations

List of Figures

List of Appendices

Chapter 1

Chapter 2

Chapter 3

Chapter 4

Chapter 5

References

Appendices
General Introduction 1

General Materials and Methods

Roles for KAT acetyltransferases in the 28 regulation of transcriptional control and metabolic depression during mammalian hibernation

Responses of the SIRT family of $\mathrm{NAD}^{+}$50 dependent protein deacetylases in tissues of ground squirrels during hibernation

General Discussion 


\section{List of Abbreviations}

ANOVA Analysis of variance

APS Ammonium persulfate

ATP Adenosine triphosphate

BAT Brown adipose tissue

CBP CREB-binding protein

CoA Coenzyme-A

DNA Deoxyribonucleic acid

DTT Dithiothreitol

EA Early arousal

EC Euthermic in the cold room

EDTA Ethylenediamine tetraacetic acid

EN Entrance to torpor

ET Early torpor

FABP Fatty acid binding protein

FOXO1 Forkhead box, class O-1

GAPDH Glyceraldehyde-3-phosphate dehydrogenase

GCN5L2 General control of amino acid synthesis yeast homolog-like 2

GDP Guanosine diphosphate

HAT1 Histone acetyltransferase 1

HDAC Histone deacetylase

HEPES 4-(2-hydroxyethyl)-1-piperazineethanesulfonic acid

HRP Horse radish peroxidase 


\begin{tabular}{|c|c|}
\hline HST & Homologue of SIR2 \\
\hline IA & Interbout arousal \\
\hline IкB & Inhibitor of $\kappa \mathrm{B}$ \\
\hline KAT & Protein lysine acetyltransferase \\
\hline LDH & Lactate dehydrogenase \\
\hline LIV & Liver \\
\hline $\mathbf{L T}$ & Late torpor \\
\hline mRNA & Messenger ribonucleic acid \\
\hline MUS & Muscle \\
\hline NAD & Nicotinamide adenine dinucleotide \\
\hline NF-кB & Nuclear factor kappa-B \\
\hline PCAF & p300/CBP-associated factor \\
\hline PGC-1 $\alpha$ & PPAR $\gamma$ coactivator 1-alpha \\
\hline PKA & Protein kinase $\mathrm{A}$ \\
\hline PMSF & Phenylmethylsulfonyl fluoride \\
\hline PPAR $\gamma$ & Peroxisome proliferator-activated receptor gamma \\
\hline PVA & Polyvinyl alcohol \\
\hline ROS & Reactive oxygen species \\
\hline RPP & Reversible protein phosphorylation \\
\hline SDS & Sodium dodecyl sulfate \\
\hline SIR2 & Silent information regulator 2 \\
\hline SIRT & Sirtuin \\
\hline SOD2 & Superoxide dismutase- 2 \\
\hline
\end{tabular}


TBST Tris-Buffered Saline with Tween 20

TCA Tricarboxylic acid

TEMED Tetramethylethylenediamine

Tris Tris(hydroxymethyl)aminomethane

TSA Trichostatin-A

UCP1 Uncoupling protein-1

WAT White adipose tissue 


\section{List of Figures}

Fig. 1.1 Schematic representation of a single torpor-arousal cycle within the context of seasonal hibernation.

Fig. 1.2 Simplified representation of the protein lysine acetylation and deacetylation reactions.

Fig. 3.1 Relative protein expression of CBP, PCAF, GCN5L2 and HAT1 in liver of $I$. tridecemlineatus over the torpor-arousal cycle.

Fig. 3.2 Relative protein expression of CBP, PCAF, GCN5L2 and HAT1 in skeletal muscle of I. tridecemlineatus over the torpor-arousal cycle.

Fig. 3.3 Relative protein expression of CBP, PCAF, GCN5L2 and HAT1 in BAT of I. tridecemlineatus over the torpor-arousal cycle.

Fig. 3.4 Relative protein expression of CBP, PCAF, GCN5L2 and HAT1 in WAT of I. tridecemlineatus over the torpor-arousal cycle.

Fig. 3.5 Total HAT activity in liver and muscle of $I$. tridecemlineatus comparing euthermic control (EC) and late torpor (LT) points of the torpor-arousal cycle.

Fig. 3.6 Total HAT activity in BAT and WAT of I. tridecemlineatus comparing euthermic control (EC) and late torpor (LT) points of the torpor-arousal cycle.

Fig. 3.7 Relative protein expression of histone $\mathrm{H} 3$ acetylated at lysine 9 in liver, skeletal muscle, BAT and WAT of I. tridecemlineatus over the torpor-arousal cycle.

Fig. 3.8 Relative protein expression of histone $\mathrm{H} 3$ acetylated at lysine 14 in BAT of I. tridecemlineatus over the torpor-arousal cycle. 
Fig. 4.1 Relative protein expression of SIRT1, SIRT2, SIRT3, 68 SIRT4, SIRT5, SIRT6 and SIRT7in skeletalmuscle of I. tridecemlineatus over the torpor-arousal cycle.

Fig. 4.2 Relative protein expression of SIRT1, SIRT2, SIRT3, SIRT4, SIRT5, SIRT6 and SIRT7 in WAT of I. tridecemlineatus over the torpor-arousal cycle.

Fig. 4.3 Total SIRT activity in liver of I. tridecemlineatus comparing euthermic control (EC) and late torpor (LT) points of the torpor-arousal cycle with assays at two temperatures, $37^{\circ} \mathrm{C}$ and $4^{\circ} \mathrm{C}$.

Fig. 4.4 Total SIRT activity in muscle of I. tridecemlineatus comparing euthermic control (EC) and late torpor (LT) points of the torpor-arousal cycle with assays at two temperatures, $37^{\circ} \mathrm{C}$ and $4^{\circ} \mathrm{C}$.

Fig. 4.5 Total SIRT activity in BAT and WAT of I. tridecemlineatus comparing euthermic control (EC) and late torpor (LT) points of the torpor-arousal cycle with assays at two temperatures, $37^{\circ} \mathrm{C}$ and $4^{\circ} \mathrm{C}$.

Fig. 4.6 Relative protein expression of SOD2 acetylated at lysine 68 in liver, muscle, BAT and WAT of I. tridecemlineatus over the torpor-arousal cycle.

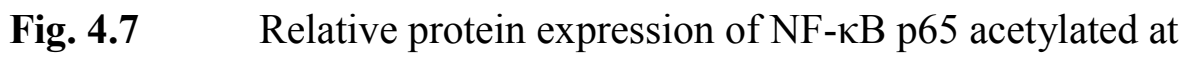
lysine 310 in liver, muscle, BAT and WAT of I. tridecemlineatus over the torpor-arousal cycle. 


\section{$\underline{\text { List of Appendices }}$}

Appendix A Antibodies Used for Western Blotting 95

Appendix B Western Blotting Conditions 96

$\begin{array}{lll}\text { Appendix C } & \text { Validation of Commercial Activity Assays } & 98\end{array}$

$\begin{array}{lll}\text { Appendix D } \quad \text { Data Collected External to Thesis } & 100\end{array}$

$\begin{array}{lll}\text { Appendix E } & \text { Loading Controls for Western Blotting }\end{array}$

Appendix F Mechanistic Details for Commercial Activity Assays 104

Appendix G Justification of Tissue and Target Choices 106

Appendix H Methods for the Measurement of Cellular Oxidative 108

Damage 
Chapter 1

\section{General Introduction}


Under conditions of severe environmental stress, many organisms within the animal kingdom enable their survival by employing the strategy of metabolic rate depression, a systemic reduction in cellular and metabolic processes (Storey, 2010). By entering torpor - a state of reduced energy expenditure and biological function - such animals may endure external pressures such as exposure to extremes of cold, drought, anoxia, and limited access to food resources, allowing a subsequent return to normal activity once the period of stress has subsided (Storey, 2010). One form of hypometabolism is mammalian hibernation, which is a seasonal phenomenon characterized by prolonged bouts (days to weeks) of metabolic depression interspersed with brief (hours to a day) periods of arousal (Fig. 1.1), when cellular metabolism temporarily returns to normal levels (Carey et al., 2003). During the periods of sustained deep torpor, metabolic rate may plummet to $2-4 \%$ of euthermic values, a remarkable shift which is promoted by equally drastic physiological changes that enable such a dramatic reduction in energy use (Carey et al., 2003). For example, among these major shifts in ground squirrels are reductions in heart rate (from $350-400$ beats/min to as low as $5-10$ beats/min), breathing rate (from greater than 40 breaths/min to as little as less than 1 breath $/ \mathrm{min}$ ), and organ perfusion rates (to below $10 \%$ of euthermic values), in addition to a remarkable decrease in core body temperature from a euthermic $35-38^{\circ} \mathrm{C}$ to nearambient temperatures during deep torpor, which may be less than $5^{\circ} \mathrm{C}$ (Carey et al., 2003). The energy economy of the hibernator also undergoes drastic changes during torpor, whereby a shift from carbohydrate pathways of energy production to those fueled by lipid catabolism and fatty acid oxidation is promoted (Carey et al., 2003). Indeed, during the summer months leading up to the hibernation season, these animals 
accumulate large internal energy stores in the form of lipid deposits in white adipose tissue (WAT), in order to sustain their physiological needs during the period of inactivity (Dark, 2005). The increased production and mobilization of ketone bodies by the liver is thus essential at this time (Andrews et al., 2009), as is the upregulation of lipolysis in WAT and the enhanced expression of fatty-acid binding proteins and lipid-processing enzymes in the peripheral tissues (Eddy and Storey, 2004; Storey and Storey, 2010). In contrast to the state of reduced energy expenditure, the intermittent periods of arousal that are interspersed throughout hibernation are characterized by a reversal of the aforementioned changes. During these brief periods, enormous increases in oxygen consumption and fatty acid oxidation fuel massive thermogenesis from uncoupled respiration in the specialized mitochondria of brown adipose tissue, as well as shivering thermogenesis in skeletal muscle (albeit to a lesser extent). These energy-intensive processes promote the return of body temperature to euthermic levels and subsequently re-establish the essential physiological functions that were previously depressed (Carey et al., 2003). In this way, the hibernator's metabolic rate and physiological activities are subject to rapid and drastic regulation to an extent that is uncommon in animals that do not use torpor as a response to the burdens of severe environmental stress. In addition to this strict regulation of metabolism, hibernators also employ many protective strategies to mitigate the cellular damage that would otherwise occur under such stressful conditions. Indeed, these animals endure little to no damage to their tissues despite prolonged periods of cellular inactivity and exposure to the production of high levels of reactive oxygen species that occurs as a result of the sharp increases in oxygen consumption during arousal (Storey, 2010). Examples of these protective strategies include the active 
regulation of antioxidant defenses (increased antioxidant capacity and antioxidant enzyme expression) (Morin and Storey, 2007; Eddy et al., 2005; Storey, 2005; Allan and Storey, 2012; Vucetic et al., 2013; James et al., 2013), pro-survival signals (e.g. antiapoptotic protein expression) (Rouble et al., 2013), transcription factors and genes associated with muscle performance (Tessier and Storey, 2010), and heat shock proteins (Storey and Storey, 2011), each ultimately contributing to the maintenance of cellular integrity during the stressful transitions to and from the hibernation state. Because of this capacity to circumvent the harmful repercussions of enduring torpor, and due to their remarkable ability to rapidly and effectively modulate their metabolic processes and energy requirements, hibernators have become a very interesting subject for studies of metabolic disorders and stress-related cellular damage and are proving to be useful models for conditions such as diabetes, obesity, and aging (Wu et al., 2013).

The drastic reductions in biological function that occur over the course of hibernation are controlled at the molecular level by mechanisms that promote a nearly universal cessation of gene expression via global reductions in gene transcription and mRNA translation. Over this background of global suppression, however, is the upregulation of a small number of genes that are essential to the control of the transitions between euthermia and torpor, and which allow the hibernator to maintain the integrity of its cells while in the metabolically depressed state (as described above). The control of this simultaneous wide-scale gene suppression and concurrent upregulation of selected biological pathways is governed in many instances by the post-translational modification of downstream protein effectors that regulate most cell functions. For instance, the modification of transcription factors (causing increases/decreases in their activity or 
DNA-binding capabilities), histones (leading to enhanced/lowered accessibility of transcriptional machinery to chromatin), and metabolic enzymes (resulting in an increase/decrease in their activity) may contribute to either reductions in global gene expression or an enhancement of the activities of specific pathways (Morin and Storey, 2006; Malatesta et al., 2008; Storey, 2010). Of such modifications, reversible protein phosphorylation (RPP) has been shown to be an especially critical regulator of global metabolic suppression in nearly all models of hypometabolism (Storey, 2010). Indeed, RPP is responsible for suppressing numerous ATP-expensive processes during hibernation via the direct modification of the associated proteins. For example, the activities of $\mathrm{Na}^{+} \mathrm{K}^{+}$-ATPase and sarcoplasmic reticulum $\mathrm{Ca}^{2+}$-ATPase membrane ion pumps (which require large amounts of energy in the form of ATP to move ions against their concentration gradients) are drastically reduced in hibernator tissues during torpor by the reversible phosphorylation of the enzymes (Storey and Storey 2004). Likewise, the aforementioned reductions in protein translation during hibernation are also achieved in part by the phosphorylation and deactivation of ribosomal initiation and elongation factors (Frerichs et al., 1998). The activities of key enzymes involved in carbohydrate metabolism, including hexokinase, glycogen phosphorylase, and pyruvate dehydrogenase, are also significantly suppressed in the hibernating mammal by differential phosphorylation, functioning to reduce levels of glycolysis and thereby promoting the shift to a lipid-based energy-economy (Storey, 2010; Storey and Storey, 2004). Epigenetic controls - changes in gene expression that are mediated by mechanisms that do not affect the underlying DNA sequence - also involve RPP. For example, histone modifications that cause conformational changes to the protein-DNA 
complexes of nucleosomes, leading to either the increased or decreased accessibility of transcriptional machinery to affected promoter regions, is a widely-studied form of epigenetic regulation. Dephosphorylation of histone residues leads to an inactive chromatin conformation which results in decreased levels of transcription (Morin and Storey, 2009). In the hibernator, reduced phosphorylation of histone H3 (Ser 10) has been shown to occur during torpor, and likely contributes to the global suppression of transcription at this time (Morin and Storey, 2006). Thus, RPP is an indispensable tool used by these animals to control many of the remarkable changes that enable them to transition to and from the hypometabolic state.

While much of the current research regarding the post-translational modification of proteins in the hibernator system has focused on RPP and the enzymes (protein kinases and phosphatases) which mediate the process, the roles of other types of protein covalent modifications and protein-modifying enzymes have not been as extensively characterized in this context (Morin and Storey, 2009). One such type of modification that has been a focus of much research in non-hibernating systems of metabolic regulation is that of reversible protein acetylation. In this process, an acetyl moiety $\left(\mathrm{COCH}_{3}\right)$ is covalently bound to a lysine residue of the target protein, thereby neutralizing its positive charge and changing its intermolecular interactions (Fig. 1.2). The extensive role that protein acetylation plays in mammalian cells has only been recently demonstrated. Over 2000 acetylated proteins have now been identified in mammals, making this mechanism comparable in scale to other forms of posttranslational modification such as phosphorylation and ubiquitylation (Choudhary and Mann, 2010). In fact, not only is reversible acetylation comparable to RPP in terms of the number of proteins targeted by 
the modification, it also serves similar - and in some cases, complimentary - functions to its phosphorylation counterpart (Xiong and Guan, 2012). For instance, much like RPP, reversible acetylation can influence enzyme activity and protein function by numerous mechanisms. By neutralizing the positive charge of lysine residues found within active/binding sites, acetylation may reduce the affinity of interactions with negatively charged substrate groups, thereby affecting enzyme activity or other protein-substrate interactions (Xiong and Guan, 2012). Indeed, the activity of acetyl-CoA synthetase, the enzyme responsible for the synthesis of the metabolic intermediate acetyl-CoA from acetate and coenzyme-A (CoA) is thought to be regulated by this mechanism. Acetylation of a highly conserved lysine residue located in the enzyme's active site reduces its activity, likely due to the neutralization of the lysine's positive charge and its interaction with its negatively charged acetate substrate (Xiong and Guan, 2012). Like RPP, lysine acetylation may also cause conformational changes in a protein's active site, leading to the repositioning of catalytically active residues or increased/decreased physical accessibility for substrate binding (Xiong and Guan, 2012). Similarly, the addition of an acetyl group to a lysine residue may physically prevent the binding of a substrate or allosteric regulator by directly blocking the associated interaction (Xiong and Guan, 2012). Furthermore, acetylation can also affect protein activity indirectly by controlling subcellular localization (Xiong and Guan, 2012). For example, the acetylation of glyceraldehyde-3-phosphate dehydrogenase (GAPDH, a glycolytic enzyme) appears to promote its accumulation in the nucleus, leading to increased nuclear GAPDH activity that serves various roles in transcriptional regulation and DNA repair (Ventura et al., 2010; Xiong and Guan, 2012). Protein stability can also be affected by acetylation. 
Among other examples (Xiong and Guan, 2012), the stability of phosphoenolpyruvate carboxykinase (the rate-limiting enzyme in gluconeogenesis) is reduced in response to high glucose via the acetylation-stimulated recruitment of an E3 ubiquitin ligase (ubiquitylation targets the protein for eventual proteasomal degradation) (Zhao et al., 2010; Jiang et al., 2011). Interestingly, and perhaps most indicative of its intricate role in the cell, reversible acetylation is also known to affect the status of other post-translational modifications (Xiong and Guan, 2012). For instance, acetylation-mediated proteasomal degradation of certain proteins relies upon the absence of acetylation on specific lysine residues; in the presence of acetyl-lysine, these proteins are not ubiquitylated, while their deacetylation promotes ubiquitin addition and subsequent degradation (Yu et al., 2012; Xiong and Guan, 2012). This correlation is hypothesized to be due to competition for the same modification site (Yu et al., 2012). Interactions are also seen between acetylation and phosphorylation, whereby a protein's acetylation status may affect its phosphorylation, and vice-versa (Xiong and Guan, 2012; Lee et al., 2010). An example of this occurs with the enzyme glycogen phosphorylase (one of the carbohydratemetabolism enzymes inactivated by dephosphorylation during hibernation, as mentioned above). Acetylation of the enzyme at lysine 470 enhances the recruitment of a phosphatase that facilitates the subsequent dephosphorylation and inactivation of glycogen phosphorylase (Zhang et al., 2012). Similar phenomena are also apparent in an epigenetic context. Like phosphorylation, histone acetylation affects the structure of chromatin, whereby lysine acetylation of histone tails generally leads to a transcriptionally-active "relaxed" conformation, and deacetylation promotes a transcriptionally-silent "closed" conformation (Zentner and Henikoff, 2013). It has been 
shown that histone acetylation and phosphorylation interact dynamically within the context of a greater "histone code" (i.e. the synergistic effects of all histone modifications on gene expression). For example, phosphorylation of histone $\mathrm{H} 3$ on serine 10 promotes the acetylation of $\mathrm{H} 3$ at lysine 14 by the enhanced recruitment of an acetyltransferase (Cheung et al., 2000), in addition to other interactions involving these and other histone modifications (Lee et al., 2010).

The diverse presence of lysine acetylation - and its analogous functions to RPP suggests fundamental roles for this post-translational modification in the regulation of cellular processes. Indeed, reversible acetylation has been demonstrated to serve important functions in chromosomal remodelling, transcriptional regulation, and the control of many different metabolic pathways (Xiong and Guan, 2012; Guan and Xiong, 2011). In fact, almost every enzyme involved in glycolysis, gluconeogenesis, fatty acid oxidation, the TCA cycle, nitrogen metabolism, and glycogen metabolism, in addition to many of the transcription factors that regulate these processes, are known to be acetylated in vivo (Zhao et al., 2010; Li and Kazgan, 2011), suggesting an especially important role for this post-translational modification in the context of metabolic regulation. For this reason, the enzymes responsible for the catalysis of reversible acetylation have become an important topic of research for studies of metabolic homeostasis, especially those related to the pathological dysregulation of metabolic processes (Guan and Xiong, 2011).

The dynamic process of reversible acetylation is mediated by the antagonistic actions of protein lysine acetyltransferases (KATs) and histone deacetylases (HDACs). KATs, the enzymes which catalyze the transfer of an acetyl group from acetyl-CoA to a substrate lysine residue, constitute a diverse class of enzymes that are grouped according 
to their sequence similarities and catalytic domains (Lee and Workman, 2007; Sterner and Berger, 2000). The most well-studied KATs, including CREB-binding protein (CBP), p300/CBP-associated factor (PCAF), general control of amino acid synthesis yeast homolog-like 2 (GCN5L2), and histone acetyltransferase 1 (HAT1), span several different families of proteins, but are related by their conserved acetyltransferase activity and similar regulatory functions (Lee and Workman, 2007). KATs are found in multiple subcellular compartments (nucleus, cytoplasm, mitochondria) and thus target a wide range of proteins that are involved in diverse cellular functions (Roth et al., 2001; Scott et al., 2012). The opposing HDACs - referred to as histone deacetylases for their initial characterization as modifiers of histone proteins - comprise those enzymes that function to remove an acetyl group from lysine residues of their protein substrates. These enzymes are divided into four classes (I-IV) based on sequence homology, with certain classes sharing more similar functional characteristics than others (De Ruijter et al., 2003; Guan and Xiong, 2011). In mammals, Class I and II HDACs (comprising HDACs 1-10, and typically referred to as the "classical" HDACs) are more strongly implicated as epigenetic regulators of gene expression, and are differentiated by their ability to be inhibited by the compound trichostatin-A (TSA) (De Ruijter et al., 2003). In contrast, Class III HDACs (known as sirtuins (SIRTs), with seven members in mammals), while known to serve distinct epigenetic functions, are more recently understood to be major regulators of metabolic homeostasis and other important cellular pathways, and are not inhibited by TSA (Schwer and Verdin 2008; Guan and Xiong, 2011). The single Class IV HDAC (HDAC11), however, serves similar functions to its Class I and II counterparts, but is not inhibited by TSA (De Ruijter et al., 2003; Guan and Xiong, 2011). Much like 
KATs, HDACs are found throughout the cell, with specific members localized in the nucleus, cytoplasm, and mitochondria, and others that travel between subcellular compartments (De Ruijter et al., 2003). As mentioned, the opposing actions of KATs and HDACs constitute a dynamic and intricate mechanism of protein regulation that is proven to serve numerous roles in the regulation of transcription, stress responses, and overall metabolic homeostasis. Taken with their remarkable conservation throughout evolution (with HDAC and KAT homologs occurring from bacteria to humans) (Lee and Workman, 2007; Smith et al., 2000), these functions underscore an essential role for KATs and HDACs in the maintenance of normal cellular function.

Given the known importance of RPP in the regulation of the remarkable metabolic fluctuations that occur during hibernation, and considering that reversible acetylation mediates control over many of the same pathways in non-hibernating systems (either separately from RPP or in a complimentary manner), an intriguing question presents itself. Does reversible protein acetylation contribute to the facilitation of metabolic rate depression in the context of mammalian hibernation? Based on the established ubiquity of acetylation as a modification of many metabolically-relevant proteins, the answer to this question is most likely yes. Indeed, it appears that many of the enzymes that are differentially phosphorylated during hibernation are also known targets of acetylation, and the regulation of many cellular protective pathways relevant to hibernators are known to be mediated by the actions of KATs and HDACs (Storey 2010; Guan and Xiong, 2011; Haigis and Sinclair, 2010). Evidence also exists to suggest a role for histone deacetylation as a mechanism of global transcriptional suppression during torpor (Morin and Storey, 2006). Furthermore, other animal models of metabolic rate 
depression have also demonstrated a likely role for this post-translational modification in the regulation of the metabolic suppression. For example, increased HDAC activity and histone deacetylation is characteristic of anoxia tolerance in turtles (Trachemys scripta elegans) exposed to 20h of oxygen deprivation (Krivoruchko and Storey, 2010).

Reduced acetylation of the metabolic enzyme lactate dehydrogenase (LDH) in an anoxiatolerant marine invertebrate (the intertidal snail Littorina littorea) also occurred during anoxic exposure concurrent with reduced LDH activity (Shahriari et al., 2013). Thus, it seems likely that the differential acetylation of certain proteins, and perhaps the differential expression/activity of the KATs and HDACs that mediate the reversible protein acetylation, may be characteristic of the hibernation phenotype. The hypothesis for this thesis is derived from this possibility.

\section{Hypothesis:}

The molecular regulation of mammalian hibernation involves reversible protein acetylation and changes to the expression and/or activity of the enzymes that mediate the process.

To address this hypothesis, this thesis characterizes the expression and activities of KATs and HDACs and selected targets of these enzymes in tissues of a well-studied model of mammalian hibernation, the thirteen-lined ground squirrel (Ictidomys tridecemlineatus), tracing their responses over the torpor-arousal cycle.

\section{Specific hypothesis 1:}


KATs will be differentially expressed throughout hibernation, their activity will fluctuate during torpor, and the acetylation status of their downstream histone targets will change accordingly.

Chapter 3 focuses on the expression of several of the most highly characterized KATs (CBP, GCN5L2, PCAF and HAT1), the overall activity of KAT enzymes, and the acetylation status of two of their downstream histone targets (histone H3K9 and H3K14), over the course of the torpor-arousal cycle in four tissues (liver, skeletal muscle, brown adipose and white adipose) of $I$. tridecemlineatus.

\section{Specific hypothesis 2:}

\section{SIRTs will be differentially expressed throughout hibernation, their activity} will fluctuate during torpor, and the acetylation status of their downstream protein targets will change accordingly.

To address the other side of reversible acetylation, Chapter 4 focuses on the expression of Class III HDACs (the sirtuins or SIRTs), whose deacetylation activity is most strongly implicated in the regulation of metabolism and cellular protective responses. The expression and total activity of the seven mammalian SIRTs is assessed in the aforementioned tissues throughout hibernation, in addition to the acetylation status of

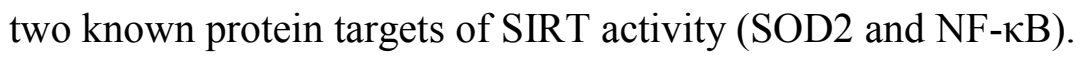

By characterizing some of the main factors that regulate the process, this thesis provides an important starting point for understanding the role of differential protein acetylation in the context of mammalian hibernation. The studies described herein further illustrate the conserved nature of reversible acetylation and thus its widespread 
importance to both fundamental cellular biology and extreme examples of metabolic regulation. 


\section{Figures}

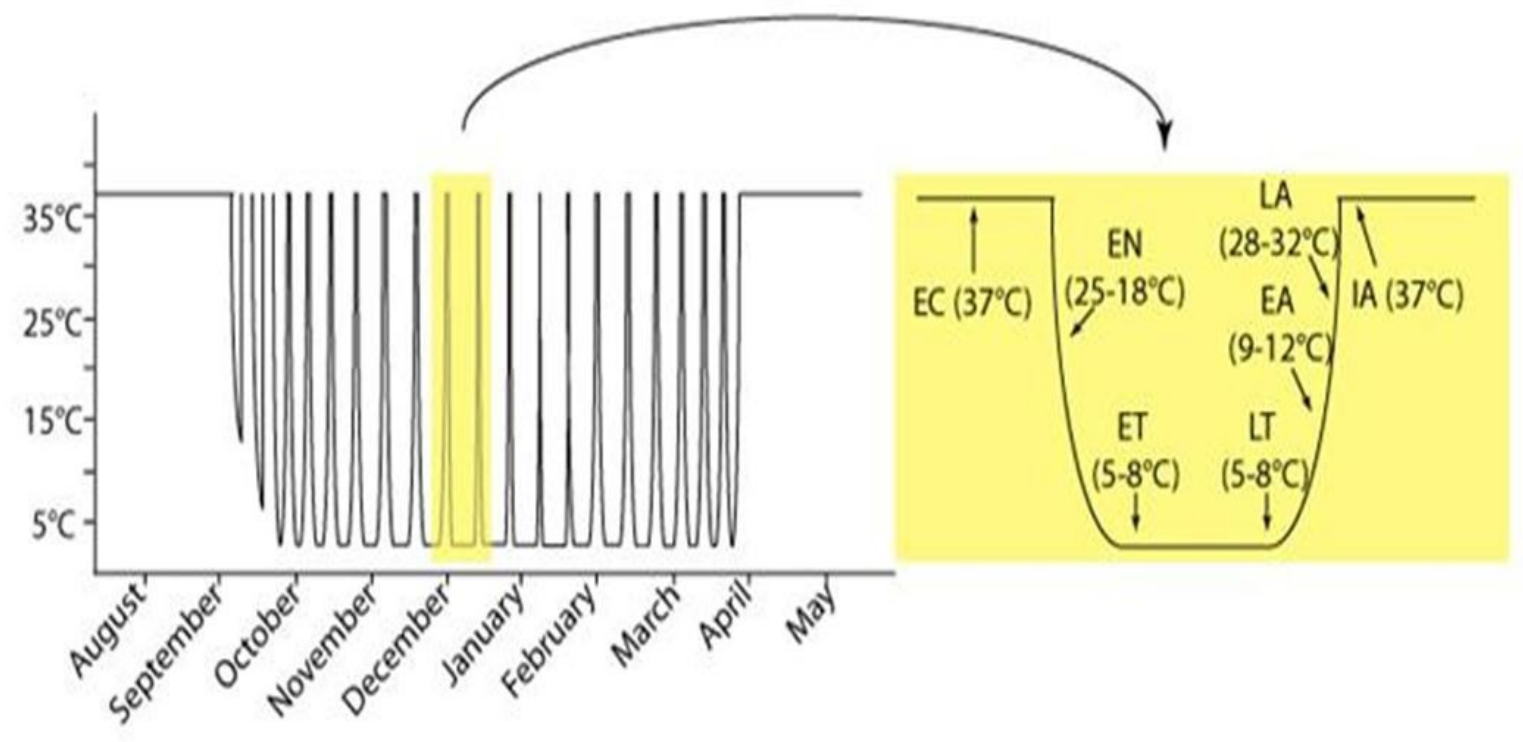

Fig. 1.1. Schematic representation of a single torpor-arousal cycle (inset) within the context of seasonal hibernation (September-April). Inset: the graph depicts the fluctuations in body temperature typically experienced by these animals during the hibernation bout. EC: Euthermic; EN: Entrance to torpor; ET: Early torpor; LT: Late torpor; EA: Early arousal; LA: Late arousal; IA: Interbout arousal. Figure adapted from Carey et al., 2003. 
A)

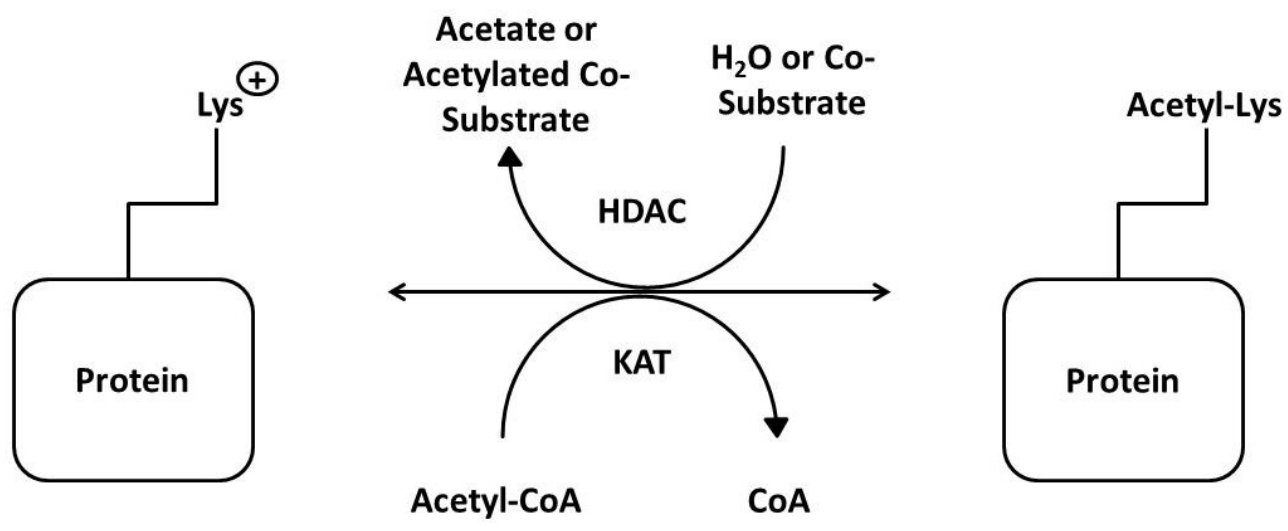

B)

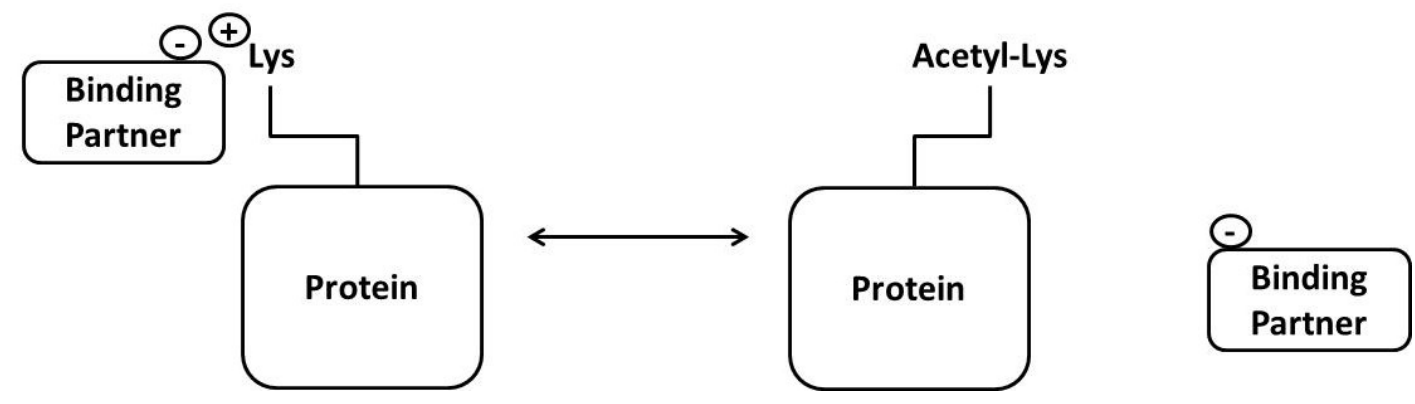

Fig. 1.2. (A) Simplified representation of the protein lysine acetylation and deacetylation reactions. A positively charged lysine residue of a protein substrate is neutralized by the protein lysine acetyltransferase (KAT)-catalyzed addition of an acetyl group from acetyl$\mathrm{CoA}$ to the $\varepsilon$-amino terminus of the lysine. The reverse reaction is catalyzed by histone deacetylases (HDACs) which remove the acetyl moiety to produce acetate or an acetylated co-substrate. (B) The acetylation-mediated neutralization of the positively charged lysine residue may affect the protein's intermolecular interactions. 


\section{Chapter 2}

\section{General Materials and Methods}




\section{A.N. Rouble's Contribution Statement}

The procedures presented under the heading of "Animal Experiments" below were performed by researchers other than A.N. Rouble. All remaining techniques, data collection, and data analysis outlined under all other headings within this Chapter were performed solely by A.N. Rouble.

\section{Animal Experiments}

Thirteen-lined ground squirrels (Ictidomys tridecemlineatus), weighing 150-300 g, were wild-captured by a United States Department of Agriculture-licensed trapper (TLS Research, Bloomingdale, IL) and transported to the National Institute of Neurological Disorders and Stroke Animal Hibernation Facility (NIH, Bethesda, MD), where hibernation experiments were carried out in the laboratory of Dr. J.M. Hallenbeck. The animals were kept in individual shoebox cages at a constant ambient temperature of $21^{\circ} \mathrm{C}$. Body temperature was monitored using subcutaneously-injected sensor chips (IPTT-300; Bio Medic Data Systems) that were implanted in each squirrel while the animals were anesthetized with 5\% isofluorane. The animals were fed a standard rodent diet with water ad libitum until sufficient lipid stores were accumulated to facilitate entry into hibernation. Torpor was induced naturally by transferring the animals to a holding room in constant darkness, with an ambient temperature of $4-6^{\circ} \mathrm{C}$. The stage of the torporarousal cycle at which each individual animal was sampled was determined by monitoring of the animal's body temperature and the time at that temperature. Animals were sacrificed at various points throughout torpor-arousal cycle, and tissues were rapidly 
excised and immediately frozen in liquid nitrogen. Squirrels were sampled from the following conditions:

(1) Euthermic in the cold room (EC) - these euthermic animals had not previously entered torpor for at least 72 hours and had maintained a stable body temperature of 36$37^{\circ} \mathrm{C}$ during this time.

(2) Entrance to torpor (EN) - these animals had begun to enter torpor, and were identified by a decreasing body temperature that had lowered to $18-31^{\circ} \mathrm{C}$.

(3) Early torpor (ET) - these animals had undergone torpor for 24 hours, indicated by a stable body temperature of $5-8^{\circ} \mathrm{C}$ for the 24 hour period.

(4) Late torpor (LT) - these animals had remained in the deep torpor phase of the hibernation bout for at least 120 hours ( 5 days), indicated by a stable body temperature of $5-8^{\circ} \mathrm{C}$ during this period.

(5) Early arousal (EA) - these animals were characterized by a rising body temperature to $9-12^{\circ} \mathrm{C}$.

(6) Interbout arousal (IA) - these animals had naturally aroused from torpor for approximately 18 hours with a body temperature of about $37^{\circ} \mathrm{C}$.

Tissues were delivered to Carleton University on dry ice and stored in a $-80^{\circ} \mathrm{C}$ freezer.

\section{Total Protein Extraction}

Total protein extraction was performed on tissues (liver, hind leg skeletal muscle, BAT, and WAT) isolated from individual animals sampled from each of the six time points of 
the torpor-arousal cycle $(\mathrm{N}=4$ samples separately extracted from different individuals at each time point). Tissue samples were crushed under liquid nitrogen and homogenized 1:2 w/v using a Polytron P10 homogenizer in homogenizing buffer [20 mM 4-(2hydroxyethyl)-1-piperazineethanesulfonic acid (HEPES), $200 \mathrm{mM} \mathrm{NaCl}, 0.1 \mathrm{mM}$ ethylenediamine tetraacetic acid (EDTA), $10 \mathrm{mM} \mathrm{NaF}, 1 \mathrm{mM} \mathrm{Na}_{3} \mathrm{VO}_{4}, 10 \mathrm{mM} \beta$ glycerophosphate] with $1 \mathrm{mM}$ phenylmethylsulfonyl fluoride (PMSF) and $1 \mu \mathrm{L}$ of protease inhibitor cocktail (Sigma Genosys) added immediately prior to homogenization. The samples were then centrifuged at $10000 \mathrm{rpm}$ for $15 \mathrm{~min}$ at $4^{\circ} \mathrm{C}$, after which the supernatants containing soluble proteins were removed. Quantification of the protein concentration of each sample was carried out by the Coomassie blue dye-binding assay using the BioRad reagent (BioRad Laboratories, Hercules, CA) with absorbance read at $595 \mathrm{~nm}$ on a MR5000 microplate reader. Small aliquots of homogenization buffer were then added to each sample to adjust the concentration to a constant $10 \mu \mathrm{g} / \mu \mathrm{L}$. A subsequent 1:1 v/v addition of $2 X$ sodium dodecyl sulfate (SDS) loading buffer [100 mM Tris(hydroxymethyl)aminomethane (Tris)-base $\mathrm{pH} 6.8,4 \% \mathrm{w} / \mathrm{v}$ sodium dodecyl sulfate (SDS), $20 \% \mathrm{v} / \mathrm{v}$ glycerol, $0.2 \% \mathrm{w} / \mathrm{v}$ bromophenol blue, $10 \% \mathrm{v} / \mathrm{v} 2$-mercaptoethanol] to each sample achieved a final sample concentration of $5 \mu \mathrm{g} / \mu \mathrm{L}$. Samples were then heated in boiling water for $5 \mathrm{~min}$ and stored at $-20^{\circ} \mathrm{C}$.

\section{Cytoplasmic/Nuclear Protein Extraction}

Cytoplasmic and nuclear fractions of tissues (liver and muscle) were prepared for two of the time points of the torpor-arousal cycle ( $\mathrm{EC}$ and $\mathrm{LT}, \mathrm{N}=4$ samples separately extracted from different individuals at each time point). Tissue samples were homogenized using a Dounce homogenizer with 4 (liver) or 10 (muscle) piston strokes and $1 \mathrm{~mL}$ of 
homogenization buffer (10 mM HEPES pH 7.9, $10 \mathrm{mM} \mathrm{KCl,} 10 \mathrm{mM}$ EDTA, $20 \mathrm{mM} \beta$ glycerophosphate) with $10 \mu \mathrm{L}$ of $100 \mathrm{mM}$ dithiothreitol (DTT) and $10 \mu \mathrm{L}$ protease inhibitor cocktail (Bioshop) added immediately before homogenization. Samples were then centrifuged at $10000 \mathrm{rpm}$ for $10 \mathrm{~min}$ at $4^{\circ} \mathrm{C}$, and the cytoplasmic fractions (supernatants) removed. The pellets were resuspended in $75 \mu \mathrm{L}$ extraction buffer $(20 \mathrm{mM}$ HEPES pH 7.9, 400 mM NaCl, 1 mM EDTA, 10\% v/v glycerol, $20 \mathrm{mM} \beta$ glycerophosphate) with $0.75 \mu \mathrm{L}$ of $100 \mathrm{mM}$ DTT and $0.75 \mu \mathrm{L}$ protease inhibitor cocktail (Bioshop) added immediately before use. The samples were then incubated horizontally on ice while rocking for 1 hour, followed by centrifugation at $10000 \mathrm{rpm}$ for $10 \mathrm{~min}$ at $4^{\circ} \mathrm{C}$. The supernatants containing nuclear extracts were removed, and their individual protein concentrations were quantified by the Coomassie blue dye-binding assay using the BioRad reagent (BioRad Laboratories, Hercules, CA) with absorbance read at $595 \mathrm{~nm}$ on a MR5000 microplate reader. Nuclear extract purity was confirmed via SDS-PAGE followed by immunoblotting with an anti-histone H3 antibody (Cell Signalling). Extracts were stored at $-80^{\circ} \mathrm{C}$ until use or further processing with SDS loading buffer for Western Blotting (as per the method described under Total Protein Extraction, above).

\section{Western Blotting}

Western Blotting was performed using the BioRad Mini Protean III system. Equal amounts of protein from each sample $(5-60 \mu \mathrm{g}$ depending on the particular protein to be detected and the tissue used) and 3-4 $\mu \mathrm{L}$ of either PiNK Plus pre-stained protein ladder (10.5-175 kDa, FroggaBio) or BLUeye pre-stained protein ladder (11-245 kDa, FroggaBio) were loaded and separated on 6-12\% SDS-polyacrylamide gels (gel percentage acrylamide again depending on the specific protein target/tissue). SDS- 
polyacrylamide gels were a discontinuous gel system. The stacking gel $\mathrm{pH} 6.8$ was composed of $130 \mu \mathrm{L} 1.0 \mathrm{M}$ Tris- $\mathrm{HCl}, 170 \mu \mathrm{L} \mathrm{30 \%}$ acrylamide, $680 \mu \mathrm{L}$ water, $10 \mu \mathrm{L} 10 \%$ SDS, $10 \mu \mathrm{L}$ 10\% ammonium persulfate (APS), and $1 \mu \mathrm{L}$ N,N,N',N'tetramethylethylenediamine (TEMED). Conditions for a $10 \%$ resolving gel $\mathrm{pH} 8.8$ were

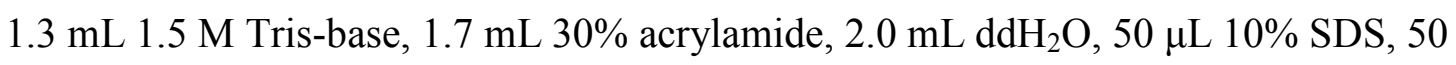
$\mu \mathrm{L} 10 \%$ APS, and $2 \mu \mathrm{L}$ TEMED. After loading protein samples, gels were run at $180 \mathrm{~V}$ for 45-120 min in running buffer that had been diluted 10-fold from the stock solution (25.5 g Tris-base, $460 \mathrm{~g}$ glycine, $25 \mathrm{~g}$ SDS, adjusted to $2.5 \mathrm{~L}$ with $\mathrm{ddH}_{2} \mathrm{O}$ ). Proteins were transferred from the SDS-polyacrylamide gel to a PVDF membrane by electroblotting at room temperature for $90-180 \mathrm{~min}$ at $160 \mathrm{~mA}$ in a transfer buffer containing $25 \mathrm{mM}$ Tris (pH 8.5), $192 \mathrm{mM}$ glycine and 10\% v/v methanol. To prevent non-specific binding of antibodies, membranes were blocked with either skim milk (2.5-5.0\%, incubated with membrane at room temperature on a rocker for 20-30 min) or polyvinyl alcohol (PVA) (1 $\mathrm{mg} / \mathrm{mL}, 30-70 \mathrm{kDA}$ PVA, incubated with membrane at room temperature on a rocker for 45-60 sec) made up in TBST (20 mM Tris-base, pH 7.6, $140 \mathrm{mM} \mathrm{NaCl,} \mathrm{0.05 \%} \mathrm{Tween-}$ 20). Blocked blots were then probed with specific primary antibodies (1:1000 to 1:12000 v/v dilution in TBST) at $4^{\circ} \mathrm{C}$ for approximately 18 hours overnight (please refer to Appendix A: Antibodies Used for Western Blotting for a list of the primary antibodies used). Subsequently, blots were washed 3 times for 10 min each with TBST, and then membranes were incubated with horse radish peroxidase (HRP)-conjugated secondary antibodies $(1: 1500$ to $1: 8000 \mathrm{v} / \mathrm{v}$ dilution in TBST) for 30-60 min at room temperature, before a final 3 washes of 10 min each with TBST. Specific protein bands were visualized by enhanced chemiluminescence $\left(\mathrm{H}_{2} \mathrm{O}_{2}\right.$ and Luminol), using the ChemiGenius 
Bio Imaging System (Syngene, Frederick, MD). Membranes were then stained with Coomassie blue $(0.25 \% \mathrm{w} / \mathrm{v}$ Coomassie brilliant blue, $7.5 \% \mathrm{v} / \mathrm{v}$ acetic acid, $50 \%$ methanol) to visualize all protein bands for standardization.

For a detailed list of the experimental conditions used for each protein target in each studied tissue, please refer to Appendix B: Western Blotting Conditions.

\section{SIRT Deacetylase Activity Assay}

SIRT activity was separately assayed at $37^{\circ} \mathrm{C}$ and $4{ }^{\circ} \mathrm{C}$ for nuclear (liver and muscle) and total (liver, muscle, brown adipose tissue, and white adipose tissue) protein extracts using the Epigenase Universal SIRT Activity/Inhibition Assay Kit from Epigentek (Farmingdale, NY), according to the manufacturer's instructions. To measure total SIRT activity, total protein extracts were prepared from tissues sampled from two of the six time points of the torpor-arousal cycle (EC and LT, N=4 independent samples from different individuals at each time point) using the procedure described previously under Total Protein Extraction, but modified such that a) the concentration of each sample was adjusted to a constant $3.25 \mu \mathrm{g} / \mu \mathrm{L}$ (liver, muscle and brown adipose tissue) or $2 \mu \mathrm{g} / \mu \mathrm{L}$ (white adipose tissue) by addition of small aliquots of SIRT assay buffer (included with the assay kit) and b) tissue extracts were not mixed with 2X SDS loading buffer. For the preparation of samples to measure nuclear SIRT activity, nuclear extracts were prepared using liver and muscle tissue as described under Cytoplasmic/Nuclear Protein Extraction above, with protein concentrations adjusted to $3.25 \mu \mathrm{g} / \mu \mathrm{L}$ by addition of small aliquots of SIRT assay buffer. 
In separate wells of the assay microplate supplied by the manufacturer, $4 \mu \mathrm{L}$ of each 3.25 or $2 \mu \mathrm{g} / \mu \mathrm{L}$ sample of total or nuclear protein extracts was added to the following reagents (all provided by the manufacturer): $46 \mu \mathrm{L}$ of SIRT assay buffer, $1 \mu \mathrm{L}$ of SIRT substrate, $1 \mu \mathrm{L}$ of HDAC inhibitor trichostatin A (TSA), and $1 \mu \mathrm{L} \mathrm{NAD}^{+}$cofactor. The microplate was then incubated for $90 \mathrm{~min}$ at $37^{\circ} \mathrm{C}$ on a shaker while covered with Parafilm, followed by washing each reaction well three times with $150 \mu \mathrm{L}$ of $1 \mathrm{X}$ wash buffer ( $\mathrm{pH} 7.39,10 \mathrm{X}$ stock solution provided by the manufacturer). A $50 \mu \mathrm{L}$ aliquot of 1:1000 capture antibody (provided by the manufacturer) was then added to each reaction well, and allowed to incubate at room temperature for $60 \mathrm{~min}$ on a shaker while covered with Parafilm. The reaction wells were then washed three times with $150 \mu \mathrm{L}$ of $1 \mathrm{X}$ wash buffer, followed by the addition of $50 \mu \mathrm{L}$ of 1:2000 detection antibody (provided by the manufacturer) and incubation at room temperature for $30 \mathrm{~min}$ on a shaker while covered with Parafilm. Each reaction well was then washed four times with $150 \mu \mathrm{L}$ of $1 \mathrm{X}$ wash buffer, followed by the addition of $100 \mu \mathrm{L}$ of developer solution (provided by the manufacturer) and incubation at room temperature for $10 \mathrm{~min}$ on a shaker away from light. A $100 \mu \mathrm{L}$ aliquot of stop solution (provided by the manufacturer) was then added to each well and allowed to incubate at room temperature for $2 \mathrm{~min}$. The absorbance of each sample was then immediately measured at $450 \mathrm{~nm}$ (reference wavelength $=655 \mathrm{~nm}$ ) using a Powerwave HT spectrophotometer (BioTek). This procedure was then repeated with the initial reaction incubated for $90 \mathrm{~min}$ at $4^{\circ} \mathrm{C}$. For each assay, three control wells containing all reaction components except the $\mathrm{NAD}^{+}$cosubstrate were also run concurrently for each tissue. The average absorbance of these 
three wells was used as the negative control absorbance for their respective tissue, as per the manufacturer's instructions.

For information regarding the validation of this activity assay (including the determination of protein load amounts, confirmation of the linear range of the assay, and confirmation of selected results), please refer to Appendix C: Validation of Commercial Activity Assays.

\section{HAT Acetyltransferase Activity Assay}

HAT activity was assayed at $37^{\circ} \mathrm{C}$ for total the protein fractions of liver, muscle, brown adipose tissue, and white adipose tissue using the EpiQuick Hat Activity/Inhibition Assay Kit from Epigentek (Farmingdale, NY), according to the manufacturer's instructions. For the preparation of samples to measure total HAT activity, total protein extraction was conducted on liver, muscle, brown adipose, and white adipose tissue samples isolated from individual animals sampled from two of the six time points of the torpor-arousal cycle (EC and LT, N=4 samples separately extracted from different individuals at each time point) using the procedure described previously under Total Protein Extraction, but modified such that a) the concentration of each sample was adjusted to a constant 4 $\mu \mathrm{g} / \mu \mathrm{L}$ (liver, muscle and brown adipose tissue) or $2 \mu \mathrm{g} / \mu \mathrm{L}$ (white adipose tissue) by addition of small aliquots of HAT assay buffer (included with the assay kit) and b) tissue extracts were not mixed with 2 X SDS loading buffer. In each reaction well of the assay microplate supplied by the manufacturer, $50 \mu \mathrm{L}$ of 1:50 HAT substrate (supplied by the manufacturer) was incubated at room temperature for $45 \mathrm{~min}$, followed by aspiration and washing of each well three times with $150 \mu \mathrm{L}$ of $1 \mathrm{X}$ wash buffer $(\mathrm{pH} 7.2-7.5,10 \mathrm{X}$ stock 
solution provided by the manufacturer). In separate reaction wells now containing the HAT substrate, $2 \mu \mathrm{L}$ of each 4 or $2 \mu \mathrm{g} / \mu \mathrm{L}$ sample of total protein extracts was added to $26 \mu \mathrm{L}$ of HAT assay buffer and $2 \mu \mathrm{L}$ of diluted acetyl CoA (1:20 dilution from $30 \mathrm{mM}$ stock, diluted using HAT assay buffer), both provided by the manufacturer. The microplate was then incubated for $60 \mathrm{~min}$ at $37^{\circ} \mathrm{C}$ on a shaker while covered with Parafilm, followed by washing of each reaction well three times with $150 \mu \mathrm{L}$ of $1 \mathrm{X}$ wash buffer. A $50 \mu \mathrm{L}$ aliquot of 1:100 capture antibody (provided by the manufacturer) was then added to each reaction well, and allowed to incubate at room temperature for $60 \mathrm{~min}$ on a shaker while covered with Parafilm. The reaction wells were then washed four times with $150 \mu \mathrm{L}$ of $1 \mathrm{X}$ wash buffer, followed by the addition of $50 \mu \mathrm{L}$ of 1:1000 detection antibody (provided by the manufacturer) and incubation at room temperature for $30 \mathrm{~min}$ on a shaker while covered with Parafilm. Each reaction well was then washed five times with $150 \mu \mathrm{L}$ of $1 \mathrm{X}$ wash buffer, followed by the addition of $100 \mu \mathrm{L}$ of developer solution (provided by the manufacturer) and incubation at room temperature for $10 \mathrm{~min}$ on a shaker away from light. A $50 \mu \mathrm{L}$ aliquot of stop solution (provided by the manufacturer) was then added to each well and allowed to incubate at room temperature for $2 \mathrm{~min}$. The absorbance of each sample was then immediately measured at $450 \mathrm{~nm}$ using a Powerwave HT spectrophotometer (BioTek). Three control wells containing only HAT assay buffer during the enzyme reaction step were also run concurrently during the assay. The average absorbance of these three wells was used as the negative control absorbance, as per the manufacturer's instructions.

For information regarding the validation of this activity assay, please refer to Appendix C: Validation of Commercial Activity Assays. 


\section{Quantification and Statistics}

Band densities on chemiluminescent immunoblots were quantified using the ChemiGenius Bio Imaging System GeneTools Software (Syngene, Frederick, MD). Immunoblot band density was standardized against the summed intensity of a group of Coomassie stained protein bands from the same sample lane, chosen based on their lack of variation between experimental conditions, and because they were not located close to the protein band of interest. Data for each time point are expressed as a mean $\pm \mathrm{SEM}$, with $n=3-4$ samples, each from a different animal. Statistical analysis of the data used a one-way ANOVA and a post-hoc test (Tukey).

Absorbance values obtained for the SIRT and HAT activity assays were corrected using their respective negative control absorbance, and expressed as activity/g wet weight starting tissue. Data for each time point are expressed as a mean \pm SEM, with $n=3-4$ samples, each from a different animal. For the SIRT activity assay, statistical analysis compared the activity for a given tissue between time points and assay temperatures using a one-way ANOVA with a post-hoc Tukey test. For the HAT activity assay, analysis compared the activity for a given tissue between time points using the Student's t-test. 


\section{Chapter 3}

\section{Roles for KAT acetyltransferases in the regulation of transcriptional control and metabolic depression during mammalian hibernation}




\section{$\underline{\text { Introduction }}$}

The enzymatic activity of KATs is widely known to be a major mechanism of transcriptional regulation (Lee and Workman, 2007; Carrozza et al., 2003). Indeed, via the reversible acetylation of transcription factors, KATs can exhibit control over the expression of many genes, by altering transcription factor-DNA binding affinities, controlling the formation of transcriptional complexes, and influencing the stability and specificity of the targeted factors (Chen et al., 2001; Carrozza et al., 2003; Spange et al., 2009). Typically, KATs themselves are associated with multi-subunit protein complexes that control the transcription of specific genes, and thereby act as co-transcriptional regulators for recruited transcription factors (Lee and Workman, 2007). Within this framework, the effects of KAT activity are often dictated by the protein composition of the complex, whereby association with different complex members can affect KAT substrate preference and gene-specific targeting (Carrozza et al., 2003). KAT complexformation is also associated with the epigenetic regulation of gene expression independent of transcription factors. By associating with different proteins, KATs are recruited to specific locations throughout the genome to enable the histone-acetylationdependent remodeling of chromatin, and thereby promote the activation of transcription at specific loci (Lee and Workman, 2007; Carrozza et al., 2003). Additionally, KAT activity is also implicated in the post-translational regulation of many non-transcriptional proteins, reflecting the wide role of their enzyme activity in the regulation of diverse cellular processes that include metabolism, DNA repair, cell death, and proliferation (Chen et al., 2001; Spange et al., 2009; Xiong and Guan, 2012). 
Numerous KATs have been identified in mammalian cells, many of which share overlapping functions and target substrates, while others are defined by a more narrow scope of activity (Roth et al., 2001; Carrozza et al., 2003). Four of the best-characterized KATs are CBP, PCAF, GCN5L2, and HAT1; over the past two decades, these enzymes have been shown to serve a multitude of functions in the cell, and are in many cases absolutely indispensable to the proper regulation of certain processes (Iyer et al., 2004; Nagy and Tora, 2007; Nagarajan et al., 2013; Roth et al., 2001; Lee and Workman, 2007). For example, CBP is known to be a major co-transcriptional regulator of many important transcription factors (functioning in their recruitment, complex formation, and the acetylation-mediated modification of their activities (Chan and La Thangue, 2001; Kalkhoven, 2004; Spange et al., 2009), in addition to targeting multiple histone residues and other cellular proteins for lysine acetylation (Spange et al., 2009; Henry et al., 2013; Xiong and Guan, 2012). This is also true of PCAF and GCN5L2 - both of these enzymes have been implicated as serving diverse roles in the regulation of transcription factors, histones, and metabolic proteins, and are essential to the maintenance of normal cell function (Nagy and Tora, 2007; Dominy et al., 2010; Xiong and Guan, 2012). HAT1 is similarly involved in transcriptional regulation and histone modification, and is also indispensable to the cell (Nagarajan et al., 2013; Roth et al., 2001). Indeed, the integral functions of these proteins in processes such as cell death, DNA repair, proliferation, metabolism, and general transcriptional activation (Xiong and Guan, 2012; Spange et al., 2009; Chen et al., 2001) is exemplified by the fact that their aberrant function or deregulation is associated with the development of cancer (Nagy and Tora, 2007; Iyer et al., 2004). Because of these important roles, and their implications for the manifestation 
of disease, these KATs are of great interest to researchers seeking novel approaches to the treatment of various diseases. For the same reason, these and other KATs are also of interest as potential targets for the regulation of transcriptional suppression and other processes that allow hibernating mammals to initiate and maintain metabolic rate depression during torpor.

In this chapter, the responses of KATs are characterized in the context of mammalian hibernation. Protein expression levels of the four well-established KATs (CBP, PCAF, GCN5L2 and HAT1) were measured over the torpor-arousal cycle in liver, skeletal muscle, brown adipose tissue (BAT), and white adipose tissue (WAT) of thirteen-lined ground squirrels (I. tridecemlineatus). In addition, total KAT activities were evaluated in these tissues, comparing euthermic control animals to those sampled during the late torpor phase of hibernation. Finally, the acetylation status of two KAT-targeted histone lysine residues (H3K9 and H3K14) was assessed in these tissues for the six time-points of the torpor-arousal cycle. The results suggest a possible role for KATs in the regulation of hibernation, and thereby provide further evidence to support a role for differential protein acetylation in the context of the hibernation phenotype.

\section{Materials and Methods}

\section{Animal Experiments and Total Protein Extraction}

These methods were conducted as described in Chapter 2.

\section{Western Blotting}


Western blotting was performed as described in Chapter 2. Protein levels of the four studied KATs (CBP, PCAF, GCN5L2 and HAT1) and the downstream histone target H3K9 were measured in total protein extracts of liver, muscle, BAT, and WAT, while protein levels of $\mathrm{H} 3 \mathrm{~K} 14$ were measured in BAT only. Antibodies used: anti-CBP, antiPCAF, anti-GCN5L2, anti-HAT1, anti-H3(acetyl-K9), anti-H3(acetyl-K14) (please refer to Appendix A: Antibodies Used for Western Blotting for full details for each antibody). For a detailed list of the experimental conditions used for each protein target in each studied tissue, please refer to Appendix B: Western Blotting Conditions.

\section{KAT Acetyltransferase Activity Assay}

Total KAT activity was separately assayed in soluble protein extracts of liver, muscle, BAT, and WAT, using the EpiQuick HAT Activity/Inhibition Assay Kit from Epigentek (Farmingdale, NY), as described in Chapter 2.

\section{Quantification and Statistics}

Quantification and statistics were carried out as described in Chapter 2.

\section{$\underline{\text { Results }}$}

Analysis of KAT protein levels over the torpor-arousal cycle

Relative protein levels of CBP, PCAF, GCN5L2 and HAT1 were assessed in ground squirrel liver (Fig. 3.1), muscle (Fig. 3.2), BAT (Fig. 3.3) and WAT (Fig. 3.4) over the six sampling-points of the torpor-arousal cycle using primary antibodies specific for each protein. In liver, protein levels of CBP were significantly reduced to $0.4 \pm 0.08$ during interbout arousal (IA) as compared to values for animals that were euthermic in the cold 
room (EC), while levels of PCAF were significantly elevated over controls during four stages (see expanded definitions in Chapter 2): entrance into torpor (EN), early torpor, $<24 \mathrm{~h}(\mathrm{ET})$, late torpor, $>5 \mathrm{~d}(\mathrm{LT})$ and early arousal (EA) (by $4.7 \pm 0.2,2.2 \pm 0.09,3.0 \pm$ 0.2 , and $4.6 \pm 0.3$ fold, respectively). Protein levels of GCN5L2 were also significantly decreased to $0.6 \pm 0.03$ during LT when compared to EC, and subsequently increased during EA by $1.4 \pm 0.2$ fold over controls. No significant fluctuations were observed for protein levels of HAT1 in liver over the torpor-arousal cycle. In muscle, CBP protein levels were significantly reduced during LT to $0.3 \pm 0.06$ of EC values, while levels of GCN5L2 were also significantly lowered during EN, LT, EA and IA (to $0.7 \pm 0.03,0.6 \pm$ $0.03,0.7 \pm 0.1$, and $0.7 \pm 0.06$ of EC, respectively), but not during ET. Protein levels of PCAF and HAT1 did not change significantly over torpor-arousal. In BAT, protein levels of PCAF were significantly elevated during EN by $1.9 \pm 0.1$ fold over EC, while levels of GCN5L2 were also elevated during LT by $1.4 \pm 0.04$ fold before significantly decreasing during IA to $0.7 \pm 0.01$ of EC. Protein levels of HAT1 were also significantly reduced during ET and IA to $0.6 \pm 0.02$ and $0.4 \pm 0.05$ of EC values, respectively. In contrast, levels of CBP did not fluctuate significantly over the course of the torpor-arousal cycle. In WAT, protein levels of HAT1 decreased significantly during LT to $0.5 \pm 0.04$ of the EC value, whereas levels of CBP, PCAF and GCN5L2 did not change significantly at any of the sampled time points.

Analysis of total KAT activity

Total KAT activity was measured in the total soluble protein fraction of liver (Fig. 3.5A), muscle (Fig. 3.5B), BAT (Fig. 3.6A) and WAT (Fig. 3.6B), comparing EC and LT stages. Activities were assayed at $37^{\circ} \mathrm{C}$. In liver and muscle, mean total KAT activity did 
not change significantly during LT as compared to EC control. In contrast, mean total KAT activity in BAT was significantly elevated during LT by $2.0 \pm 0.2$ fold as compared to EC, whereas total KAT activity in WAT was significantly reduced during LT to $0.5 \pm$ 0.07 of the EC value.

Analysis of the acetylation status of KAT target histone $\mathrm{H} 3$ residues (K9 and K14) during hibernation

Relative protein levels of histone $\mathrm{H} 3$ acetylated at lysine 9 (Fig. 3.7) were assessed in ground squirrel liver, muscle, BAT and WAT, over the six sampling-points of the torporarousal cycle, while levels of histone $\mathrm{H} 3$ acetylated at lysine 14 (Fig. 3.8) were assessed in ground squirrel BAT during the same time points. Primary antibodies specific for each protein only when acetylated at the indicated lysine residue were used. Relative amounts of acetylated $\mathrm{H} 3 \mathrm{~K} 9$ protein increased significantly in BAT during ET and LT (by $2.4 \pm$ 0.2 and $2.2 \pm 0.2$ fold, respectively) and in muscle during ET (by $1.8 \pm 0.1$ fold) as compared to the respective EC controls. In WAT, H3K9 levels decreased significantly during ET to $0.4 \pm 0.02$ before increasing by $2.2 \pm 0.2$ fold during IA, as compared to EC. In liver, no significant fluctuations in H3K9 levels were observed. Similar to the pattern observed in BAT for H3K9, protein levels of H3K14 also increased during ET and LT by $2.7 \pm 0.2$ and $2.2 \pm 0.3$ fold, respectively, when compared to EC control.

\section{$\underline{\text { Discussion }}$}

KATs such as CBP, PCAF, GCN5L2 and HAT1 are established players in the regulation of a wide range of cellular processes, particularly the control of transcriptional activation or suppression via their actions on histone residues and transcription factors, or their 
presence/absence in transcriptional complexes (Roth et al., 2001; Nagy and Tora, 2007; Chan and La Thangue, 2001; Kalkhoven, 2004). Many of these KAT-influenced processes - especially transcription - are tightly controlled during hypometabolism in hibernating mammals, suggesting that the functions of these enzymes might also be regulated throughout the torpor-arousal cycle. However, given that KATs have never previously been characterized in hibernators, their regulation in the context of this form of metabolic suppression has been unknown, representing a major gap in knowledge within the field of hibernation research. With the goal of filling this gap, this study has attempted to provide an initial characterization of KAT involvement in hibernation, and succeeds in providing evidence to suggest a role for these enzymes within this context.

The differential expression of KATs has been associated with both increases and decreases in the activity of numerous cellular pathways, with the effects of the changes being specific to the identity of the factor, the tissue in consideration, and the relevant KAT complex formation/post-translational modifications present under those conditions (Roth et al., 2001; Lee and Workman, 2007). Thus, the first step towards characterizing these acetyltransferases in the context of the hibernator system was to determine the relative protein expression of KATs throughout the course of the torpor-arousal cycle, so that initial insight might be gained into possible roles for these factors during hibernation. The results of my analysis indicated that, of the four KATs considered, these enzymes are differentially expressed in a tissue-specific manner at various points during hibernation, but do not exhibit an overall pattern of universal protein suppression or activation (Fig. 3.1-3.4). This observation would suggest that, in these animals, each of the studied factors likely serves some distinct role(s) at different times, and in different tissues, 
throughout hibernation. For example, PCAF protein expression was strongly enhanced in liver from EN through to EA (returning to euthermic levels during the interbout period), while this same pattern was not observed in any other tissue. This suggests that the increased expression of PCAF serves a specific role in liver during torpor that does not appear to be required in other tissues. Interestingly, under conditions that inhibit glycolysis, PCAF is known to acetylate and reduce the activity of pyruvate kinase ( $\mathrm{Lv}$ et al., 2011), a major glycolytic enzyme that is also suppressed by RPP during hibernation (Storey and Storey, 2010). The increased expression of PCAF in liver throughout hibernation may therefore contribute to the inhibition of certain metabolic processes such as glycolysis, in a manner analogous to the increased activities of specific kinases/phosphatases that also occur during this time in the liver. Protein levels of CBP also demonstrated a tissue-specific response, most notably being suppressed during late torpor only in muscle tissue. Given CBP's role as a diverse transcriptional co-activator (Chan and La Thangue 2001; Kalkhoven, 2004), this fluctuation may serve an important purpose in the regulation of the metabolic suppression in hibernator muscle. This is because its presence and acetyltransferase activity in certain transcriptional complexes is responsible and necessary for the regulation of many different genes; therefore, a decrease in CBP expression could contribute to the widespread transcriptional suppression that is characteristic of the torpid state. In fact, this proposed function would also complement current evidence that suggests an epigenetic contribution to global transcriptional arrest. In hibernator muscle, the acetylation of histone $\mathrm{H} 3$ at lysine residue 23 is known to be significantly reduced during torpor, which is consistent with the notion of suppressed transcriptional activity at loci associated with this histone modification 
(Morin and Storey, 2006). This change is also correlated with an increase in the expression levels of several HDACs which target this residue, in addition to levels of total HDAC activity (Morin and Storey, 2006). CBP also targets this residue as a substrate for its acetyltransferase activity (Henry et al., 2013). Thus, the observed decrease in CBP expression during late torpor may compliment the increase in HDAC activity to promote the deacetylation of certain histone residues, and thereby promote transcriptional suppression. This may also be true for GCN5L2, the protein levels of which were also significantly reduced during late torpor in muscle. GCN5L2 targets H3K23 for acetylation (Jin et al., 2011), so downregulation of GCN5L2 may contribute to the reduced acetylation of histone $\mathrm{H} 3$. Like $\mathrm{CBP}, \mathrm{GCN} 5 \mathrm{~L} 2$ is also a major transcriptional co-activator in a non-epigenetic sense (Nagy and Tora, 2007), so it's decreased expression in muscle and liver may also generally reflect the global suppression of transcription during torpor. In contrast, the enhanced expression of GCN5L2 at the same time in BAT could suggest an increase in the transcriptional activation of GCN5L2 target-genes, which could be functional in this tissue given its active role in regulating thermogenesis when body temperature drops below acceptable limits during torpor, or to initiate arousal. While the actual functions of these and other observed changes in KAT protein expression cannot be conclusively determined by the current study, the fact that such changes do occur is evidence to suggest that these enzymes likely serve roles in the regulation of the various processes implicated during hibernation.

To further characterize the possible function of KATs in the context of the hibernator, total KAT activity in the four tissues was compared between euthermic (EC) and late 
torpor (LT) stages (Fig. 3.5-3.6). While no change in KAT activity occurred in liver or muscle between these stages, the adipose tissues demonstrated significant fluctuations in KAT activity. In BAT, KAT activity levels doubled during torpor as compared to control, thereby further supporting a role for increased KAT function in this tissue during hypometabolism. As mentioned, increased KAT activity in BAT might reflect the need for this tissue to maintain the expression of certain pathways involved in the thermoregulatory response, perhaps via acetylation-induced increases in the transcriptional activation of specific genes. In contrast, KAT activity in WAT was reduced by half during torpor, suggesting that a reduction in the function of these enzymes is required in this tissue during metabolic depression. Interestingly, the activity fluctuations in both of these tissues seem to correlate with some of the observed protein data - in BAT, GCN5L2 levels increase with total KAT activity during torpor, while levels of HAT1 decrease with total activity in WAT, possibly supporting the notion that these increases/decreases in protein levels make an actual contribution to the total measureable acetyltransferase activity within the tissues. However, given that these measurements only accounted for total KAT activity - and not the activity of specific KATs - no conclusions can be made regarding the relationship between relative changes in the protein expression of one or two enzymes, and total KAT activity. This concept also applies to the lack of change in activity observed in muscle and liver - although protein fluctuations occurred in both tissues, observable changes in total activity will not necessarily follow, even if the activities of specific KATs do change. Regardless of the specificity of the measurements, however, the current data support a role for overall enhanced KAT activity in BAT and decreased KAT activity in WAT during torpor, 
thereby providing further evidence to implicate these enzymes in the regulation of hibernation.

In terms of current research in the field of epigenetics, it is now clear that the KATmediated regulation of transcription via the selective acetylation of histone residues is an incredibly important function of these enzymes within the cell, and is responsible for the activation of numerous genes and downstream cellular processes (Lee et al., 2010; Sterner and Berger, 2000). Thus, in order to more fully characterize KATs in the context of hibernation, the acetylation status of two KAT-targeted histone residues was determined over the course of the torpor-arousal cycle in select tissues. Acetylation of histone $\mathrm{H} 3$ lysine residues 9 and 14 is generally associated with increased transcriptional activation, and is known to function in the regulation of a wide variety of genes and biological pathways (Karmodiya et al., 2012). Numerous KATs target these residues for acetylation, including GCN5L2, PCAF and CBP studied here (Karmodiya et al., 2012). In the current hibernator model, fluctuations of acetylated H3K9 and H3K14 were observed in several of the tested tissues (Fig 3.7-3.8), suggesting that transcriptional activation/deactivation of certain processes by differential histone acetylation may occur at various points throughout the torpor-arousal cycle. Indeed, this supports previous findings, discussed above (Morin and Storey, 2006). Most notably, acetylation of both residues was significantly elevated in BAT during torpor, which is consistent with the transcriptional activation of gene programs regulated by these two residues being a part of this tissue's response to torpor. In fact, acetylation of these two residues may be related to the thermoregulatory functions of this tissue. Evidence exists to suggest that the regulation of uncoupling protein-1 (UCP1, the main protein responsible for uncoupled 
respiration and non-shivering thermogenesis in the mitochondria of BAT) is controlled by histone $\mathrm{H} 3$ acetylation, whereby decreased levels of the modification are associated with reductions in ucpl gene expression (Kiskinis et al., 2007). Given that UCP1 expression is absolutely integral to the thermoregulatory function of BAT (Golozoubova et al., 2001), and is therefore indispensable for the survival of the hibernating mammal, the transcriptional activation of the $u c p 1$ gene by $\mathrm{H} 3 \mathrm{~K} 9$ and $\mathrm{H} 3 \mathrm{~K} 14$ acetylation in BAT during torpor would be unsurprising. Similarly, the significant fluctuation in H3K9 acetylation between early torpor and interbout arousal in WAT may reflect general changes in transcriptional activity that occur over this period (i.e. suppression during the initial metabolic decline, followed by strong reactivation during arousal). Interestingly, the results in BAT correlate with the observed increases in total KAT activity and GCN5L2 protein levels that also occur in BAT at this time, possibly reflecting the expected change in downstream substrate acetylation that should occur with fluctuations in KAT activity/expression. Taken together with these results, the observed increases in H3K9 and H3K14 acetylation in BAT therefore add evidence to support the argument for an important role for KATs in the hibernator system. Perhaps more intriguing, the presence of differential histone acetylation in multiple tissues of the hibernator also further supports the notion that epigenetic mechanisms likely contribute to the mediation of the processes responsible for the success of the hibernation phenotype. While the exact functions of the observed changes in $\mathrm{H} 3 \mathrm{~K} 9$ and $\mathrm{H} 3 \mathrm{~K} 14$ acetylation remain unknown, the current data provide important insight into the status of histone modifications during hypometabolism, in addition to aiding the further characterization of KATs in the hibernator system. 
This study serves as the first known investigation to provide significant evidence to suggest that the differential expression of KATs may be characteristic of the hibernation phenotype. Indeed, the results discussed herein identify fluctuations in the protein levels of four of the best-studied KATs in the literature, changes in total KAT activity, and differential acetylation of downstream KAT histone targets, at various points throughout the torpor-arousal cycle and in a tissue-specific manner. Some of these changes also appear to correlate. For example, during torpor in BAT, the increased expression of the major transcriptional co-activator GCN5L2 occurs concurrently with increases in total KAT activity and H3K9/K14 acetylation, all of which are changes that point towards enhanced transcriptional activation via KAT-mediated regulation. Thus, in addition to fulfilling the primary goal of characterizing these enzymes in the current system, these data support an active role for KATs in the regulation of hibernation, most likely within an epigenetic or other transcriptional-regulatory context. Further, and perhaps more interestingly, this conclusion likely represents another example of the widespread function of reversible protein acetylation in the regulation of diverse cellular processes, and suggests its importance to hibernator biology. 


\section{Figures}

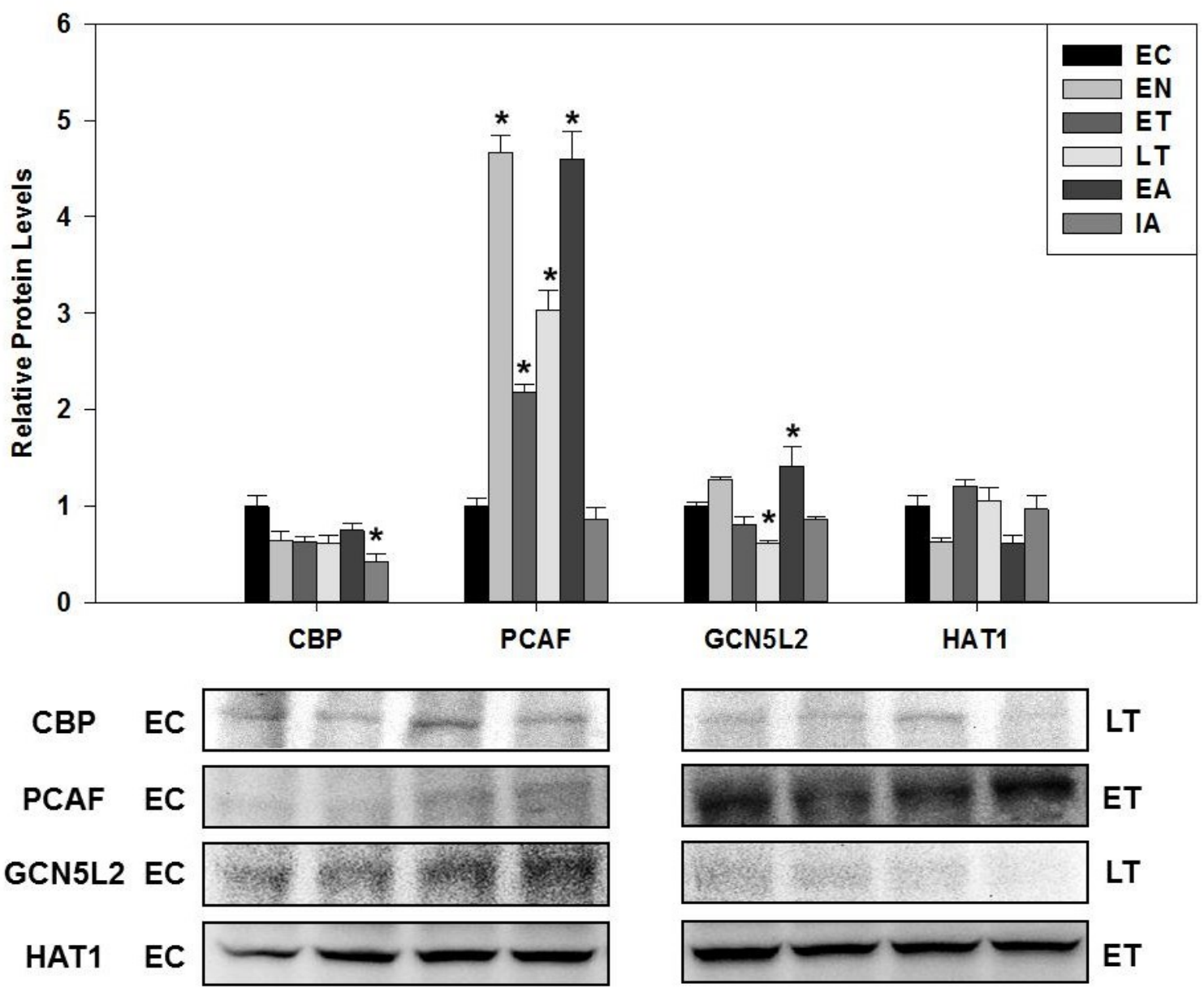

Fig. 3.1. Relative protein expression of CBP, PCAF, GCN5L2 and HAT1 in liver of $I$. tridecemlineatus over the torpor-arousal cycle. Representative protein bands are shown for selected sampling points (labelled to the left and right of the blots). Histogram shows mean standardized band densities ( \pm SEM, $n=3-4$ independent trials on tissue from different animals). Protein bands were standardized against the summed intensity of a group of Coomassie-stained protein bands from the same sample lane. Data were analyzed using a one-way ANOVA with a post hoc Tukey test. $*=$ Significantly different from the respective $\mathrm{EC}$ control, $\mathrm{p}<0.05$. 


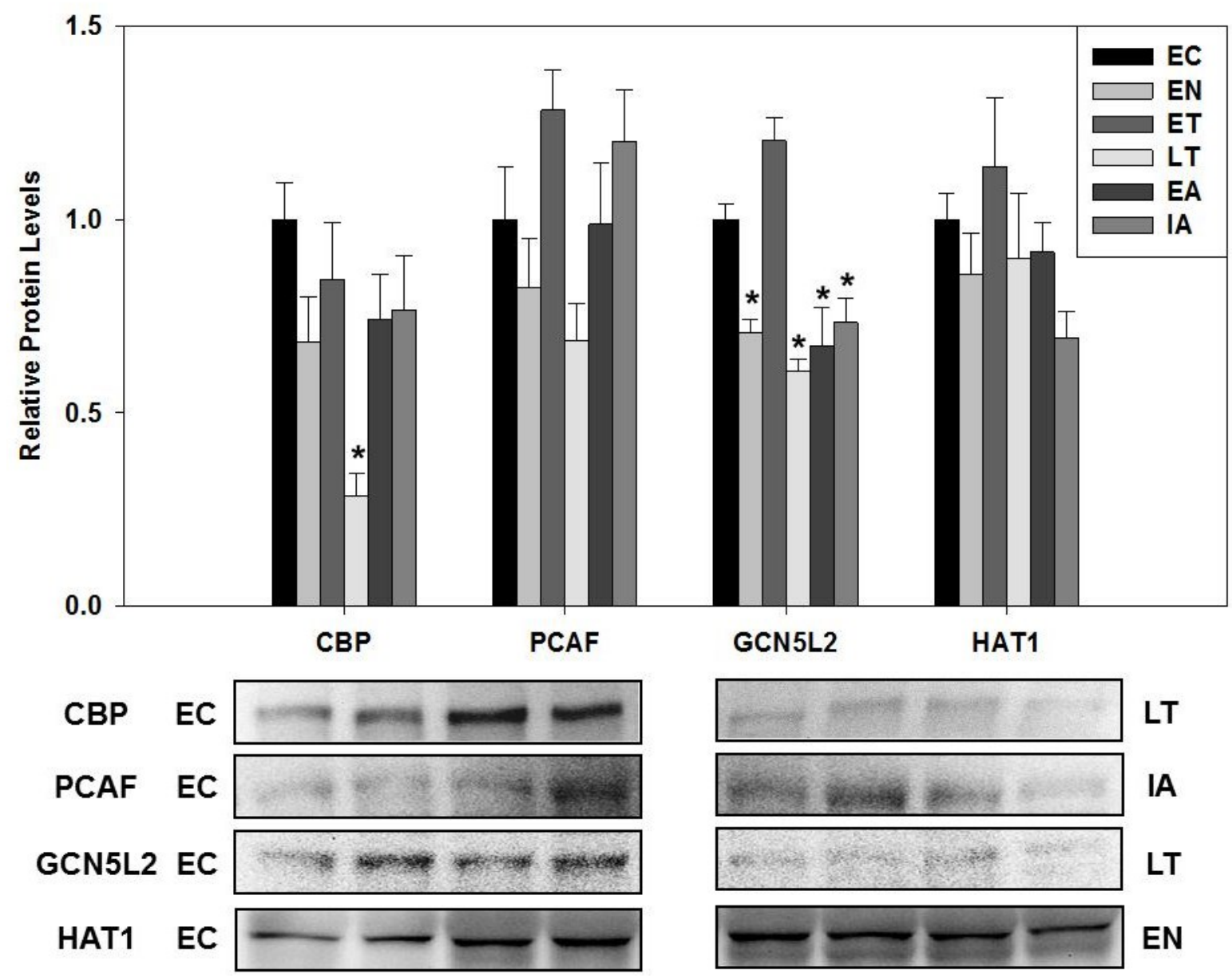

Fig. 3.2. Relative protein expression of CBP, PCAF, GCN5L2 and HAT1 in skeletal muscle of I. tridecemlineatus over the torpor-arousal cycle. All other information as in Fig. 3.1. 


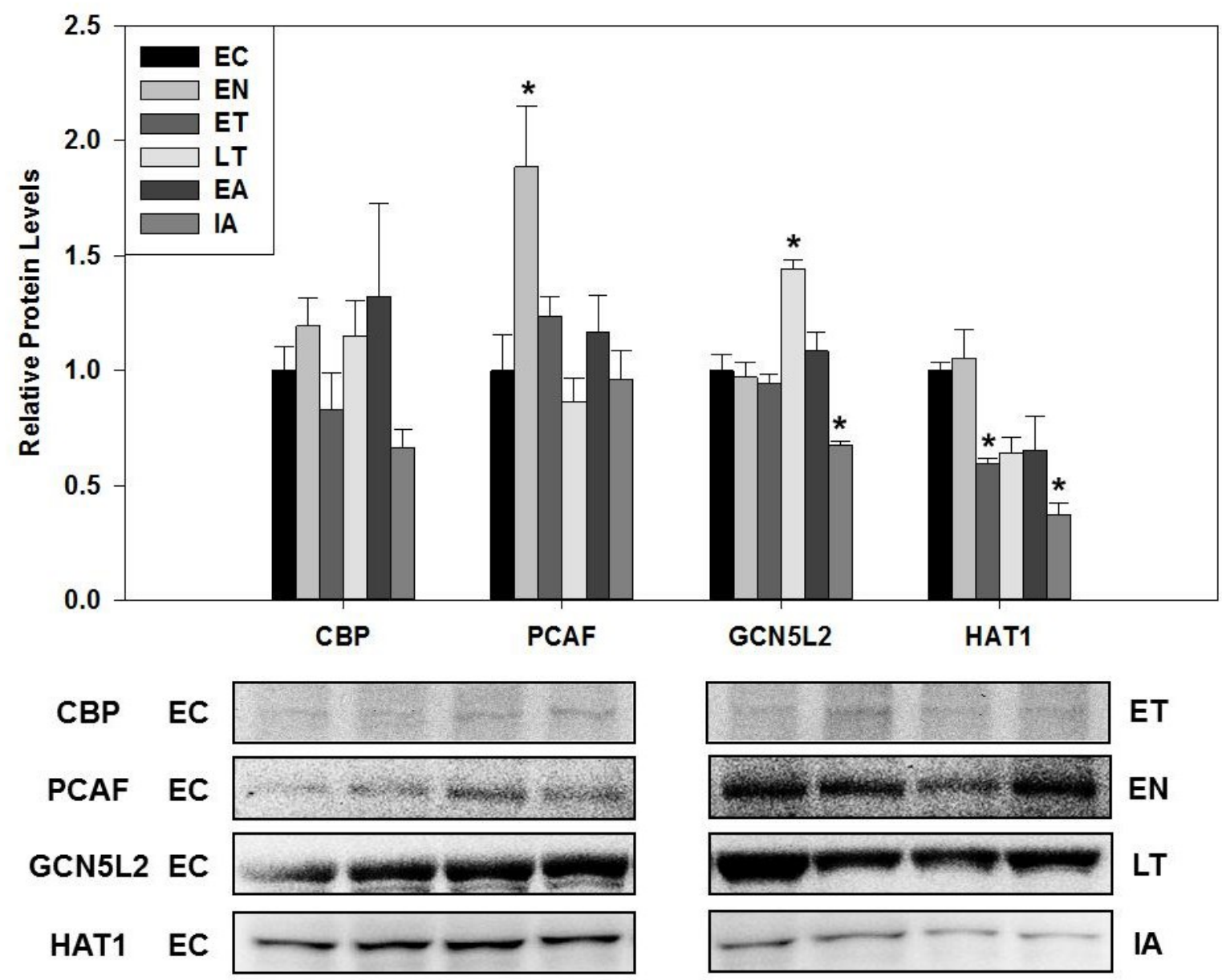

Fig. 3.3. Relative protein expression of CBP, PCAF, GCN5L2 and HAT1 in BAT of $I$. tridecemlineatus over the torpor-arousal cycle. All other information as in Fig. 3.1. 


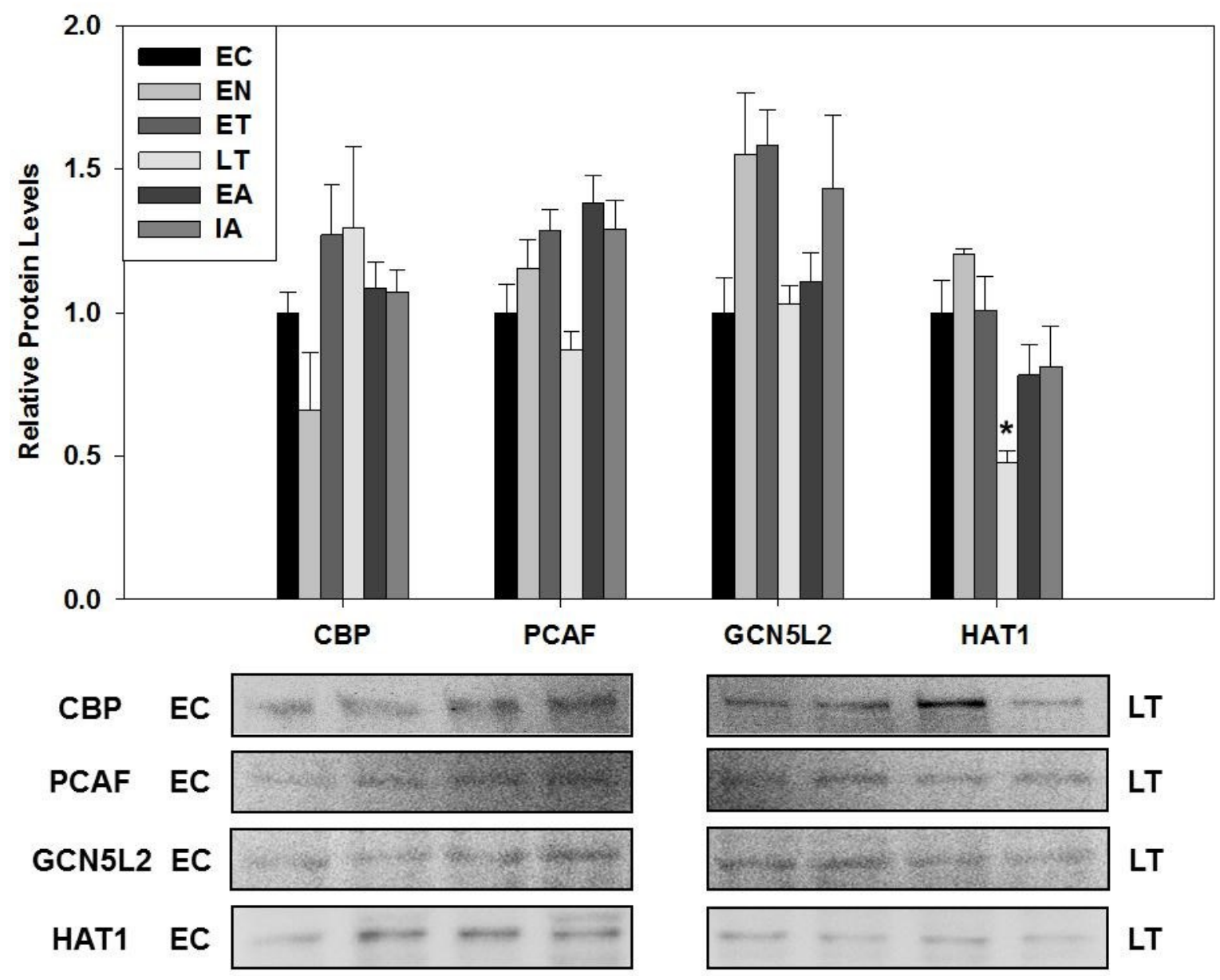

Fig. 3.4. Relative protein expression of CBP, PCAF, GCN5L2 and HAT1 in WAT of $I$. tridecemlineatus over the torpor-arousal cycle. All other information as in Fig. 3.1. 
A)

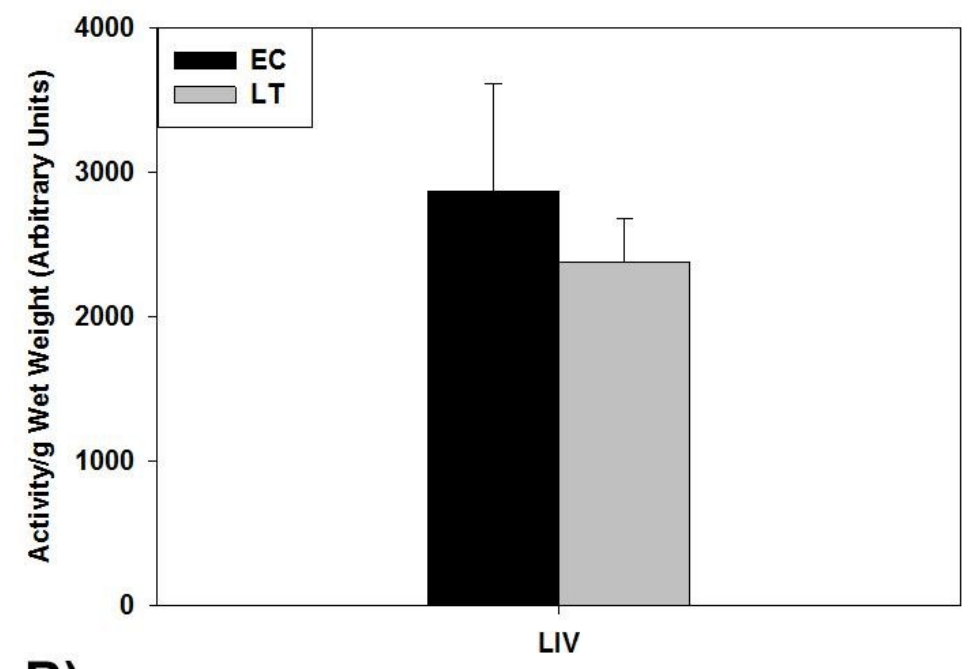

B)

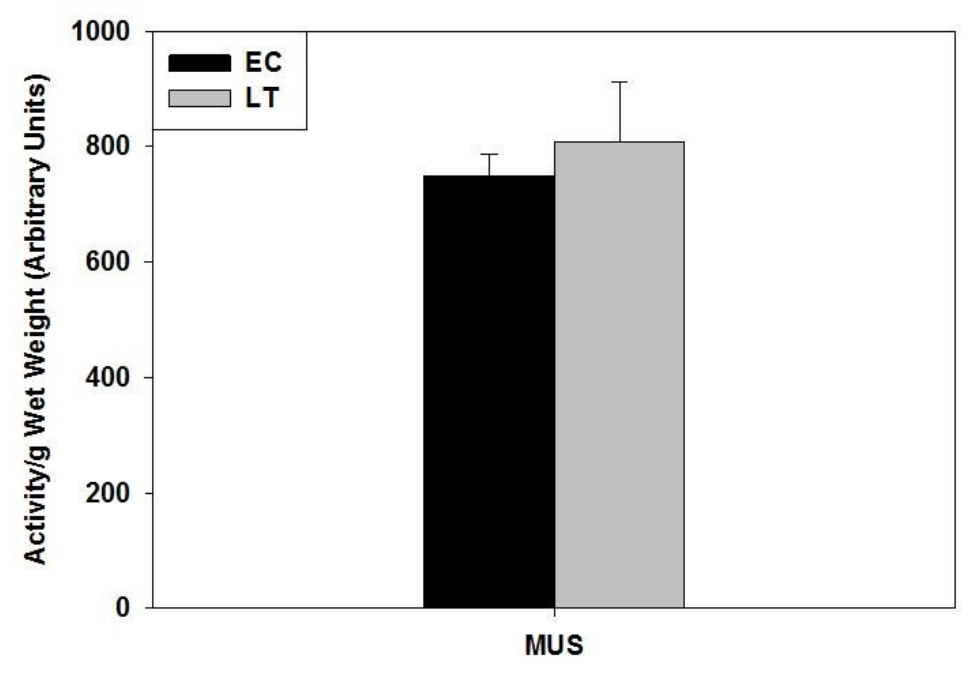

Fig. 3.5. Total HAT activity in A) liver (LIV) and B) muscle (MUS) of $I$.

tridecemlineatus comparing euthermic control (EC) and late torpor (LT) points of the torpor-arousal cycle (assay temperature $=37^{\circ} \mathrm{C}$ ). Enzyme activities in total soluble extracts are expressed as activities (arbitrary units) per gram wet weight of tissue. Histograms show means \pm SEM, $n=3-4$ independent assays on tissue from different animals. Data were analyzed using the Student's t-test. * = Significantly different from the respective EC control, $\mathrm{p}<0.05$. 
A)

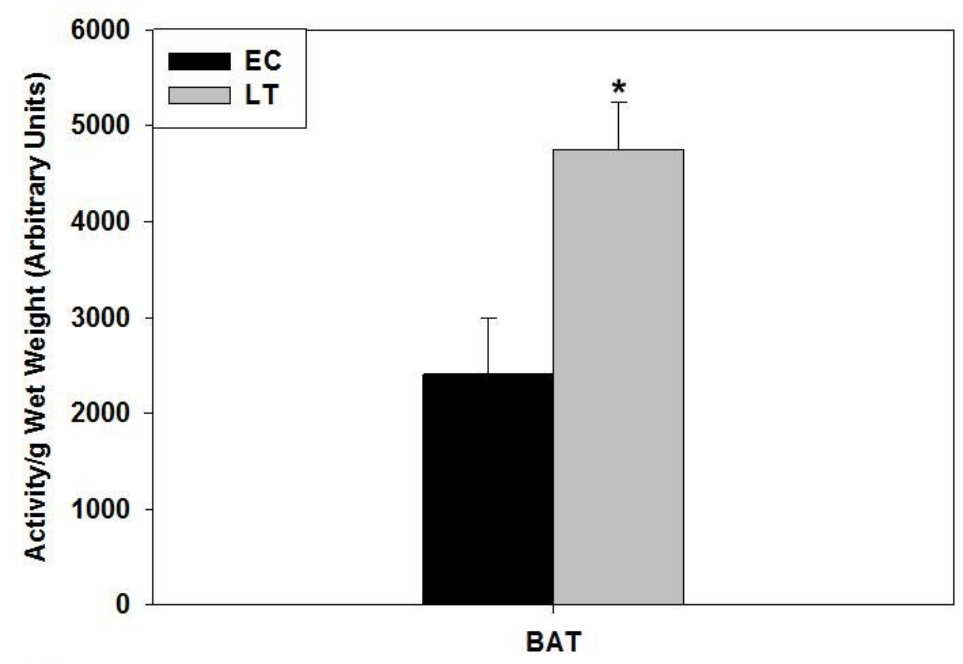

B)

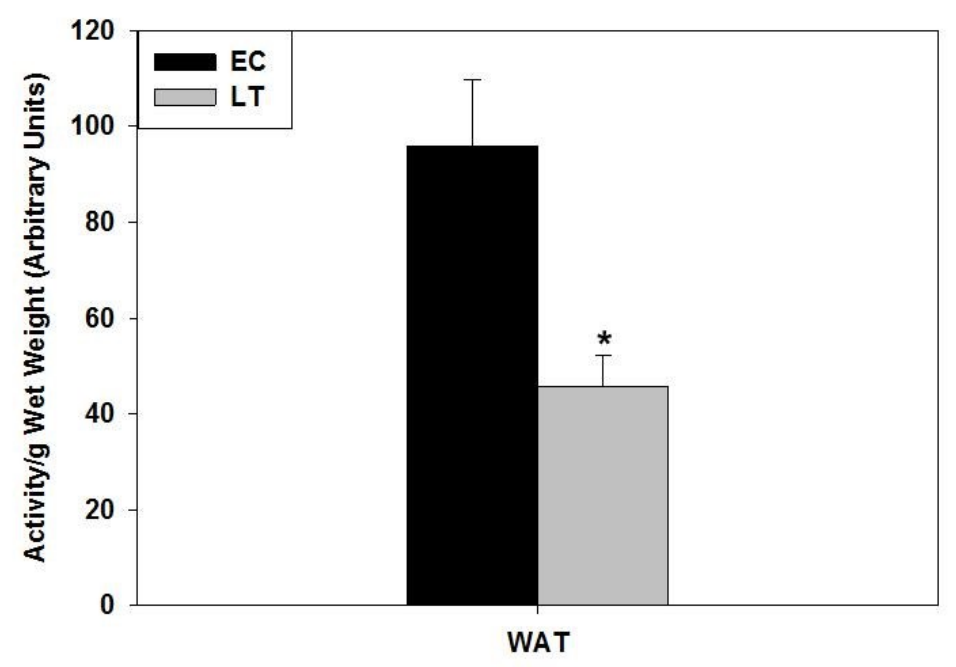

Fig. 3.6. Total HAT activity in A) BAT and B) WAT of I. tridecemlineatus comparing euthermic control (EC) and late torpor (LT) points of the torpor-arousal cycle (assay temperature $=37^{\circ} \mathrm{C}$ ). All other information as in Fig. 3.5. 


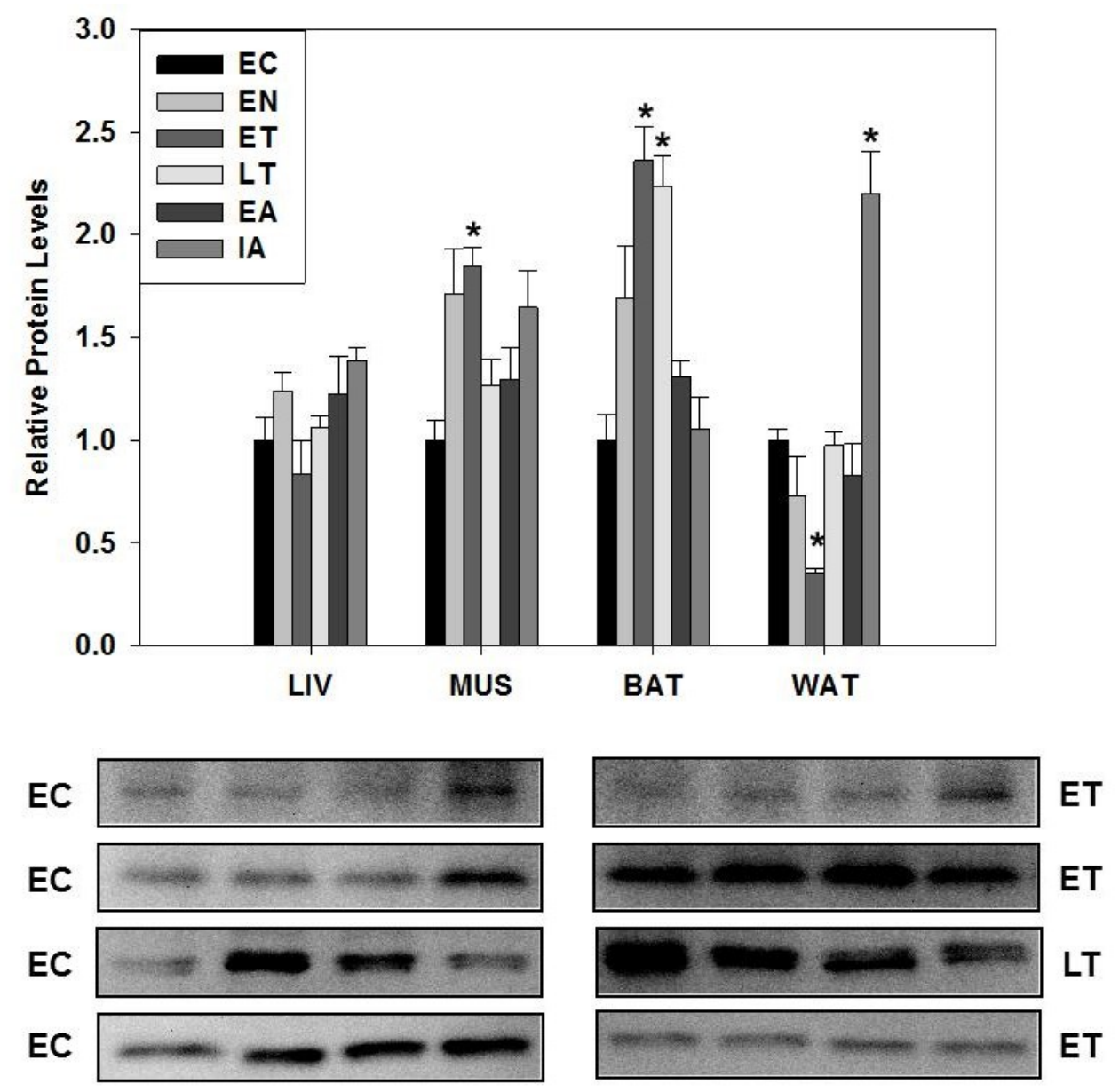

Fig. 3.7. Relative protein expression of histone $\mathrm{H} 3$ acetylated at lysine 9 in liver (LIV), skeletal muscle (MUS), BAT and WAT of I. tridecemlineatus over the torpor-arousal cycle. All other information as in Fig. 3.1. 


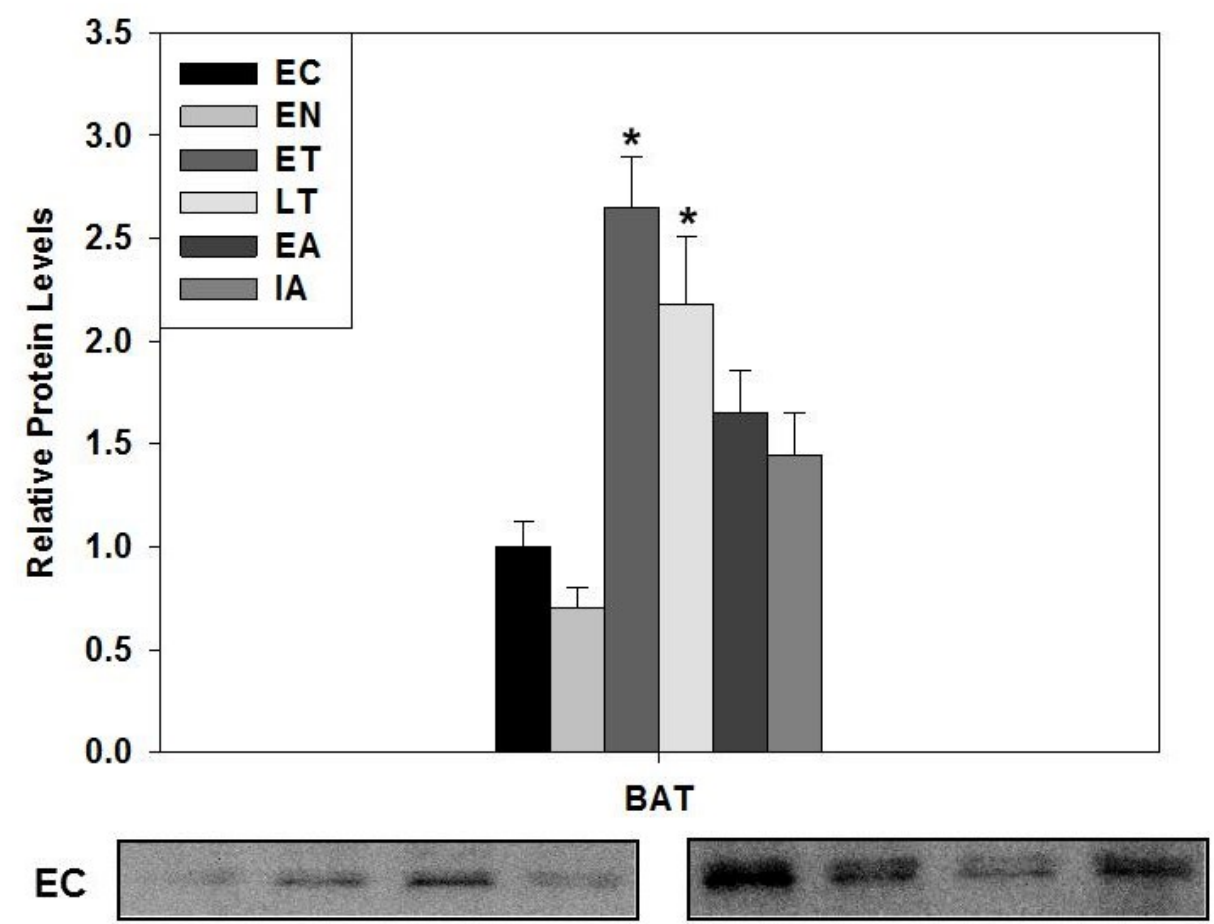

Fig. 3.8. Relative protein expression of histone $\mathrm{H} 3$ acetylated at lysine 14 in BAT of $I$. tridecemlineatus over the torpor-arousal cycle. All other information as in Fig. 3.1. 


\section{Chapter 4}

\section{Responses of the SIRT family of NAD ${ }^{+}$-dependent protein deacetylases in tissues of ground squirrels during hibernation}




\section{$\underline{\text { Introduction }}$}

As described in Chapter 1-General Introduction, histone deacetylases (HDACs) are divided into separate groups based on their sequence similarities (De Ruijter et al., 2003). While Class I and II HDACs are most commonly associated with transcriptional silencing via epigenetic processes, Class III HDACs, known as sirtuins, have been shown to serve an incredibly diverse range of functions in the regulation of many cellular processes (Schwer and Verdin, 2008). The sirtuins are a family of $\mathrm{NAD}^{+}$-dependent protein deacetylases that were first identified in the yeast Saccharomyces cerevisiae (Klar et al., 1979). The first known sirtuin gene, SIR2 (silent information regulator 2), was characterized by its role in gene-silencing at the yeast mating-type loci, and was quickly shown to share high homology with four other S. cerevisiae genes, HST1-4 (homologues of SIR2 1-4), all of which demonstrated several other physiologically important functions, including involvement in cell cycle progression and the maintenance of genomic integrity (Brachmann et al., 1995). SIR2 homologues - referred to generally as the sirtuin family - have been identified in essentially every kingdom of life (Brachmann et al., 1995; Smith et al., 2000), demonstrating a remarkable degree of conservation throughout evolution, and suggesting an ancient origin for the protein family.

Seven mammalian sirtuins (SIRT1-7, referred to collectively as SIRTs and localized differentially throughout the cell) have been identified, whose significant roles in metabolism and cellular stress responses have suggested that they are fundamental regulators of metabolic homeostasis and cellular protection (Schwer and Verdin, 2008; Bosch-Presegué and Vaquero, 2013). For example, the most widely studied member of the family, SIRT1, can deacetylate and regulate major transcription factors involved in 
glucose and lipid metabolism, such as PPAR $\gamma$ and FOXO1 and the transcriptional coactivator PGC-1 $\alpha$, to promote fatty acid oxidation under fasting conditions when glucose availability is low (Picard et al., 2004; Frescas et al., 2005; Rodgers et al., 2005; Dominy et al., 2010; Gerhart-Hines et al., 2007). SIRT1 also serves protective and anti-apoptotic roles in response to cellular stress via numerous pathways, including its direct modification of transcription factor p53 and specific histone targets (Chen et al., 2006; Alcendor et al., 2004; Luo et al., 2001). Likewise, SIRT2 and SIRT3 play significant roles in promoting lipid metabolism and in controlling responses to oxidative stress (Wang and Tong, 2009; Wang et al., 2007; Shi et al., 2005; Hirschey et al., 2010; Qiu et al., 2010; Tao et al., 2010) and similar metabolic and cellular protective functions have also been described for other members of the mammalian SIRT family (reviewed in Schwer and Verdin, 2008; Li and Kazgan, 2011; Bosch-Presegué and Vaquero, 2013). Therefore, these deacetylases are intriguing subjects for study as potential targets for novel therapies to treat metabolic disorders and to mitigate cellular damage caused during natural processes such as aging (Haigis and Sinclair, 2010). For similar reasons they are also of interest as potential regulators of the processes that enable hibernating mammals to control metabolism and tissue damage during transitions to and from torpor.

In the present chapter, responses of the SIRT family of deacetylases are characterized in the context of mammalian hibernation. Expression levels of protein were measured for the seven mammalian SIRTs (SIRT1, SIRT2, SIRT3, SIRT4, SIRT5, SIRT6 and SIRT7) over the torpor-arousal cycle in muscle and white adipose tissue of thirteen-lined ground squirrels (Ictidomys tridecemlineatus). In addition, total SIRT activities were evaluated in liver, muscle, brown adipose and white adipose tissues comparing euthermic controls 
with the late torpor phase at assay temperatures representative of both euthermic $\left(37^{\circ} \mathrm{C}\right)$ and torpid $\left(4^{\circ} \mathrm{C}\right)$ conditions. Finally, the acetylation status of two proteins known to be targeted by SIRT activity at specific lysine residues was determined in the four tissues for the six time-points of the torpor-arousal cycle. These are the antioxidant enzyme superoxide dismutase-2 (SOD2), the mitochondrial Mn-dependent form, that is acetylated on lysine 68 (Chen et al., 2011) and the transcription factor nuclear factor kappa-B (NF$\kappa \mathrm{B})$ that is acetylated on its p65 subunit at lysine 310 (Rothgiesser et al., 2010; Yeung et al., 2004). The results suggest a possible role for SIRTs in the regulation of hibernation, and thereby provide further evidence to support an important role for differential protein acetylation in the context of the hibernation phenotype.

\section{Materials and Methods}

\section{Animal Experiments, Total Protein Extraction, and Cytoplasmic/Nuclear Protein}

\section{Extraction}

All of these methods were conducted as described in Chapter 2.

\section{Western Blotting}

Western blotting was performed as described in Chapter 2. Relative protein levels of the seven mammalian SIRTs (SIRT1-7) were measured in total protein extracts of muscle and WAT, whereas relative levels of acetylated SOD2 (acetyl-K68) and NF-кB p65 (acetyl-K310) were measured in liver, muscle, brown adipose, and white adipose tissue. Antibodies used: anti-SIRT1, anti-SIRT2, anti-SIRT3, anti-SIRT4, anti-SIRT5, antiSIRT6, anti-SIRT7, anti-SOD2 (acetyl-K68), anti-NF-кB p65 (acetyl-K310) (please refer to Appendix A: Antibodies Used for Western Blotting for full details for each antibody). 
For a detailed list of the experimental conditions used for each protein target in each studied tissue, please refer to Appendix B: Western Blotting Conditions.

\section{SIRT Deacetylase Activity Assay}

Total SIRT activity was separately assayed at $37^{\circ} \mathrm{C}$ and $4^{\circ} \mathrm{C}$ for nuclear (liver and muscle) and total (liver, muscle, brown adipose tissue, and white adipose tissue) protein fractions using the Epigenase Universal SIRT Activity/Inhibition Assay Kit from Epigentek (Farmingdale, NY), as described in Chapter 2.

\section{Quantification and Statistics}

Quantification and statistics were carried out as described in Chapter 2.

\section{$\underline{\text { Results }}$}

Analysis of SIRT protein levels over the torpor-arousal cycle

Relative protein levels of the seven SIRTs were assessed in ground squirrel skeletal muscle (Fig. 4.1), and WAT (Fig. 4.2) over the six sampling-points of the torpor-arousal cycle using primary antibodies specific for each protein. In skeletal muscle, protein levels of SIRT3 were significantly elevated by $1.9 \pm 0.2$ and $2.6 \pm 0.09$ fold over controls during ET and LT, respectively, whereas levels of SIRT6 were elevated by $1.7 \pm 0.2$ fold over EC during interbout arousal. In contrast, protein levels of SIRT2 decreased significantly during EN to $0.7 \pm 0.05$ as compared with EC. No significant changes were observed for protein levels of SIRT1, SIRT4, SIRT5, or SIRT7 at any of the sampled time points. In WAT, protein levels of SIRT3, SIRT4 and SIRT5 were observed to decrease significantly during both torpor stages (ET and LT) as compared to controls; 
SIRT3 decreased to $0.5 \pm 0.06$ and $0.6 \pm 0.04$ of control values; SIRT4 to $0.6 \pm 0.03$ and $0.6 \pm 0.02$; and SIRT5 to $0.5 \pm 0.1$ and $0.4 \pm 0.07$ for ET and LT, respectively. Additionally, SIRT3 levels remained depressed at $0.4 \pm 0.02$ during EA as compared to EC, whereas SIRT4 levels also remained low during EA and IA at $0.6 \pm 0.1$ and $0.6 \pm$ 0.08 of EC values. In contrast, protein levels of SIRT2 increased significantly during LT by $1.7 \pm 0.1$ fold over EC, as did those of SIRT7 during IA by $1.9 \pm 0.3$ fold.

\section{Analysis of total SIRT activity}

Total SIRT activity was measured in total soluble protein fractions of liver (Fig. 4.3A), skeletal muscle (Fig. 4.4A), BAT (Fig. 4.5A) and WAT (Fig. 4.5B), and in the nuclear protein fractions of liver (Fig. 4.3B) and muscle (Fig. 4.4B), comparing EC and LT stages. Activities were assayed at temperatures of $37^{\circ} \mathrm{C}$ and $4^{\circ} \mathrm{C}$ to mimic the ground squirrel core body temperature in euthermic and torpid states. In liver, mean total SIRT activity measured in either total or nuclear protein fractions did not change significantly during LT as compared to the EC control at $37^{\circ} \mathrm{C}$. However, in assays conducted at $4^{\circ} \mathrm{C}$, activity in the total soluble protein fraction was significantly elevated by $1.7 \pm 0.1$ fold over EC. Activities in both fractions significantly decreased when assayed at $4^{\circ} \mathrm{C}$ as compared to the corresponding values at $37^{\circ} \mathrm{C}$; thus, activities measured at $4^{\circ} \mathrm{C}$ for SIRTs in total protein extracts were just $0.4 \pm 0.05$ and $0.7 \pm 0.05$ for EC and LT as compared with the $37^{\circ} \mathrm{C}$ values. Relative activities were even more strongly reduced when nuclear SIRT activity was measured, being just $0.08 \pm 0.03$ and $0.3 \pm 0.04$ at $4{ }^{\circ} \mathrm{C}$ as compared with $37^{\circ} \mathrm{C}$. In muscle, mean total SIRT activity in the total soluble protein fraction was significantly increased during LT as compared to EC at $37^{\circ} \mathrm{C}$ (by $3.6 \pm 0.1$ fold) and $4^{\circ} \mathrm{C}$ $(1.9 \pm 0.1$ fold $)$, while no activity changes were observed between EC and LT in the 
nuclear protein fraction at either temperature (Fig. 4.4). Interestingly, activities in the total protein fraction were not significantly different at $4^{\circ} \mathrm{C}$ when compared to the corresponding values at $37^{\circ} \mathrm{C}$, while those in the nuclear fraction did decrease significantly at $4^{\circ} \mathrm{C}$ over those at $37^{\circ} \mathrm{C}$ (to $0.3 \pm 0.05$ and $0.5 \pm 0.06$ of $37^{\circ} \mathrm{C}$ values for EC and LT). In BAT and WAT, total SIRT activity did not change significantly between $\mathrm{EC}$ and $\mathrm{LT}$ at either temperature (Fig. 4.5). However, BAT activities at $4^{\circ} \mathrm{C}$ were not significantly different from the corresponding values at $37^{\circ} \mathrm{C}$, while those in WAT were significantly decreased at $4^{\circ} \mathrm{C}$ (to $0.08 \pm 0.02$ and $0.2 \pm 0.05$ for $\mathrm{EC}$ and $\mathrm{LT}$ of the $37^{\circ} \mathrm{C}$ values).

Analysis of the acetylation status of SIRT targets SOD2 (K68) and NF- $\kappa B$ p65 (K310) during hibernation

Relative protein levels of acetylated SOD2 (K68) (Fig. 4.6) and NF-kB p65 (K310) (Fig. 4.7) were assessed in ground squirrel liver, skeletal muscle, BAT and WAT over the six sampling-points of the torpor-arousal cycle using primary antibodies specific for each protein only when acetylated at the indicated lysine residue. The content of acetylated SOD2 (K68) decreased significantly in liver, muscle, and WAT during LT to $0.4 \pm 0.05$, $0.5 \pm 0.1$ and $0.4 \pm 0.07$, respectively, of EC control values. SOD2 (K68) levels also decreased in muscle during IA to $0.5 \pm 0.06$ of EC. In contrast, levels of SOD2 (K68) increased significantly in BAT by $1.7 \pm 0.1$ and $1.5 \pm 0.1$ fold during ET and EA, respectively, over the EC value. Acetylated NF-kB p65 (K310) protein content decreased significantly in liver during LT to just $0.3 \pm 0.04$ as compared to EC, but increased strongly again during IA to $1.8 \pm 0.3$ fold above EC. Levels of NF- $\mathrm{kB}(\mathrm{K} 310)$ also 
increased significantly in BAT during EA by $1.6 \pm 0.2$ fold as compared to control, while no changes were observed in skeletal muscle or WAT over the torpor-arousal cycle.

\section{$\underline{\text { Discussion }}$}

Numerous studies have identified diverse functions for protein deacetylases in the control of eukaryotic gene expression and cellular metabolism, including potential roles in transcriptional suppression previously implicated for Class I and II deacetylases in the context of mammalian hibernation (Morin and Storey, 2006) or turtle anoxia tolerance (Krivoruchko and Storey, 2010). Previous studies also hypothesized a possible role for Class III sirtuin deacetylases in the regulation of the major metabolic changes that occur over the hibernation torpor-arousal cycle, with pathways of lipid catabolism, oxidative stress resistance, and transcriptional suppression being likely candidates for regulation by SIRTs (Melvin and Andrews, 2009; Morin and Storey, 2009). With the goal of providing a preliminary characterization of SIRT involvement in hibernation, the current work offers the first experimental evidence to support some of the aforementioned suggestions, with observed changes in SIRT protein expression, total SIRT activity (in some cases possibly characterized by temperature-independence), and acetylation status of SIRT downstream targets potentially reflecting a novel regulatory mechanism operating in a tissue-specific manner over the course of the torpor-arousal bouts of hibernation.

Previous unpublished initial studies identified significant fluctuations in the protein levels of SIRTs in both liver and brown adipose tissues of I. tridecemlineatus during hibernation (Appendix D: Data Collected External to Thesis, Fig. D1 and D2). Specifically, levels of SIRT1 increased significantly during early arousal in both tissues, with sustained 
elevation also observed during interbout arousal in liver. A similar pattern was observed for levels of SIRT2 (significantly elevated throughout arousal as well as during entrance to torpor), while SIRT3 protein increased only during early torpor. These data provided initial insight into the possibility that this group of deacetylases function in the regulation of hibernation. The results of the current study reinforce this - the analysis of SIRT protein levels in ground squirrel skeletal muscle (Fig. 4.1) and white adipose tissue (Fig. 4.2) revealed further changes in the relative abundance of specific SIRTs at various points over the torpor-arousal cycle. In muscle, protein levels of SIRT2, SIRT3 and SIRT6 fluctuated significantly during hibernation, with SIRT3 showing a particularly interesting increase in expression during early and late torpor (Fig. 4.1). Likewise, protein levels of SIRT2, SIRT3, SIRT4, SIRT5 and SIRT7 also demonstrated patterns of differential regulation in WAT, notably characterized by significant reductions in the three mitochondrial SIRTs (SIRT3-5) during early and late torpor, and an increase in SIRT2 and SIRT7 levels during late torpor and interbout arousal, respectively (Fig. 4.2). Taken together with the initial liver and BAT data, these results outline what appear to be distinct tissue-specific patterns of differential SIRT expression during hibernation, suggesting that these factors may serve tissue-specific roles in the context of this form of metabolic rate depression.

When considering the current literature, these results are perhaps not surprising; SIRT proteins are involved in the control of an incredibly diverse range of metabolic and protective processes, including those that are highly relevant to the tissues of mammalian hibernators. SIRT3, for example, is known to mitigate oxidative stress in multiple tissues (Qui et al., 2010; Tao et al., 2010; Jing et al., 2011), and regulates fatty acid oxidation 
and alternative energy pathways via the deacetylation of mitochondrial enzymes (Hirschey et al., 2010; Anderson and Hirschey, 2012). In fact, SIRT3 is responsible for the majority of the SIRT activity present in the mitochondria (SIRT4 and SIRT5 have little influence on the acetylation status of most proteins within the mitochondrial compartment), whereby loss of SIRT3 results in global hyperacetylation of mitochondrial proteins (Lombard et al., 2007). Thus, the apparent elevation of SIRT3 protein levels in hibernator skeletal muscle during deep torpor suggests that the regulation of mitochondrial protein acetylation is implicated at this time. By extension, this would likely indicate that some of the metabolic and protective functions of SIRT3 are also relevant in this tissue during torpor. A SIRT3-mediated regulation of processes that reduce oxidative stress, for example, would serve a useful role in skeletal muscle during this time, when antioxidant responses are also known to be active in torpid tissues to prevent irreversible cellular damage at low temperatures, and to prepare for the drastic increases in oxygen consumption/ROS production that occur during arousal (Morin and Storey, 2007; Eddy et al., Storey, 2005; Allan and Storey, 2012; Vucetic et al., 2013).

The observed increase in SIRT6 protein levels during interbout arousal may also function with a similar purpose: SIRT6 protein levels are known to be elevated in response to oxidative stress, and directly promote DNA double-strand-break repair to mitigate genomic damage as a result of the increased prevalence of ROS (Mao et al., 2011). Since skeletal muscle experiences drastic increases in ROS production as a result of shivering thermogenesis during arousal from torpor, this function of elevated SIRT6 in muscle of arousing (an upward trend) and aroused (significantly higher) hibernators may help protect the tissue during this exposure to oxidative stress. In WAT, the increase in SIRT2 
levels during late torpor (together with rising trends before LT and decreases after LT) may reflect this tissue's integral function in sustaining the systemic energy requirements of the animal throughout hibernation. Food deprivation has been shown to increase the expression of SIRT2 in white adipocytes of mice, directly leading to the promotion of fatty acid mobilization via lipolysis and the inhibition of adipocyte differentiation (Wang and Tong, 2009). The increased expression of SIRT2 in hibernator WAT could therefore serve a similar purpose, and may contribute to the mobilization of lipid stores that are absolutely necessary to maintain the hibernation state (Dark, 2005). The decreased expression of mitochondrial SIRT3, SIRT4 and SIRT5 during torpor (and arousal for SIRT3 and SIRT4) in WAT are surprising considering the known functions of SIRT3 in promoting lipid mobilization in other systems. However, they provide insight into the possible role of mitochondrial protein acetylation in this tissue, suggesting a possible emphasis on lower levels of deacetylation during this time. While the exact functions of the observed changes in SIRT protein expression remain to be determined, these results clearly suggest a role for the differential regulation of SIRT proteins in multiple tissues of the mammalian hibernator.

To gain further insight into the possible significance of the observed fluctuations in SIRT protein levels throughout hibernation, total SIRT activity was assayed and compared between tissues from euthermic (EC time point) and torpid (LT time point) animals (Fig. 4.3-4.5). Interestingly, the only significant fluctuation in activity between the two tested time points at an assay temperature of $37^{\circ} \mathrm{C}$ was observed for total protein extracts of muscle tissue (Fig. 4.4A), where total SIRT activity was 3.6-fold higher during torpor as compared to euthermia. Given that the activity of muscle nuclear protein extracts did not 
change significantly under the same conditions (Fig. 4.4B), these results suggest that the increase in total SIRT activity was localized outside of the nucleus, encompassing those SIRTs located in the cytoplasm and mitochondria. This possibility is compelling given the strong increase in SIRT3 protein levels observed in muscle tissue in ET and LT (Fig. 4.1). Since SIRT3 is mainly a mitochondrial enzyme (Lombard et al., 2007), any increase in its activity would be expected to be detected in total protein extracts as opposed to nuclear extracts. However, given that the current assay does not allow the measurement of the activities of specific SIRT isozymes, but instead only total SIRT activity, no conclusions can be drawn regarding the responses of individual SIRTs. Nonetheless, the correlated increase in SIRT3 protein levels and total SIRT activity in muscle total protein extracts provides further support for a role of SIRTs in the torpid state.

In addition to determining total SIRT activity at an assay temperature that is reflective of a euthermic animal $\left(37^{\circ} \mathrm{C}\right)$, the measurements were also repeated at $4^{\circ} \mathrm{C}$ to simulate the core body temperature of a torpid animal. At this lowered assay temperature, the increase in SIRT activity observed in muscle total protein extracts at $37^{\circ} \mathrm{C}$ was again apparent (Fig. 4.4A), in addition to a significant increase in activity in liver total protein extracts (Fig. 4.3A). Remarkably, however, when the activities in muscle total protein were compared between assays at $37^{\circ} \mathrm{C}$ and $4^{\circ} \mathrm{C}$, the values were not statistically different for each respective time-point. This same effect was also observed in BAT: while no significant changes occurred between euthermic and torpid animals in this tissue, the activities determined at $37^{\circ} \mathrm{C}$ were not statistically different from those at $4^{\circ} \mathrm{C}$ (Fig. 4.5A). This would suggest that SIRT activity in these tissues is maintained at the low temperatures experienced during torpor, indicating a role for continued SIRT function 
during metabolic suppression. While such a discovery is certainly remarkable, it is also not unique - numerous examples of temperature-independence and cold-adapted function exist within the hibernator proteome (reviewed by Storey and Storey, 2010). For instance, the maximal binding capacity and substrate dissociation constant (measure of protein affinity for its ligand, and therefore its efficiency) of the mitochondrial uncoupling protein UCP1 for GDP were found to remain constant in hibernator brown adipose tissue when temperature was significantly reduced (Malan and Mioskowski, 1988). This indicates that this essential protein of thermogenesis could function effectively over the full range of the body temperatures experienced during torpor-arousal. Similar conclusions were drawn for fatty acid binding protein (FABP), an important component of lipid catabolism responsible for the delivery of fatty acids to mitochondria for subsequent oxidation. Hibernator FABP showed temperature-insensitive binding affinities for numerous fatty acids over the temperature range of $37^{\circ} \mathrm{C}-5^{\circ} \mathrm{C}$, while the same was not true for FABP from a non-hibernating animal (Stewart et al., 1998), indicating the ability of the hibernator protein to maintain its function at the low temperatures of torpor, when fatty acid oxidation is key to the animal's survival. Protein kinase A (PKA), a kinase involved in cellular signal transduction and the activation of thermogenesis in brown adipose tissue, is also known to be positively regulated by temperature reductions (MacDonald and Storey, 1998). The $\mathrm{K}_{\mathrm{m}}$ of hibernator PKA in brown adipose tissue decreased by $50-80 \%$ for particular substrates when assays were compared between $5^{\circ} \mathrm{C}$ and $37^{\circ} \mathrm{C}$, indicating increased substrate affinity and enhanced function at torpor-level temperatures (MacDonald and Storey, 1998). Thus, when taken in light of these known cold-adaptations of hibernator proteins, the discovery of maintained 
SIRT activity at $4^{\circ} \mathrm{C}$ is not overly surprising. It is interesting, however, that this apparent effect was only observed for SIRT activity in muscle and brown adipose - the two tissues responsible for thermogenesis during arousal. As is the case for UCP1 and PKA, it is possible that SIRT activity may be important in regulating the activation of thermogenesis during the rewarming period of arousal, and would therefore benefit from a temperature-independent activity profile; i.e. to initiate the warming between torpor and arousal, activity would need to be maintained at the low body temperature of the torpid state. Given that SIRTs have previously been implicated as regulators of thermogenesis in other animals (Shi et al., 2005), this suggested role is possible. Regardless, the association of temperature-independence with total SIRT activity in selected hibernator tissues - while still needing further study - certainly suggests an important role for these enzymes in the context of the hibernation phenotype.

An incredibly diverse range of proteins are influenced by SIRT activity. Indeed, SIRT deacetylation of downstream targets serves a wide range of purposes, including the induction of conformational changes, the modulation of protein binding affinities, and the regulation of enzyme activities (Li and Kazgan, 2011; Haigis and Sinclair, 2010). Two examples of SIRT-targeted proteins are the antioxidant enzyme SOD2 (Chen et al., 2011), and the p65 subunit of the transcription factor NF- $\kappa \mathrm{B}$ (Rothgiesser et al., 2010). SOD2 is a mitochondrial ROS-scavenging enzyme that prevents the accumulation of the reactive superoxide anion that is generated as a result of normal aerobic metabolism (Finkel and Holbrook, 2000). In response to caloric restriction and oxidative stress, SIRT3 - the major mitochondrial sirtuin - deacetylates SOD2 at lysine residue 68 (K68), causing an increase in its antioxidant activity (Chen et al., 2011). Interestingly, levels of 
SOD2 acetylated at K68 were found to decrease significantly in hibernator liver, muscle, and white adipose during late torpor, as well as in muscle during interbout arousal (Fig. 4.6), suggesting that SOD2 activity is increased in these tissues during those times. Intriguing still, SOD2 acetylation at K68 appears to decrease in muscle in correlation with increased SIRT3 protein levels and total SIRT activity during late torpor. These correlated observations might suggest the SIRT-mediated control of an oxidative stress response in hibernator muscle during torpor, possibly representing a novel protective strategy employed by these animals. While similar correlations were not observed during interbout arousal or in liver or white adipose during late torpor, the observed decrease in levels of SOD2 K68 acetylation still supports the general notion of increased antioxidant activity in these tissues as a result of differential acetylation, be it mediated by SIRTs or otherwise. Previous studies have also provided evidence of a role for increased SOD2 activity in the tissues of mammalian hibernators (Vucetic et al., 2013; Allan and Storey, 2012), but the current results represent the first support for differential acetylation acting as a possible mechanism for promoting SOD2 activity in this context.

Similar conclusions were also drawn for the NF- $\mathrm{BB}$ subunit $\mathrm{p} 65$. NF- $\mathrm{\kappa B}$ itself is an inducible transcription factor that is a heterodimer of p50 and p65 subunits, and is typically present in a latent inactive state in the cytoplasm via its binding to an inhibitor

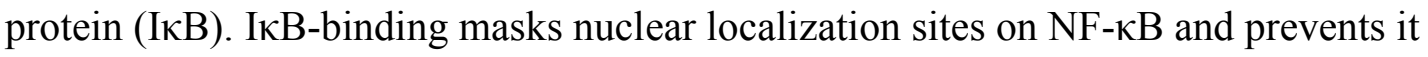
from entering the nucleus, but various stimuli induce phosphorylation of I $\mathrm{I} B$ to target it for ubiquitination and degradation, thereby freeing NF- $\mathrm{kB}$ and allowing it to translocate to the nucleus (Karin and Ben Neriah, 2000). There, NF- $\kappa B$ mediates the expression of downstream genes that control oxidative stress responses, inflammation, apoptosis, and 
other important cellular processes (Vallabhapurapu and Karin, 2009; Morgan and Liu, 2011; Kaltschmidt et al., 2000). The transactivation potential of NF- $\kappa \mathrm{B}$ is also regulated by reversible phosphorylation, whereby p65 phosphorylation on serine residue 536 leads to the enhanced activity of the transcription factor (Viatour et al., 2005). Perhaps unsurprisingly, the p65 subunit is also regulated by SIRT deacetylation at lysine residue 310 (K310), whereby decreased levels of K310 acetylation result in the decreased

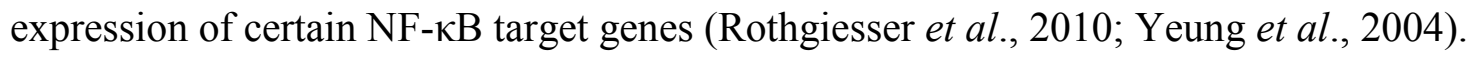
In the hibernator, K310 acetylation of p65 decreased significantly in liver during late torpor, but increased during interbout in liver and early arousal in brown adipose tissue (Fig. 4.7). In the case of liver, these results appear to suggest that the transcriptional activity of NF- $\kappa \mathrm{B}$ may be decreased during late torpor, but stimulated once the animal has returned to euthermia. This differential regulation could serve the hibernator well, depending on the gene targets controlled by such a process. For example, if a reduction in NF- $\kappa \mathrm{B}$ activity during late torpor reduced its pro-apoptotic effects (Kaltschmidt et al., 2000), this could serve as a protective mechanism for maintaining cellular integrity during this period of inactivity. Indeed, evidence exists for a role of anti-apoptotic pathways as a protective mechanism in hibernator tissues (Rouble et al., 2013). Similarly, if the stimulation of NF- $\kappa$ B downstream targets during arousal in liver and BAT lead to enhanced antioxidant responses (Morgan and Liu, 2011), this would be an adaptive strategy of regulation for the hibernator. Alternatively, since NF- $\kappa \mathrm{B}$ is a diverse transcriptional regulator, a decrease/increase in $\mathrm{NF}-\kappa \mathrm{B}$ activity could simply reflect the global decrease in transcriptional activity that occurs during torpor, and the subsequent reactivation that proceeds during arousal. 
Whatever the ultimate purpose for the observed fluctuations in the acetylation status of these SIRT-targeted lysine residues of NF- $\mathrm{BB}$ p65 and SOD2, the current results provide further evidence to support a role for SIRT activity during hibernation. While it is possible that other uncharacterized deacetylases may be responsible for these changes, the simple occurrence of such fluctuations is also further evidence to support the notion that differential protein acetylation likely plays some role in the regulation of the torporarousal cycle.

The evolutionarily conserved SIRT family of protein deacetylases has been shown to play fundamental roles in the regulation of a diverse array of metabolic processes. The current study appears to expand upon these previously established functions by providing evidence to support a role for SIRTs in the regulation of the metabolic and protective pathways that mediate the process of mammalian hibernation. With the combined observation of tissue-specific differential SIRT protein expression, enhanced - and in some cases, apparently temperature-insensitive - SIRT activity, and fluctuating acetylation of downstream SIRT targets, the data suggest that these enzymes are involved in the control of this form of reversible hypometabolism. Specifically, it appears that SIRT activity may play an important role in skeletal muscle during torpor, given the interesting correlation between increased SIRT3 protein expression, increased overall SIRT activity in total protein extracts, and the decreased acetylation of the SIRT3 downstream target SOD2 (K68) observed at this time. Interestingly, Morin and Storey (2006) reported a similar correlation in hibernator muscle for the expression of class I and II HDACs, whereby specific HDAC protein levels and total HDAC activity increased with a concurrent decrease in downstream acetylation of relevant histone targets, 
suggesting now that all classes of histone deacetylases may be involved in the regulation of hibernation. Further, the apparent temperature independence of total SIRT activity in both muscle and BAT suggests a need for the continued function of these enzymes at the low temperatures experienced during torpor, and possibly indicates their relevance to the thermoregulatory functions of these tissues. Despite these intriguing insights, the present data have only just begun to characterize the SIRT family of deacetylases in the context of the mammalian hibernator, and much work remains to be done to fully elucidate the possible roles that these enzymes play in regulating the metabolic and protective pathways that are central to hypometabolism. However, it appears that the expression of SIRTs may indeed be characteristic of this natural process, and is likely another example of the conserved function of sirtuins in the universal regulation of metabolic homeostasis and cellular protective responses. Perhaps more importantly, this also represents the further establishment of a likely role for differential protein acetylation in the context of hibernation. 


\section{Figures}

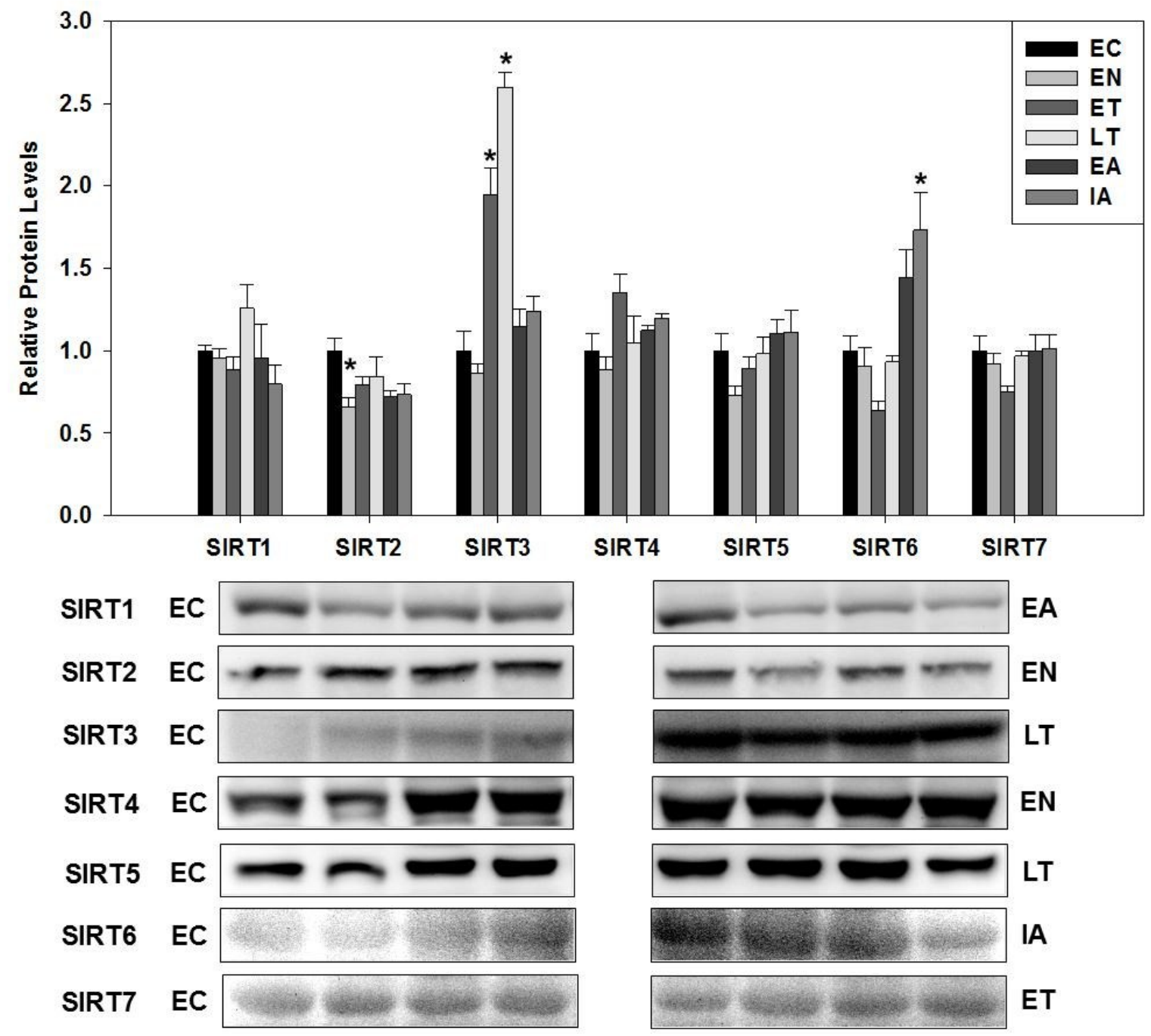

Fig. 4.1. Relative protein expression of SIRT1, SIRT2, SIRT3, SIRT4, SIRT5, SIRT6 and SIRT7 in skeletal muscle of I. tridecemlineatus over the torpor-arousal cycle. Representative protein bands are shown for selected sampling points (labelled to the left and right of the blots). Histogram shows mean standardized band densities ( \pm SEM, $n=3-4$ independent trials on tissue from different animals). Protein bands were standardized against the summed intensity of a group of Coomassie-stained protein bands from the same sample lane. Data were analyzed using a one-way ANOVA with a post hoc Tukey test. ${ }^{*}=$ Significantly different from the respective EC control, $\mathrm{p}<0.05$. 


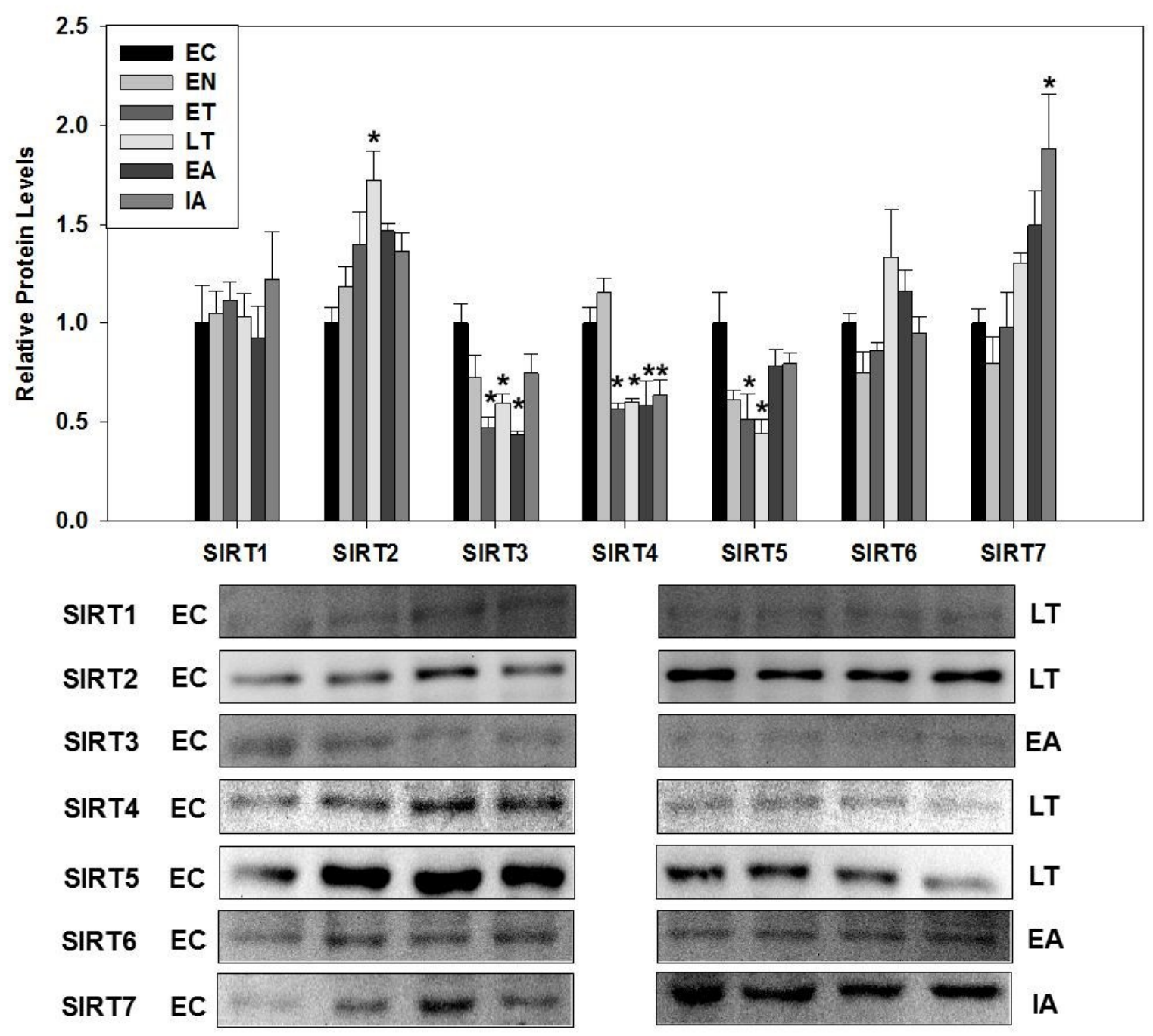

Fig. 4.2. Relative protein expression of SIRT1, SIRT2, SIRT3, SIRT4, SIRT5, SIRT6 and SIRT7 in WAT of I. tridecemlineatus over the torpor-arousal cycle. All other information as in Fig. 4.1. 
A)

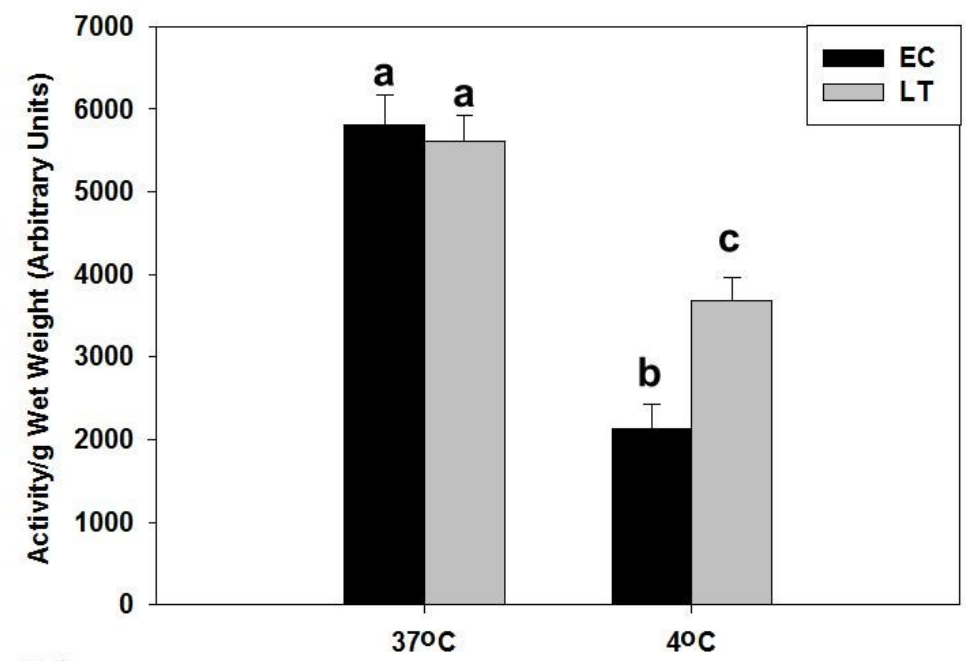

B)

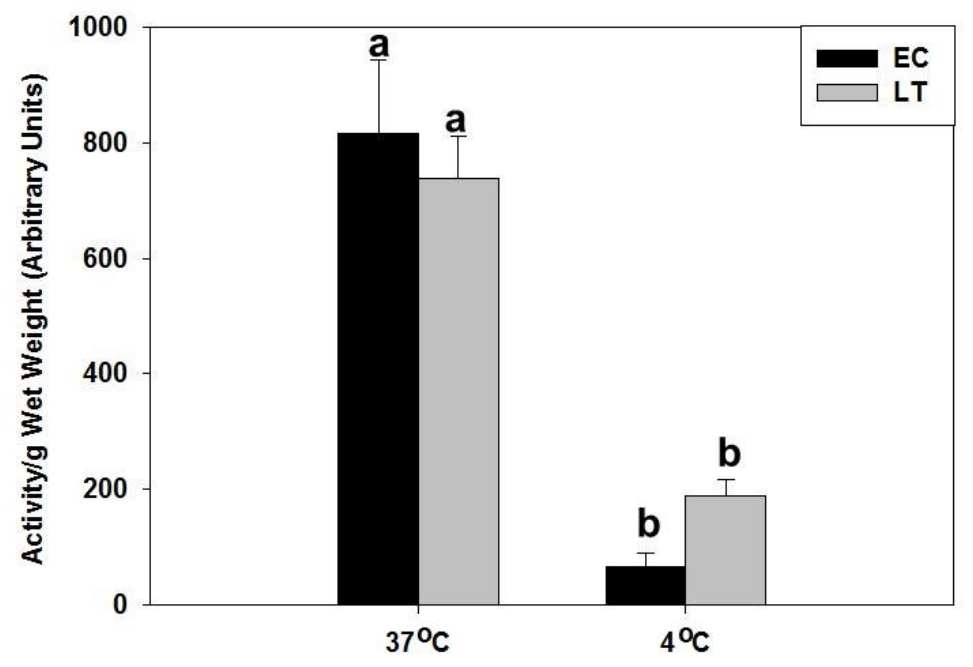

Fig. 4.3. Total SIRT activity in liver of I. tridecemlineatus comparing euthermic control (EC) and late torpor (LT) points of the torpor-arousal cycle with assays at two temperatures, $37^{\circ} \mathrm{C}$ and $4^{\circ} \mathrm{C}$. Enzyme activities in A) total soluble extracts and B) nuclear extracts are expressed as activities (arbitrary units) per gram wet weight of starting tissue. Histograms show means \pm SEM, $n=3-4$ independent assays on tissue from different animals. Data were analyzed using a one-way ANOVA with a post-hoc Tukey test. Values that share the same letter notation are not significantly different from one another $(\mathrm{p}>0.05)$. 
A)

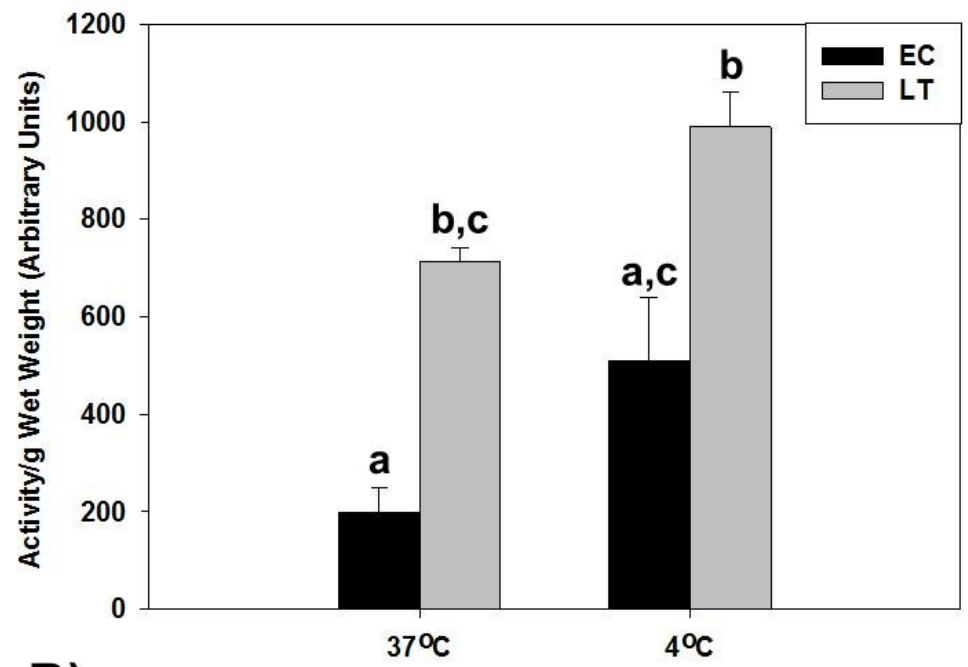

B)

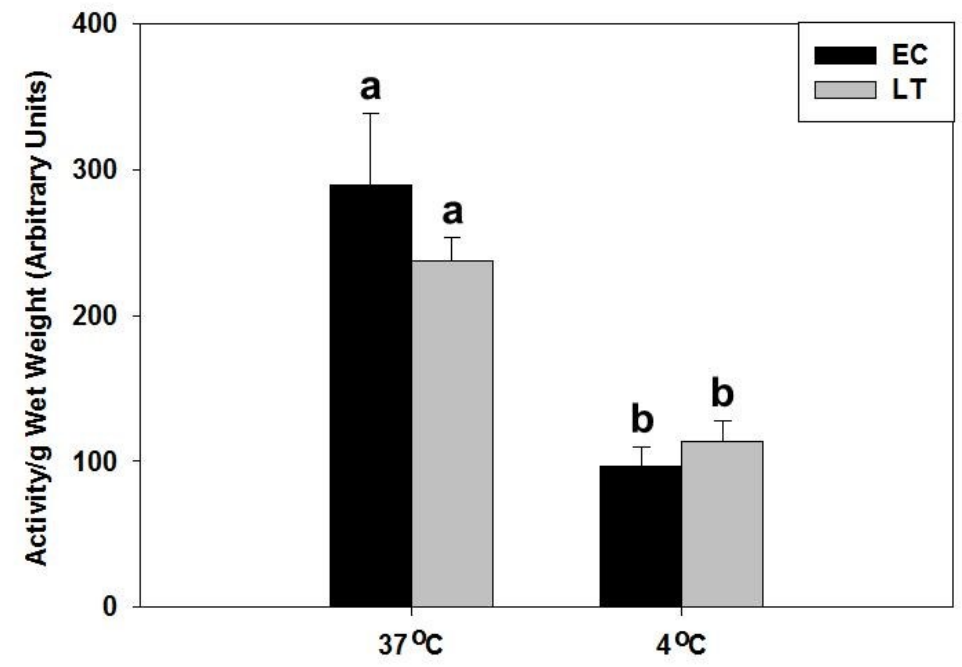

Fig. 4.4. Total SIRT activity in skeletal muscle of I. tridecemlineatus comparing euthermic control (EC) and late torpor (LT) points of the torpor-arousal cycle with assays at two temperatures, $37^{\circ} \mathrm{C}$ and $4^{\circ} \mathrm{C}$. Enzyme activities in A) total soluble extracts and $\mathrm{B}$ ) nuclear extracts are expressed as activities (arbitrary units) per gram wet weight of starting tissue. All other information as in Fig. 4.3. 
A)

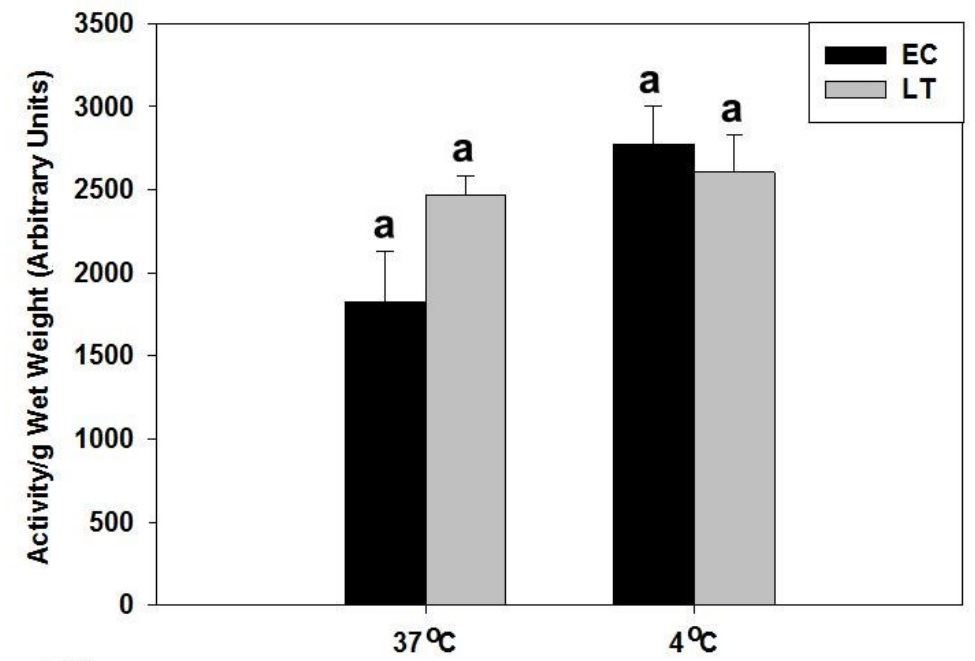

B)

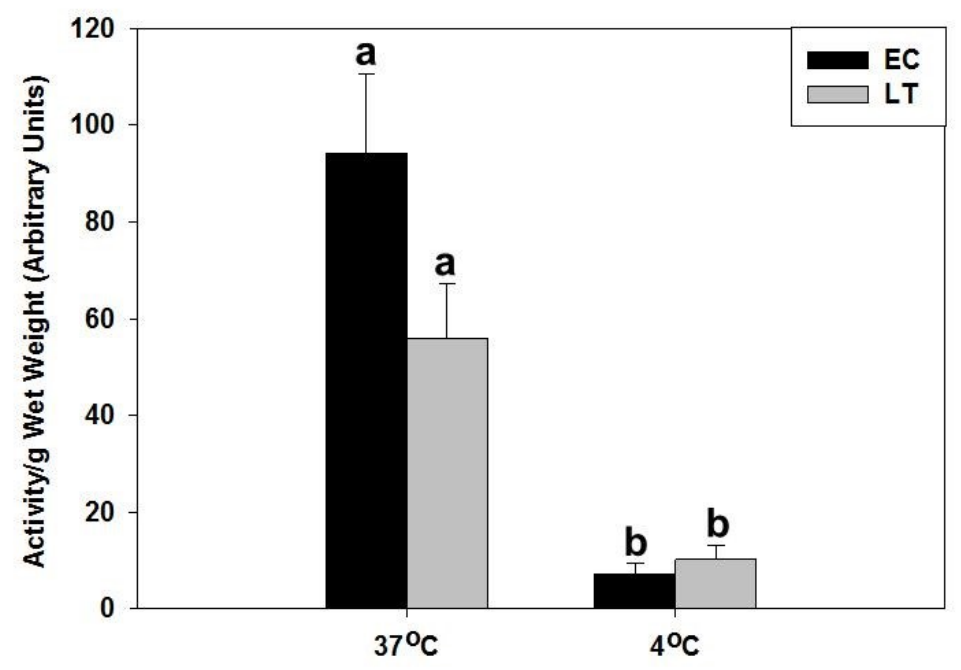

Fig. 4.5. Total SIRT activity in A) BAT and B) WAT of I. tridecemlineatus comparing euthermic control (EC) and late torpor (LT) points of the torpor-arousal cycle with assays at two temperatures, $37^{\circ} \mathrm{C}$ and $4^{\circ} \mathrm{C}$. Enzyme activities in total soluble extracts are expressed as activities (arbitrary units) per gram wet weight of starting tissue. All other information as in Fig. 4.3. 


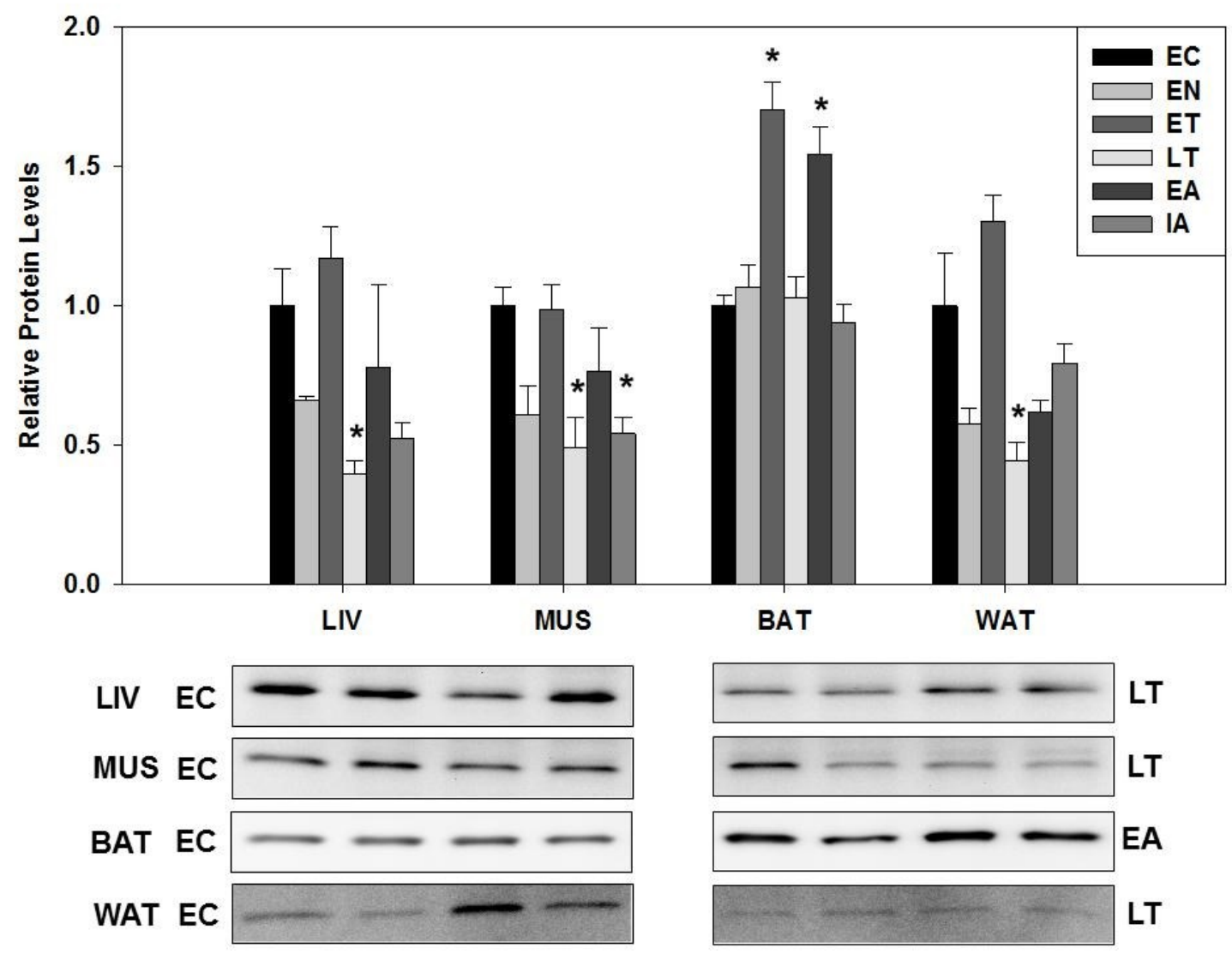

Fig. 4.6. Relative protein expression of SOD2 acetylated at lysine 68 in liver, skeletal muscle, BAT and WAT of I. tridecemlineatus over the torpor-arousal cycle. All other information as in Fig. 4.1. 


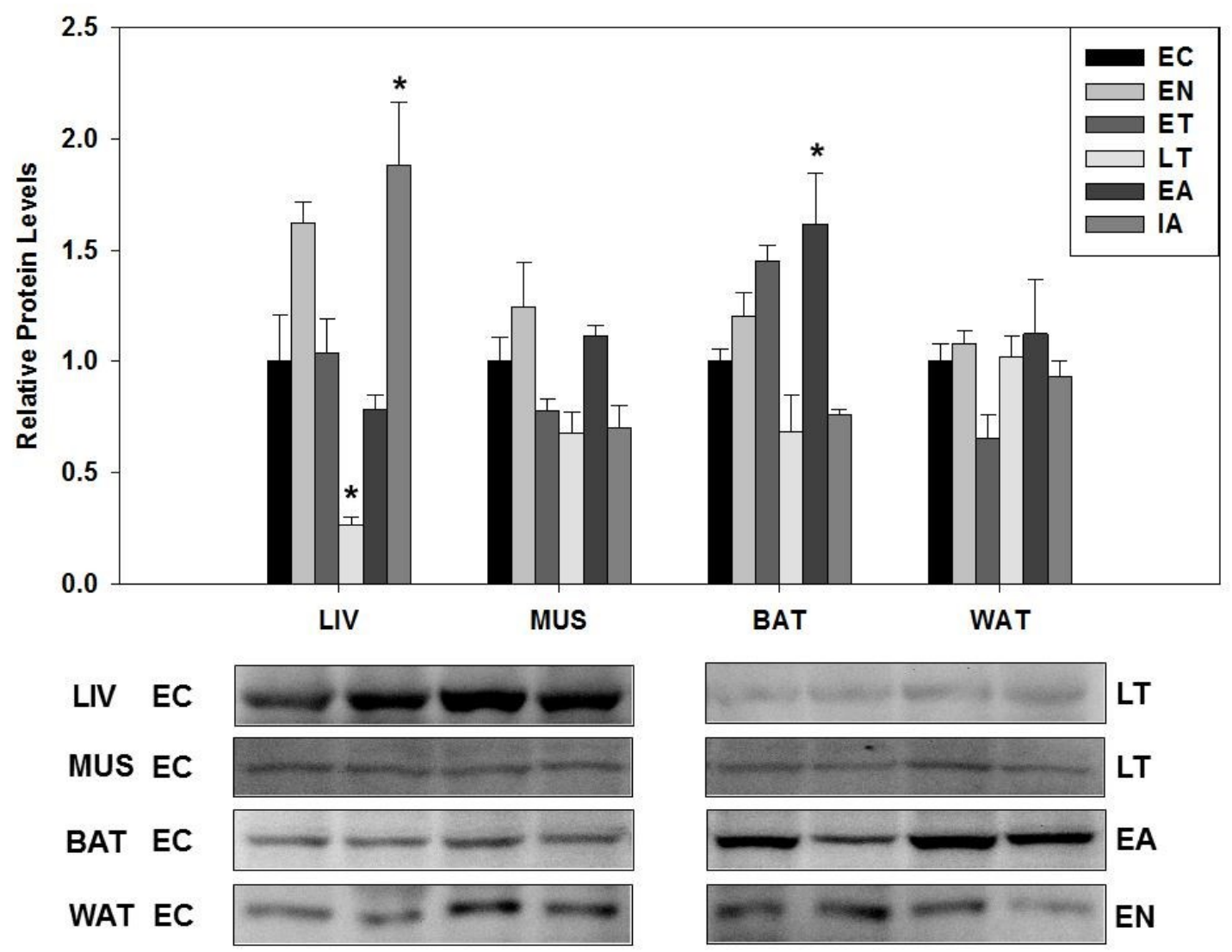

Fig. 4.7. Relative protein expression of NF- $\kappa B$ p65 acetylated at lysine 310 in liver, skeletal muscle, BAT and WAT of I. tridecemlineatus over the torpor-arousal cycle. All other information as in Fig. 4.1. 


\section{Chapter 5}

General Discussion 
Mammalian hibernation is a truly remarkable phenomenon. Whereas many animals have adopted cold-avoidance strategies that involve the physical evasion of the stressor (e.g. migration in response to winter temperatures and food shortages), or the energeticallydemanding ability to withstand such harsh conditions (e.g. large mammals or birds that endure the winter months, but which require large amounts of food/energy to do so), hibernators have evolved a very different strategy of avoidance. Indeed, hibernators are capable of easily maintaining their energy requirements in the face of low temperatures and limited access to food, simply by redefining what those requirements are. By depressing their metabolic rate and suspending many cellular processes, these animals reduce their energy needs to a level that is more easily supported by their accumulated fat stores, thus enabling their survival under conditions that would otherwise make their success unsustainable. In addition to this global control of metabolic suppression, these animals further maintain the integrity of their tissues by actively employing protective strategies that allow for the rapid recovery of physiological functions upon arousal, and which prevent irreversible cellular deterioration throughout hibernation. These exceptional abilities are the result of the wide-scale biochemical changes that occur throughout the torpor-arousal cycle, which are governed by intricate molecular mechanisms that affect the regulation of most aspects of cellular function, including transcription, translation, signal transduction, and enzyme activity. The post-translational modification of proteins serves a major role within this regulatory framework, and is responsible for much of the strong depression of enzyme activity that accompanies torpor. 
As described in Chapter 1, the reversible phosphorylation of many cellular proteins is characteristic of the hibernating state, and is also absolutely fundamental to the mediation of normal cellular processes. The control of metabolic enzyme activity, transcription factor binding affinities, and numerous other protein functions are widely mediated by RPP in eukaryotes, including in the context of other stress-responses that involve reductions in cellular energy requirements similar to those employed by hibernators, such as estivation, freeze-tolerance, and anoxia-tolerance (Storey and Storey, 2004; Storey, 2010). Thus, RPP represents a conserved regulatory mechanism that is integral for normal cellular function in most animals, and whose ubiquity translates to even the most extreme instances of metabolic regulation. For this reason, the current study has attempted to draw an analogy between RPP and another ubiquitous post-translational protein modification (Choudhary and Mann, 2010; Zhao et al., 2010) - reversible protein acetylation - in the context of the hibernator. As discussed previously, reversible acetylation is known to mediate control over an incredibly diverse range of protein functions in non-hibernating species, with many roles that may overlap, complement, or even oppose those of RPP (Xiong and Guan, 2012; Zentner and Henikoff, 2013; Zhao et al., 2010; Guan and Xiong, 2011). For example, acetylation is a major regulator of transcription (via the modification of histones and transcription factors) and metabolic proteins (including most of those involved in glycolysis, gluconeogenesis, nitrogen metabolism, lipid metabolism, and the TCA cycle), and is known to mediate the activation of cellular protective responses (Xiong and Guan, 2012; Zhao et al., 2010; Haigis and Sinclair, 2010). All of these are also affected by RPP and are relevant to the success of the hibernation phenotype. As mentioned in previous chapters, some evidence 
also currently exists to suggest a role for reversible acetylation in the context of mammalian hibernation (Morin and Storey, 2006), although such data are not as extensive as those related to RPP.

Thus, given the known functions of protein acetylation in other systems, its many similarities and overlapping roles with RPP, and the existing evidence, this thesis hypothesized that reversible protein acetylation is involved in the regulation of mammalian hibernation. To address this suggestion, this study attempted to provide a preliminary characterization of important mediators of reversible acetylation and assess the acetylation status of several of their downstream protein targets, in the context of an established model of hibernation, the thirteen-lined ground squirrel. Chapter 3 focused on the expression and activity of KATs, the enzymes responsible for the addition of an acetyl moiety to protein lysine residues, while Chapter 4 was concerned with a wellknown group of deacetylases, SIRTs, that govern the reverse reaction. When taken together, the results of these studies provide strong evidence to suggest a role for differential protein acetylation throughout the course of the torpor-arousal cycle.

One of the interesting aspects of hibernation is the somewhat counterintuitive way that protein expression is regulated during the torpor bout. While a distinct global shutdown of most protein synthesis and degradation is characteristic of hibernation (i.e. the levels of most proteins remain constant), there is also overwhelming evidence of the differential expression of specific proteins over this background of stability. Given that hibernators must minimize any unnecessary energy expenditures in order to survive over the winter months, and since protein synthesis and degradation are inherently energy-intensive processes, such fluctuations typically only occur if they serve a specific and important 
purpose to the maintenance of the hibernation cycle. Thus, the observation of changing levels of particular proteins throughout torpor-arousal typically suggests a role for those factors in the regulation of this dynamic process (e.g. one key example of this is the upregulation of fatty acid binding proteins that are crucial for intracellular transport of the primary lipid fuel used to sustain torpor (Storey and Storey, 2010)). Such is the case for the results of this thesis - protein levels of several of the studied KATs and SIRTs were observed to fluctuate differentially over the course of hibernation in a tissue-specific manner, suggesting that these changes serve a role in mediating the processes that govern the torpor-arousal cycle. While the determination of the exact functions of such changes is unfortunately beyond the scope of this study, insight can be drawn from what is known about these factors in other contexts. For example, SIRT3 activation is associated with elevation of oxidative stress responses in the tissues of other mammals (Qui et al., 2010; Tao et al., 2010), so its observed upregulation during torpor in skeletal muscle of $I$. tridecemlineatus might occur for a similar purpose (as discussed in Chapter 4, this would be advantageous for the hibernator). Similarly, the observed reductions in the protein levels of both CBP and GCN5L2 in skeletal muscle during hibernation might contribute to the global suppression of transcriptional activity that occurs in this tissue throughout torpor (as discussed in Chapter 3), since both of these enzymes are known to be major co-transcriptional activators with numerous downstream targets in other mammals (Chan and La Thangue 2001; Kalkhoven, 2004; Nagy and Tora, 2007). Thus, it is possible that the many protein changes observed in the studied tissues reflect known roles of these factors that are relevant to the regulation of hibernation. Further insight can also be drawn from the fact that such changes differed amongst the studied tissues, which would suggest 
that the activities of these enzymes are likely context-specific and not necessarily identical across all cell types during torpor. This occurrence would certainly not be surprising, given that such directed responses are known to occur for many other hibernator proteins, and since KATs and SIRTs have established tissue-specific roles in other systems. Considering the broad range of functions of these enzymes that are applicable to this unique system (e.g. metabolic regulation, protective responses, transcriptional regulation), it is reasonable to suggest that the observed protein fluctuations might be related to some of those roles. However, since these enzymes do serve such a vast array of functions in the cell (and in different cell types), it is impossible to say with certainty which of those activities are prevalent throughout torpor, since the current data are limiting in terms of what they indicate regarding functional significance. That being said, the identification of such fluctuations is still an incredibly important and valuable first step towards understanding the full picture of KAT and SIRT involvement during hibernation and, perhaps more importantly, characterizing the role of reversible acetylation within this context.

While the determination of KAT and SIRT protein expression is integral to deciphering the roles of these enzymes during the torpor-arousal cycle, the characterization of their activities is also essential. In Chapters 3 and 4, total KAT and SIRT activities were measured in tissues of I. tridecemlineatus, and much like their protein levels, were observed to change differentially in a tissue-specific manner, thereby providing further evidence to support a role for these enzymes in the hibernator system. Most intriguing, however, was the observation of several potentially interesting correlations between the activity and protein data, and with the results of previous studies. For example, in total 
protein extracts of muscle tissue, total SIRT activity was elevated during torpor as compared to controls, occurring concurrently with a significant increase in the protein levels of SIRT3, the major mitochondrial SIRT. This increase in activity, however, was not observed in nuclear protein extracts from muscle tissue, suggesting that the enhanced activity was due to the actions of non-nuclear SIRTs such as SIRT3. This notion is also supported by the observation of the decreased acetylation status of a downstream SIRT3 target, SOD2 (the mitochondrial Mn-dependent SOD), in muscle tissue at this time. Furthermore, these results coincide with those of a previous study which identified a significant increase in non-SIRT total HDAC activity during torpor in skeletal muscle of the same species, in addition to the reduced acetylation of an HDAC-targeted histone residue (Morin and Storey, 2006). When considered in the context of this past research, the current data therefore appear to indicate a wide role for deacetylase activity in this tissue during torpor. Interestingly, total KAT activity did not change significantly in muscle tissue during torpor, although the protein levels of two major KATs (CBP and GCN5L2, described above) decreased significantly. Thus, these combined results might suggest an emphasis on protein deacetylation in this tissue during torpor, which could potentially contribute to the overall decrease in transcriptional and metabolic activity that is characteristic of hibernating muscle.

In contrast to this possibility, the opposite appears to be true for BAT, in which levels of SIRT activity and protein expression did not change significantly during torpor, whereas total KAT activity increased concurrently with protein levels of GCN5L2. Additionally, the acetylation status of two histone targets of KAT activity (including that of GCN5L2) were found to increase significantly during hibernation, suggesting that acetylation might 
play a role in regulating transcriptional activation in BAT during this time. As discussed thoroughly in Chapter 3, if such transcriptional activation were to contribute to thermoregulatory pathways, this mechanism might be functional for BAT due to the tissue's role in regulating thermogenesis during torpor and arousal. Regardless of their actual purpose, these changes in KAT activity and histone acetylation are also evidence of epigenetic controls that might contribute to the maintenance of the hibernation phenotype, which is itself an interesting discovery and supports previous suggestions of the likelihood of epigenetic regulation serving a role in this system (Morin and Storey, 2006; Morin and Storey 2009).

In addition to these observed fluctuations, further evidence of the importance of reversible acetylation to the hibernation phenotype comes from the apparent temperature insensitivity of total SIRT activity measured in muscle and BAT. Indeed, the presence of such a phenomenon suggests that these enzymes may be adapted for function at the low temperatures experienced during torpor. If so, this would indicate a strong need for the continued presence of SIRT activity in these tissues during hibernation, and would certainly underscore a significant role for reversible acetylation at this time.

Unfortunately, as discussed in previous chapters, the activity measurements described here are limited by the fact that they encompass only total KAT and SIRT activities, and therefore cannot be used as evidence of activity changes or temperature independence for any specific enzyme (e.g. SIRT3, GCN5L2), regardless of the presence or absence of correlated protein fluctuations. For this reason, future studies assessing the activity of specific members of the KAT and SIRT families would be valuable for determining the true causes of the observed changes and temperature effects on total activity. However, 
despite this limitation, the current results nonetheless further support a role for these enzymes - and by extension, reversible acetylation in general - in the context of hibernation.

Perhaps most relevant to the overall hypothesis of this thesis is the observation of changing levels of protein acetylation for certain factors, as briefly mentioned above and outlined in Chapters 3 and 4 . Indeed, to establish any support for the notion that reversible protein acetylation likely contributes to the regulation of hibernation, the actual identification of differentially acetylated proteins over the course of the torpor-arousal cycle is mandatory. Thus, the observation of changing levels of this post-translational modification for all four of the acetyl-proteins that were measured is evidence to support such a notion. Furthermore, these observations also provide insight into how acetylation might affect the process of hibernation, and implicate it as a potential control mechanism for a wide range of processes. For example, it appears that this modification might contribute to the regulation of oxidative stress responses in the hibernator, given the observed fluctuations of the acetylation status of the antioxidant enzyme SOD2, which is activated by deacetylation (Chen et al., 2011). Likewise, acetylation may also contribute to the transcriptional regulation of specific gene pathways, as evidenced by the changing acetylation status of the p65 subunit of the major transcription factor NF- $\mathrm{BB}$, whose activity is affected by the modification (Yeung et al., 2004; Ghizzoni et al., 2011; Rothgiesser et al., 2010). Since NF- $\kappa B$ is responsible for the regulation of a diverse range of cellular functions (including apoptosis, oxidative stress resistance and inflammatory responses), the differential acetylation of this factor throughout the torpor-arousal cycle could affect the transcription of numerous target genes related to the success of the 
hibernation phenotype. Similarly, the differential acetylation of histone H3 residues K9 and K14 suggests further transcriptional regulation by this modification via epigenetic mechanisms, which could serve multiple purposes depending on the genes that are activated/repressed by such changes. Thus, even if considered independently from the investigation of KAT and SIRT activity, the observed changes in protein acetylation strongly establish this modification as being characteristic of mammalian hibernation. However, the current investigation has only scratched the surface of what is likely an extensive "hibernation acetylome". Given the known diversity of protein acetylation in other mammals (Choudhary and Mann, 2010; Zhao et al., 2010), the activities of thousands of other protein targets could potentially be regulated by this mechanism during hibernation. Thus, future studies ought to determine the acetylation status of other targets over the torpor-arousal cycle, whether on a large scale (i.e. mass spectrometry proteomics) or for individual proteins, in order to gain a better understanding of the true significance of this increasingly important functional group to the hibernation phenotype.

\section{$\underline{\text { Conclusion }}$}

The molecular regulation of hibernation encompasses a wide range of biochemical mechanisms that contribute to an intricate network of signaling events whose ultimate purpose is to mediate the drastic fluctuations in metabolic rate, protective responses, and other fundamental cellular processes that occur over the torpor-arousal cycle. While many of these mechanisms have been studied in depth, the potential role of reversible protein acetylation has not been previously investigated in much detail. By completing a preliminary characterization of some of the most prominent enzymes that catalyze the process - several KAT acetyltransferases and the SIRT family of deacetylases - this 
thesis has provided strong evidence to suggest that reversible acetylation functions in an important capacity during the hibernation bout. As hypothesized, protein levels and activities of KATs and SIRTs showed differential changes throughout hibernation, and were found to do so in a tissue-specific manner. Furthermore, preliminary evidence was also obtained to suggest a possible adaptation of SIRT activity to the low temperatures experienced by the hibernator during torpor, which supports the notion that the continued function of these enzymes is required during the metabolic rate depression. Most importantly, the acetylation status of several downstream KAT and SIRT targets was also observed to change throughout torpor-arousal, in some cases correlated with changes in KAT and SIRT protein levels and activity. In this way, reversible acetylation is implicated as a possible mediator of a wide variety of cellular processes - including antioxidant responses, transcription factor dynamics, and epigenetic regulation - during the hibernation bout. Although the current data represent only a brief glimpse into what is likely a comprehensive network of acetylation-mediated responses in this unique system, the work herein establishes an important foundation for future studies intended to more clearly elucidate the extent of protein acetylation in the context of mammalian hibernation. As discussed briefly, such studies would be wise to focus on determining the actual causes of the observed fluctuations in KAT and SIRT activity (e.g. by isolating and analyzing the activity of specific KATs or SIRTs from hibernator tissues), determining possible interactions between these enzymes and their more prominent targets (e.g. immunoprecipitation experiments), and identifying other protein targets that are differentially acetylated throughout the torpor-arousal cycle (e.g. mass spectrometry studies or antibody-based detection methods for acetylated lysine residues). With these 
goals, further investigations would provide significant insight into how wide-spread reversible acetylation is distributed within this system, and would likely allow a greater comparison to be drawn between this and other established regulatory processes, such as RPP. In this way, such studies would further demonstrate the fundamental importance of acetylation to cellular function, extending its ubiquity to even the most extreme examples of metabolic regulation. However, while these future directions would certainly be valuable in this respect, the current thesis still manages to establish a novel role for this post-translational modification, and appears to indicate that the differential acetylation of proteins is characteristic of mammalian hibernation. 


\section{References}


Alcendor, R.R., Kirshenbaum, L.A., Imai, S., Vatner, S.F. and Sadoshima, J. (2004)

Silent Information Regulator $2 \alpha$, a longevity factor and class III histone deacetylase, is an essential endogenous apoptosis inhibitor in cardiac myocytes. Circ. Res. 95: 971-980.

Allan M.E. and Storey K.B. (2012) Expression of NF-кB and downstream antioxidant genes in skeletal muscle of hibernating ground squirrels, Spermophilus tridecemlineatus. Cell Biochem. Funct. 30(2):166-174.

Anderson K.A. and Hirschey M.D. (2012) Mitochondrial protein acetylation regulates metabolism. Essays Biochem. 52:23-35.

Andrews, M.T., Russeth, K.P., Drewes, L.R., and Henry, P.G. (2009) Adaptive mechanisms regulate preferred utilization of ketones in the heart and brain of a hibernating mammal during arousal from torpor. Am. J. Physiol. Regul. Integr. Comp. Physiol. 296(2):R383-93.

Bosch-Presegué L. and Vaquero A. (2013) Sirtuins in stress response: guardians of the genome. Oncogene. 2013:1-12.

Brachmann C.B., Sherman J.M., Devine S.E., Cameron E.E., Pillus L. and Boeke J.D. (1995) The SIR2 gene family, conserved from bacteria to humans, functions in silencing, cell cycle progression, and chromosome stability. Genes \& Development. 9(23):28882902.

Carey, H.V., Andrews, M.T., and Martin, S.L. (2003) Mammalian hibernation: cellular and molecular responses to depressed metabolism and low temperatures. Physiol. Rev. 83, 1153-1181.

Carrozza, M.J., Utley, R.T., Workman, J.L., and Côté, J. (2003) The diverse functions of histone acetyltransferase complexes. Trends in Genetics. 19(6):321-329.

Chan, H.M. and La Thangue, (2001) N.B. p300/CBP proteins: HATs for transcriptional bridges and scaffolds. J. Cell Sci. 114(Pt 13):2363-73.

Chen Y., Zhang J., Lin Y., Lei, Q., Guan K-L., Zhao, S. and Xiong Y. (2011) Tumour suppressor SIRT3 deacetylates and activates manganese superoxide dismutase to scavenge ROS. EMBO Rep. 12(6):534-41.

Chen, H., Tini, M., and Evans, R.M. (2001) HATs on and beyond chromatin. Curr. Opin. Cell Biol. 13(2):218-24.

Chen, I.Y., Lypowy, J., Pain, J., Sayed, D., Grinberg, S., Alcendor, R.R., Sadoshima, J. and Abdellatif, M. (2006) Histone H2A.z is essential for cardiac myocyte hypertrophy but opposed by Silent Information Regulator 2a. J. Biol. Chem. 281: 19369-19377.

Cheung, P., Tanner, K.G., Cheung, W.L., Sassone-corsi, P., Denu, J.M., and Allis, C.D. (2000) Synergistic coupling of histone H3 phosphorylation and acetylation in response to epidermal growth factor stimulation. Mol. Cell. 5(6):905-15. 
Choudhary, C. and Mann, M. (2010) Decoding signaling networks by mass spectrometrybased proteomics. Nat. Rev. Mol. Cell Biol. 11:427-439.

Dark, J. (2005) Annual lipid cycles in hibernators: integration of physiology and behavior. Annu. Rev. Nutr. 25(1):469-497.

De Ruijter A.J., Van Gennip A.H., Caron H.N., Kemp S. and Van Kuilenburg A.B. (2003) Histone deacetylases (HDACs): characterization of the classical HDAC family. Biochem. J. 370(Pt 3):737-749.

Dominy, J.E., Lee, Y., Gerhart-Hines, Z., and Puigserver, P. (2010) Nutrient-dependent regulation of PGC-1alpha's acetylation state and metabolic function through the enzymatic activities of Sirt1/GCN5. Biochim. Biophys. Acta. 1804(8):1676-83.

Eddy S.F., McNally J.D. and Storey K.B. (2005) Up-regulation of a thioredoxin peroxidase-like protein, proliferation-associated gene, in hibernating bats. Arch. Biochem. Biophys. 435(1):103-11.

Eddy, S.F. and Storey, K.B. (2004) Up-regulation of fatty acid-binding proteins during hibernation in the little brown bat, Myotis lucifugus. Biochim. Biophys. Acta. 1676(1):6370 .

Finkel T. and Holbrook N.J. (2000) Oxidants, oxidative stress and the biology of ageing. Nature. 408(6809):239-247.

Frerichs, K.U., Smith, C.B., Brenner, M., DeGracia, D.J., Krause, G.S., Marrone, L., Dever, T.E., and Hallenbeck, J.M. (1998) Suppression of protein synthesis in brain during hibernation involves inhibition of protein initiation and elongation. Proc. Natl. Acad. Sci. USA. 95(24):14511-6.

Frescas, D., Valenti, L. and Accili, D. (2005) Nuclear trapping the forkhead transcription factor FoxO1 via Sirt-dependent deacetylation promotes expression of glucogenetic genes. J. Biol. Chem. 280, 20589-20595.

Gerhart-Hines, Z., Rodgers, J.T., Bare, O., Lerin, C., Kim, S., Mostoslavsky, R., Alt., F.W., Wu, Z. and Puigserver, P. (2007) Metabolic control of muscle mitochondrial function and fatty acid oxidation through SIRT1/PGC-1 $\alpha$. EMBO J. 26: 1913-1923.

Ghizzoni, M., Haisma, H.J., Maarsingh, H. and Dekker, F.J. (2011) Histone acetyltransferases are crucial regulators in NF- $\mathrm{B}$ mediated inflammation. Drug Discov. Today. 16:504-11.

Golozoubova, V., Hohtola, E., Matthias, A., Jacobsson, A., Cannon, B., and Nedergaard, J. (2011) Only UCP1 can mediate adaptive nonshivering thermogenesis in the cold. FASEB J. 15(11):2048-50.

Guan, K-L. and Xiong, Y. (2011) Regulation of intermediary metabolism by protein acetylation. Trends Biochem. Sci. 36, 108-116. 
Haigis, M.C. and Sinclair, D.A. (2010) Mammalian Sirtuins: biological insights and disease relevance. Annu. Rev. Pathol. 5: 253-295.

Henry, R.A., Kuo, Y.M., and Andrews, A.J. (2013) Differences in specificity and selectivity between $\mathrm{CBP}$ and p300 acetylation of histone $\mathrm{H} 3$ and $\mathrm{H} 3 / \mathrm{H} 4$. Biochemistry. 52(34):5746-59.

Hirschey, M.D., Shimazu, T., Goetzman, E., Jing, E., Schwer, B., Lombard, D.B., Grueter, C.A., Harris, C., Biddinger, S., Ilkayeva, O.R., Stevens, R.D., Li, Y., Saha, A.K., Ruderman, N.B., Bain, J.R., Newgard, C.B., Farese, R.V.Jr., Alt, F.W., Kahn, C.R. and Verdin, E. (2010) SIRT3 regulates mitochondrial fatty-acid oxidation by reversible enzyme deacetylation. Nature. 464, 121-126.

Iyer, N.G., Ozdag, H., and Caldas, C. (2004) p300/CBP and cancer. Oncogene. 23(24):4225-31.

James, R.S., Staples, J.F., Brown, J.C., Tessier, S.N., and Storey, K.B. (2013) The effects of hibernation on the contractile and biochemical properties of skeletal muscles in the thirteen-lined ground squirrel, Ictidomys tridecemlineatus. J. Exp. Biol. 216(Pt 14):258794.

Jiang, W., Wang, S., Xiao, M., Lin, Y., Zhou, L., Lei, Q., Xiong, Y., Guan, K-L., and Zhao, S. (2011) Acetylation regulates gluconeogenesis by promoting PEPCK1 degradation via recruiting the UBR5 ubiquitin ligase. Mol. Cell. 43(1):33-44.

Jin, Q., Yu, L-R., Wang, L., Zhang, Z., Kasper, L.H., Lee, J-E., Wang, C., Brindle, P.K., Dent, S.Y.R., and Ge, K. (2011) Distinct roles of GCN5/PCAF-mediated H3K9ac and $\mathrm{CBP} / \mathrm{p} 300-$ mediated $\mathrm{H} 3 \mathrm{~K} 18 / 27 \mathrm{ac}$ in nuclear receptor transactivation. EMBO J. 30(2):249-62.

Jing E., Gesta S. and Kahn C.R. (2007) SIRT2 regulates adipocyte differentiation through FoxO1 acetylation/deacetylation. Cell Metab. 6(2):105-114.

Kalkhoven, E. (2004) CBP and p300: HATs for different occasions. Biochem. Pharmacol. 68(6):1145-55.

Kaltschmidt B., Kaltschmidt C., Hofmann T.G., Hehner S.P., Dröge W. and Schmitz M.L. (2000) The pro- or anti-apoptotic function of NF-kappaB is determined by the nature of the apoptotic stimulus. Eur. J. Biochem. 267(12):3828-3835.

Karin, M. and Ben Neriah, Y. (2000) Phosphorylation meets ubiquitination: the control of NF-kappaB activity. Annu. Rev. Immunol. 18: 621-63.

Karmodiya, K., Krebs, A.R., Oulad-Abdelghani, M., Kimura, H., and Tora, L. (2012) $\mathrm{H} 3 \mathrm{~K} 9$ and $\mathrm{H} 3 \mathrm{~K} 14$ acetylation co-occur at many gene regulatory elements, while $\mathrm{H} 3 \mathrm{~K} 14 \mathrm{ac}$ marks a subset of inactive inducible promoters in mouse embryonic stem cells. BMC Genomics. 13(1):424. 
Kiskinis, E., Hallberg, M., Christian, M., Olofsson, M., Dilworth, S.M., White, R., and Parker, M.G. (2007) RIP140 directs histone and DNA methylation to silence Ucp1 expression in white adipocytes. EMBO J. 26(23):4831-40.

Klar, A.J.S., Fogel, S. and Macleod, K. (1979) MAR1- a regulator of the HMa and HM $\alpha$ loci in Saccharomyces cerevisiae. Genetics. 93, 37-50.

Krivoruchko, A. and Storey, K.B. (2010) Epigenetics in anoxia tolerance: a role for histone deacetylases. Mol. Cell Biochem. 342(1-2):151-61.

Lee, J.S., Smith, E., and Shilatifard, A. (2010) The language of histone crosstalk. Cell. 142(5):682-5.

Lee, K.K. and Workman, J.L. (2007) Histone acetyltransferase complexes: one size doesn't fit all. Nat. Rev. Mol. Cell Biol. 8(4):284-95.

Li, X. and Kazgan, N. (2011) Mammalian Sirtuins and energy metabolism. Int. J. Biol. Sci. 7: 575-587.

Lombard, D.B., Alt, F.W., Cheng, H.L., Bunkenborg, J., Streeper, R.S., Mostoslavsky, R., Kim, J., Yancopoulos, G., Valenzuela, D., Murphy, A., Yang, Y., Chen, Y., Hirschey, M.D., Bronson, R.T., Haigis, M., Guarente, L.P., Farese, R.V.Jr., Weissman, S., Verdin, E. and Schwer, B. (2007) Mammalian Sir2 homolog SIRT3 regulates global mitochondrial lysine acetylation. Mol. Cell Biol. 27: 8807-8814.

Luo, J., Nikolaev, A.Y., Imai, S., Chen, D., Su, F., Shiloh, A., Guarente, L. and Gu, W. (2001) Negative control of p53 by SIR $2 \alpha$ promotes cell survival under stress. Cell 107: 137-148.

Lv, L., Li, D., Zhao, D., Lin, R., Chu, Y., Zhang, H., Zha, Z., Liu, Y., Li, Z., Xu, Y., Wang, G., Huang, Y., Xiong, Y., Guan, K-L., and Lei, Q-Y. (2011) Acetylation targets the M2 isoform of pyruvate kinase for degradation through chaperone-mediated autophagy and promotes tumor growth. Mol. Cell. 42(6):719-30.

Macdonald, J.A. and Storey, K.B. (1998) cAMP-dependent protein kinase from brown adipose tissue: temperature effects on kinetic properties and enzyme role in hibernating ground squirrels. J. Comp. Physiol. B 168(7): 513-25.

Malan, A, and Mioskowski, E. (1988) $\mathrm{pH}$-temperature interactions on protein function and hibernation: GDP binding to brown adipose tissue mitochondria. J. Comp. Physiol. B 158(4): 487-493.

Malatesta, M., Biggiogera, M., Baldelli, B., Barabino, S.M.L., Martin, T.E., and Zancanaro, C. (2008) Hibernation as a far-reaching program for the modulation of RNA transcription. Microsc. Res. Tech. 71, 564-572.

Mao, Z., Hine, C., Tian, X., Meter, M.V., Au, M., Vaidya, A., Seluanov, A. and Gorbunova, V. (2011) SIRT6 promotes DNA repair under stress by activating PARP1. Science 332(6036):1443-1446. 
Melvin, R.G. and Andrews, M.T. (2009) Torpor induction in mammals: recent discoveries fueling new ideas. Trends. Endocrinol. Metab. 20(10):490-498.

Morgan, M.J. and Liu Z.G. (2011) Crosstalk of reactive oxygen species and NF- $\kappa B$ signaling. Cell Res. 21(1):103-115.

Morin, P. and Storey, K.B. (2006) Evidence for a reduced transcriptional state during hibernation in ground squirrels. Cryobiology 53: 310-318.

Morin, P. and Storey, K.B. (2007) Antioxidant defense in hibernation: cloning and expression of peroxiredoxins from hibernating ground squirrels, Spermophilus tridecemlineatus. Arch. Biochem. Biophys. 461(1):59-65.

Morin, P.Jr. and Storey, K.B. (2009) Mammalian hibernation: differential gene expression and novel application of epigenetic controls. Int. J. Dev. Biol. 53, 433-442.

Nagarajan, P., Ge, Z., Sirbu, B., Doughty, C., Garcia, P.A.A., Schlederer, M., Annunziato, A.T., Cortez, D., Kenner, L., and Parthun, M.R. (2013) Histone acetyl transferase 1 is essential for mammalian development, genome stability, and the processing of newly synthesized histones H3 and H4. PLoS Genet. 9(6):e1003518.

Nagy, Z. and Tora, L. (2007) Distinct GCN5/PCAF-containing complexes function as coactivators and are involved in transcription factor and global histone acetylation.

Oncogene. 26(37):5341-57.

Picard, F., Kurtev, M., Chung, N., Topark-Ngarm, A., Senawong, T., de Oliveira., R.M., Leid, M., McBurney, M.W. and Guarente, L. (2004) Sirt1 promotes fat mobilization in white adipocytes by repressing PPAR- $\gamma$. Nature 429, 771-776.

Qiu, X., Brown, K., Hirschey, M.D., Verdin, E. and Chen, D. (2010) Calorie restriction reduces oxidative stress by SIRT3-mediated SOD2 activation. Cell Metab. 12: 662-667.

Rodgers, J.T., Lerin, C., Haas, W., Gygi, S.P., Spiegelman, B.M. and Puigserver, P. (2005) Nutrient control of glucose homeostasis through a complex of PGC-1 $\alpha$ and SIRT1. Nature 434, 113-118.

Roth, S.Y., Denu, J.M., and Allis, C.D. (2001) Histone acetyltransferases. Annu. Rev. Biochem. 70:81-120.

Rothgiesser, K.M., Erener, S., Waibel, S., Lüscher, B. and Hottiger, M.O. (2010) SIRT2 regulates NF- $\kappa$ B dependent gene expression through deacetylation of p65 Lys310. J. Cell Sci. 123(Pt 24):4251-4258.

Rouble, A.N., Hefler, J., Mamady, H., Storey, K.B. and Tessier, S.N. (2013) Antiapoptotic signaling as a cytoprotective mechanism in mammalian hibernation. PeerJ 1:e29.

Schwer, B. and Verdin, E. (2008) Conserved metabolic regulatory functions of sirtuins. Cell Metab. 7, 104-112. 
Scott, I., Webster, B.R., Li, J.H., Sack, M.N. (2012) Identification of a molecular component of the mitochondrial acetyltransferase programme: a novel role for GCN5L1. Biochem. J. 443(3):655-61.

Shahriari, A., Dawson, N.J., Bell, R.A., and Storey, K.B. (2013) Stable suppression of lactate dehydrogenase activity during anoxia in the foot muscle of Littorina littorea and the potential role of acetylation as a novel posttranslational regulatory mechanism. Enzyme Res. 2013:461374.

Shi, T., Wang, F., Stieren, E. and Tong, Q. (2005) SIRT3, a mitochondrial Sirtuin deacetylase, regulates mitochondrial function and thermogenesis in brown adipocytes. $J$. Biol. Chem. 280, 13560-13567.

Smith, J.S., Brachmann, C.B., Celic, I., Kenna, M.A., Muhammad, S., Starai, V.J., Avalos, J.L., Escalante-Semerena, J.C., Grubmeyer, C., Wolberger, C. and Boeke J.D. (2000) A phylogenetically conserved NAD+-dependent protein deacetylase activity in the Sir2 protein family. Proc. Natl. Acad. Sci. USA. 97(12): 6658-6663.

Spange, S., Wagner, T., Heinzel, T., and Krämer, O.H. (2009) Acetylation of non-histone proteins modulates cellular signalling at multiple levels. Int. J. Biochem. Cell Biol. 41(1):185-98.

Sterner, D.E. and Berger, S.L. (2000) Acetylation of histones and transcription-related factors. Microbiology and Molecular Biology Reviews. 64(2):435-459.

Stewart, J.M., English, T.E. and Storey, K.B. (1998) Comparisons of the effects of temperature on the liver fatty acid binding proteins from hibernator and nonhibernator mammals. Biochem. Cell Biol. 76(4):593-599.

Storey, K.B. (2010) Out cold: biochemical regulation of mammalian hibernation - a mini-review. Gerontology. 56, 220-230.

Storey, K.B. and J.M. Storey (2010) Metabolic rate depression: the biochemistry of mammalian hibernation. Adv. Clin. Chem. 52, 77-108.

Storey, K.B. and Storey, J.M. (2004) Metabolic rate depression in animals: transcriptional and translational controls. Biol. Rev. 79(1):207-233.

Storey, K.B. and Storey, J.M. (2011) Heat shock proteins and hypometabolism: adaptive strategy for proteome preservation. Res. Rep. Biol. 2011-2;57-68

Tao, R., Coleman, M.C., Pennington, D.J., Ozden, O., Park, S., Jiang, H., Kim, H., Flynn, C.R., Hill, S., McDonald, W.H., Olivier, A.K., Spitz, D.R. and Gius, D. (2010) Sirt3mediated deacetylation of evolutionarily conserved lysine 122 regulates MnSOD ctivity in response to stress. Mol. Cell. 40, 893-904.

Tessier, S.N. and Storey, K.B. (2010) Expression of myocyte enhancer factor-2 and downstream genes in ground squirrel skeletal muscle during hibernation. Mol. Cell Biochem. 344(1-2):151-62. 
Vallabhapurapu, S. and Karin, M. (2009) Regulation and function of NF-kappaB transcription factors in the immune system. Annu. Rev. Immunol. 27(1):693-733.

Ventura, M., Mateo, F., Serratosa, J., Salaet, I., Carujo, S., Bachs, O., and Pujol, M.J. (2010) Nuclear translocation of glyceraldehyde-3-phosphate dehydrogenase is regulated by acetylation. Int. J. Biochem. Cell Biol. 42(10):1672-80.

Viatour, P., Merville, M-P., Bours, V. and Chariot, A. (2005) Phosphorylation of NF-kB and I $\mathrm{B}$ p proteins: implications in cancer and inflammation. TRENDS in Biochemical Sciences 30: 43-52.

Vucetic, M., Stancic, A., Otasevic, V., Jankovic, A., Korac, A., Markelic, M., Velickovic, K., Golic, I., Buzadzic, B., Storey, K.B. and Korac, B. (2013) The impact of cold acclimation and hibernation on antioxidant defenses in the ground squirrel (Spermophilus citellus): An update. Free Radic. Biol. Med. 65C:916-924.

Wang, F. and Tong, Q. (2009) SIRT2 suppresses adipocyte differentiation by deacetylating FOXO1 and enhancing FOXO1's repressive interaction with PPAR $\gamma$ Mol. Biol. Cell. 20, 801-808.

Wang, F., Nguyen, M., Qin, F.X. and Tong, Q. (2007) SIRT2 deacetylates FOXO3a in response to oxidative stress and caloric restriction. Aging Cell. 6, 505-514.

Wu, C., Biggar, K., and Storey, K. (2013) Biochemical adaptations of mammalian hibernation: exploring squirrels as a perspective model for naturally induced reversible insulin resistance. Braz. J. Med. Biol. Res. 46(1):1-13.

Xiong, Y. and Guan, K-L. (2012) Mechanistic insights into the regulation of metabolic enzymes by acetylation. J. Cell Biol. 198(2):155-64.

Yeung, F., Hoberg, J.E., Ramsey, C.S., Keller, M.D., Jones, D.R., Frye, R.A. and Mayo, M.W. (2004) Modulation of NF-kappaB-dependent transcription and cell survival by the SIRT1 deacetylase. EMBO J. 23(12):2369-80.

Yu, H., Shao, Y., Gao, L., Zhang, L., Guo, K., Wu, C., Hu, X., Duan, H. (2012) Acetylation of sphingosine kinase 1 regulates cell growth and cell-cycle progression. Biochem. Biophys. Res. Commun. 417(4):1242-7.

Zentner, G.E. and Henikoff, S. (2013) Regulation of nucleosome dynamics by histone modifications. Nat. Struct. Mol. Biol. 20(3):259-66.

Zhang, T., Wang, S., Lin, Y., Xu, W., Ye, D., Xiong, Y., Zhao, S., Guan, K-L. (2012) Acetylation negatively regulates glycogen phosphorylase by recruiting protein phosphatase 1. Cell Metab. 15(1):75-87.

Zhao, S., Xu, W., Jiang, W., Yu, W., Lin, Y., Zhang, T., Yao, J., Zhou, L., Zeng, Y., Li, H., Li, Y., Shi, J., An, W., Hancock, S.M., He, F., Qin, L., Chin, J., Yang, P., Chen, X., Lei, Q., Xiong, Y., Guan, K-L. (2010) Regulation of cellular metabolism by protein lysine acetylation. Science. 327(5968):1000-4. 


\section{Appendix A: Antibodies Used for Western Blotting}

\begin{tabular}{|c|c|c|}
\hline Protein Target & Supplier & Associated Product Code \\
\hline SIRT1 & Active Motif & 39354 \\
\hline SIRT2 & Santa Cruz & sc20966 \\
\hline SIRT3 & Genetex & GTX115701 \\
\hline SIRT4 & Santa Cruz & GTX117825 \\
\hline SIRT5 & Genetex & 39912 \\
\hline SIRT6 & Active Motif & GTX105732 \\
\hline SIRT7 & Genetex & GTX110643 \\
\hline HAT1 & Genetex & 3305 \\
\hline GCN5 & Cell Signaling & 3378 \\
\hline PCAF & Cell Signaling & 7389 \\
\hline CBP & Cell Signaling & 9649 \\
\hline H3K9 & Cell Signaling & 4318 \\
\hline H3K14 & Cell Signaling & ab137037 \\
\hline AcSOD2(K68) & Abcam & GTX86963 \\
\hline AcNfkB(K310) & Genetex & 9715 \\
\hline Histone H3 & Cell Signaling & \\
\hline
\end{tabular}


Appendix B: Western Blotting Conditions

\begin{tabular}{|c|c|c|c|c|c|c|c|}
\hline $\begin{array}{c}1^{\mathrm{o}} \\
\text { Antibody } \\
\text { Target }\end{array}$ & Tissue & $\begin{array}{c}\text { Protein } \\
\text { Load } \\
\text { Amount } \\
(\mu \mathrm{g})\end{array}$ & $\begin{array}{c}\text { Gel Percent } \\
\text { Acrylamide (\%) }\end{array}$ & $\begin{array}{l}\text { Run Time } \\
\text { (min) }\end{array}$ & $\begin{array}{l}\text { Membrane } \\
\text { Blocking }\end{array}$ & $\begin{array}{l}1^{\circ} \text { Antibody } \\
\text { Incubation }\end{array}$ & $\begin{array}{l}2^{\circ} \text { Antibody } \\
\text { Incubation }\end{array}$ \\
\hline \multirow{2}{*}{ SIRT1 } & Muscle & 20 & 8 & 45 & $2.5 \%$ milk $20 \mathrm{~min}$ & 1:1000 Overnight & Mouse 1:2000 $30 \mathrm{~min}$ \\
\hline & WAT & 40 & 8 & 45 & $2.5 \%$ milk $20 \mathrm{~min}$ & 1:1000 Overnight & Mouse 1:2000 $30 \mathrm{~min}$ \\
\hline \multirow{2}{*}{ SIRT2 } & Muscle & 15 & 10 & 45 & $5 \%$ milk $30 \mathrm{~min}$ & 1:1000 Overnight & Rabbit 1:8000 $30 \mathrm{~min}$ \\
\hline & WAT & 25 & 10 & 45 & $5 \%$ milk $30 \mathrm{~min}$ & 1:1000 Overnight & Rabbit $1: 800030 \mathrm{~min}$ \\
\hline \multirow{2}{*}{ SIRT3 } & Muscle & 25 & 10 & 45 & Low PVA $45 \mathrm{sec}$ & 1:1000 Overnight & Rabbit 1:4000 $30 \mathrm{~min}$ \\
\hline & WAT & 30 & 10 & 45 & Low PVA $45 \mathrm{sec}$ & 1:1000 Overnight & Rabbit 1:4000 $30 \mathrm{~min}$ \\
\hline \multirow{2}{*}{ SIRT4 } & Muscle & 20 & 12 & 45 & Low PVA $45 \mathrm{sec}$ & 1:1000 Overnight & Rabbit 1:4000 $30 \mathrm{~min}$ \\
\hline & WAT & 30 & 12 & 60 & Low PVA $45 \mathrm{sec}$ & 1:1000 Overnight & Rabbit 1:4000 $30 \mathrm{~min}$ \\
\hline \multirow{2}{*}{ SIRT5 } & Muscle & 25 & 12 & 45 & Low PVA $45 \mathrm{sec}$ & 1:1000 Overnight & Rabbit 1:4000 $30 \mathrm{~min}$ \\
\hline & WAT & 40 & 12 & 60 & Low PVA $45 \mathrm{sec}$ & 1:1000 Overnight & Rabbit 1:4000 $30 \mathrm{~min}$ \\
\hline \multirow{2}{*}{ SIRT6 } & Muscle & 15 & 10 & 65 & Low PVA $45 \mathrm{sec}$ & 1:1000 Overnight & Rabbit 1:4000 $30 \mathrm{~min}$ \\
\hline & WAT & 50 & 10 & 65 & Low PVA $45 \mathrm{sec}$ & 1:1000 Overnight & Rabbit 1:4000 $30 \mathrm{~min}$ \\
\hline \multirow{2}{*}{ SIRT7 } & Muscle & 15 & 10 & 65 & Low PVA $45 \mathrm{sec}$ & 1:1000 Overnight & Rabbit 1:4000 $30 \mathrm{~min}$ \\
\hline & WAT & 60 & 10 & 65 & Low PVA $45 \mathrm{sec}$ & 1:1000 Overnight & Rabbit 1:4000 $30 \mathrm{~min}$ \\
\hline \multirow{4}{*}{ HAT1 } & Liver & 15 & 12 & 80 & $2.5 \%$ milk $30 \mathrm{~min}$ & 1:5000 Overnight & Rabbit 1:4000 $30 \mathrm{~min}$ \\
\hline & Muscle & 15 & 12 & 80 & $2.5 \%$ milk $30 \mathrm{~min}$ & 1:12000 Overnight & Rabbit 1:4000 $30 \mathrm{~min}$ \\
\hline & BAT & 20 & 12 & 80 & $2.5 \%$ milk $30 \mathrm{~min}$ & 1:5000 Overnight & Rabbit 1:4000 $30 \mathrm{~min}$ \\
\hline & WAT & 50 & 12 & 80 & $2.5 \%$ milk $30 \mathrm{~min}$ & 1:5000 Overnight & Rabbit $1: 400030 \mathrm{~min}$ \\
\hline \multirow{4}{*}{ GCN5L2 } & Liver & 10 & 8 & 70 & Low PVA $60 \mathrm{sec}$ & 1:1000 Overnight & Rabbit 1:4000 $30 \mathrm{~min}$ \\
\hline & Muscle & 15 & 8 & 70 & Low PVA $60 \mathrm{sec}$ & 1:1000 Overnight & Rabbit 1:4000 $30 \mathrm{~min}$ \\
\hline & BAT & 30 & 10 & 80 & Low PVA $45 \mathrm{sec}$ & 1:1000 Overnight & Rabbit 1:4000 $30 \mathrm{~min}$ \\
\hline & WAT & 50 & 10 & 80 & Low PVA $45 \mathrm{sec}$ & 1:1000 Overnight & Rabbit 1:2000 $30 \mathrm{~min}$ \\
\hline
\end{tabular}




\begin{tabular}{|c|c|c|c|c|c|c|c|}
\hline \multirow{4}{*}{ PCAF } & Liver & 15 & 8 & 70 & Low PVA $45 \mathrm{sec}$ & 1:1000 Overnight & Rabbit 1:8000 $30 \mathrm{~min}$ \\
\hline & Muscle & 20 & 8 & 70 & Low PVA $45 \mathrm{sec}$ & 1:1000 Overnight & Rabbit $1: 800030 \mathrm{~min}$ \\
\hline & BAT & 30 & 10 & 80 & Low PVA $45 \mathrm{sec}$ & 1:1000 Overnight & Rabbit 1:4000 $30 \mathrm{~min}$ \\
\hline & WAT & 50 & 10 & 60 & Low PVA $45 \mathrm{sec}$ & 1:1000 Overnight & Rabbit 1:4000 $30 \mathrm{~min}$ \\
\hline \multirow{4}{*}{$\mathrm{CBP}$} & Liver & 5 & 6 & 120 & $2.5 \%$ milk $30 \mathrm{~min}$ & 1:1000 Overnight & Rabbit $1: 150060 \mathrm{~min}$ \\
\hline & Muscle & 20 & 6 & 120 & $2.5 \%$ milk $30 \mathrm{~min}$ & 1:1000 Overnight & Rabbit 1:4000 $30 \mathrm{~min}$ \\
\hline & BAT & 30 & 6 & 120 & $2.5 \%$ milk $30 \mathrm{~min}$ & 1:1000 Overnight & Rabbit 1:4000 $30 \mathrm{~min}$ \\
\hline & WAT & 60 & 6 & 120 & $2.5 \%$ milk $30 \mathrm{~min}$ & 1:1000 Overnight & Rabbit 1:1500 $60 \mathrm{~min}$ \\
\hline \multirow{4}{*}{ H3K9 } & Liver & 5 & 15 & 45 & $2.5 \%$ milk $20 \mathrm{~min}$ & 1:1000 Overnight & Rabbit 1:4000 $30 \mathrm{~min}$ \\
\hline & Muscle & 15 & 15 & 45 & $2.5 \%$ milk $20 \mathrm{~min}$ & 1:1000 Overnight & Rabbit 1:4000 $30 \mathrm{~min}$ \\
\hline & BAT & 30 & 15 & 45 & $2.5 \%$ milk $20 \mathrm{~min}$ & 1:1000 Overnight & Rabbit 1:4000 $30 \mathrm{~min}$ \\
\hline & WAT & 50 & 15 & 45 & $2.5 \%$ milk $30 \mathrm{~min}$ & 1:1000 Overnight & Rabbit 1:4000 $30 \mathrm{~min}$ \\
\hline \multirow{4}{*}{$\mathrm{H} 3 \mathrm{~K} 14$} & Liver & - & - & - & - & - & - \\
\hline & Muscle & - & - & - & - & - & - \\
\hline & BAT & 30 & 15 & 45 & Low PVA $45 \mathrm{sec}$ & 1:1000 Overnight & Rabbit 1:4000 $30 \mathrm{~min}$ \\
\hline & WAT & - & - & - & - & - & - \\
\hline \multirow{4}{*}{$\begin{array}{c}\text { SOD2 } \\
\text { (acetyl- } \\
\text { K68) }\end{array}$} & Liver & 5 & 15 & 45 & $2.5 \%$ milk $20 \mathrm{~min}$ & 1:1000 Overnight & Rabbit 1:4000 $30 \mathrm{~min}$ \\
\hline & Muscle & 15 & 15 & 45 & $2.5 \%$ milk $20 \mathrm{~min}$ & 1:1000 Overnight & Rabbit 1:4000 $30 \mathrm{~min}$ \\
\hline & BAT & 30 & 15 & 45 & $2.5 \%$ milk $20 \mathrm{~min}$ & 1:1000 Overnight & Rabbit 1:4000 $30 \mathrm{~min}$ \\
\hline & WAT & 50 & 15 & 45 & $2.5 \%$ milk $20 \mathrm{~min}$ & 1:1000 Overnight & Rabbit 1:4000 $30 \mathrm{~min}$ \\
\hline \multirow{4}{*}{$\begin{array}{c}\text { NFkB p65 } \\
\text { (acetyl- } \\
\text { K310) }\end{array}$} & Liver & 5 & 10 & 95 & $2.5 \%$ milk $20 \mathrm{~min}$ & 1:2000 Overnight & Rabbit 1:4000 $30 \mathrm{~min}$ \\
\hline & Muscle & 5 & 12 & 155 & Low PVA $45 \mathrm{sec}$ & 1:2000 Overnight & Rabbit 1:4000 $30 \mathrm{~min}$ \\
\hline & BAT & 15 & 10 & 95 & $2.5 \%$ milk $20 \mathrm{~min}$ & 1:1000 Overnight & Rabbit 1:4000 $30 \mathrm{~min}$ \\
\hline & WAT & 50 & 10 & 95 & $2.5 \%$ milk $20 \mathrm{~min}$ & 1:1000 Overnight & Rabbit 1:4000 $30 \mathrm{~min}$ \\
\hline
\end{tabular}




\section{Appendix C: Validation of Commercial Activity Assays}

The commercial activity assays used in this thesis - Epigenase Universal SIRT Activity/Inhibition Assay Kit (CAT\#: P-4036-96) and EpiQuick Hat Activity/Inhibition Assay Kit (CAT\#: P-4003-96), both from Epigentek (Farmingdale, NY) - were subject to rigorous validation and quality control measures by the manufacturer. However, to be certain of the validity of the results obtained from these assays when used with the ground squirrel tissues studied in this thesis, additional tests were performed. These validation measures are described herein.

\section{Epigenase Universal SIRT Activity/Inhibition Assay Kit (Epigentek)}

\section{Determination of protein load}

The amount of protein loaded into each assay well was based on the manufacturer's recommendations for the working range of the activity assay $(0.5-20 \mu \mathrm{g})$ - the final amount used for each tissue tested was within this range. Additionally, a dose-response curve was generated using protein extracted from liver tissue of I. tridecemlineatus to ensure that the manufacturer's directions were applicable to my system, and that the chosen load amounts would not produce signal saturation. This curve demonstrated that protein load amounts of up to at least $15 \mu \mathrm{g}$ did not produce signal saturation, confirming that the final load amounts chosen for the assay ( 8 or $13 \mu \mathrm{g}$, depending on the tissue) were indeed appropriate.

\section{Signal within effective range of assay}

The absorbance of each assay well was determined to be well within the effective range specified by the manufacturer $\left(\mathrm{OD}_{450 \mathrm{~nm}}\right.$ between approximately 0.1 and 1.6$)$, thus further ensuring the validity of the results.

\section{Confirmation of select results}

To provide a) confirmation that the relative SIRT activities observed at $37^{\circ} \mathrm{C}$ and $4^{\circ} \mathrm{C}$ in BAT were in fact not significantly different (Chapter 4), as opposed to being simply saturated, and $b$ ) further validate the assay, the experiments with BAT were repeated under the same conditions but using a lower protein load (6 $\mu \mathrm{g}$ instead of $13 \mu \mathrm{g}-$ approximately half the original load). Under these conditions, the observed relative activities demonstrated the same relationship (no difference between $37^{\circ} \mathrm{C}$ and $4^{\circ} \mathrm{C}$ ), whereas the actual activities were approximately halved, as expected. This confirmed the validity of the original BAT data and the overall reliability of the assay. 


\section{EpiQuick Hat Activity/Inhibition Assay Kit (Epigentek)}

\section{Determination of protein load}

The amount of protein loaded into each assay well was based on the manufacturer's recommendations for the working range of the activity assay (4-20 $\mu \mathrm{g})$.

Signal within effective range of assay

The absorbance of each assay well was determined to be well within the effective range specified by the manufacturer $\left(\mathrm{OD}_{450 \mathrm{~nm}}\right.$ between approximately 0.1 and 1.4$)$, thus further ensuring the validity of the results. 


\section{Appendix D: Data Collected External to Thesis}

Two western blotting studies focusing on SIRT protein expression in liver and BAT of $I$. tridecemlineatus were carried out by A.N.Rouble external to his M.Sc. thesis work. The results of those studies are shown below in Fig. D1 and D2.

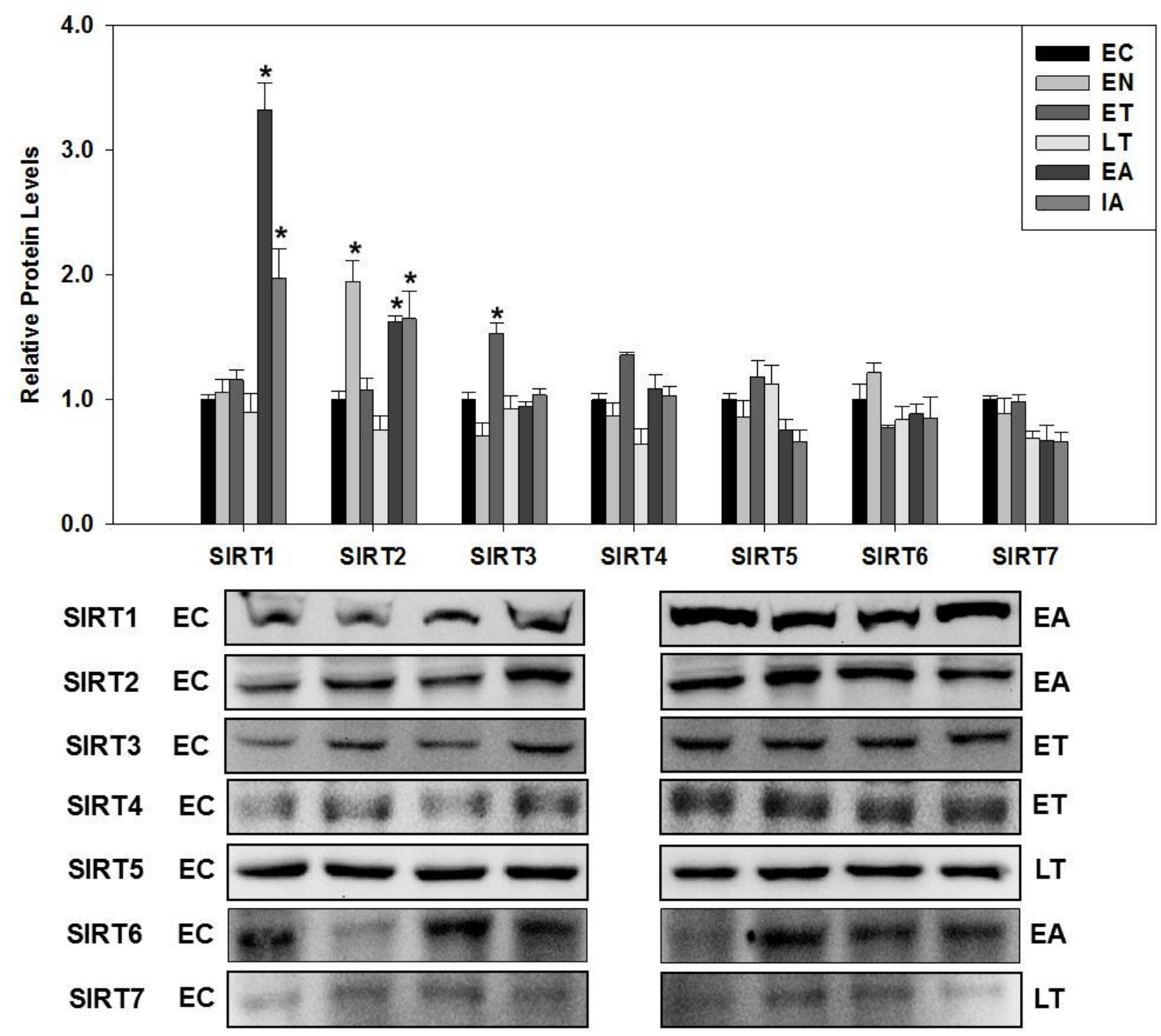

Fig. D1. Relative protein expression of SIRT1, SIRT2, SIRT3, SIRT4, SIRT5, SIRT6 and SIRT7 in liver of I. tridecemlineatus over the torpor-arousal cycle. Representative protein bands are shown for selected sampling points (labelled to the left and right of the blots). Histogram shows mean standardized band densities ( \pm SEM, $n=3-4$ independent trials on tissue from different animals). Protein bands were standardized against the summed intensity of a group of Coomassie-stained protein bands from the same sample lane. Data were analyzed using a one-way ANOVA with a post hoc Tukey test. * = Significantly different from the respective EC control, $\mathrm{p}<0.05$. 


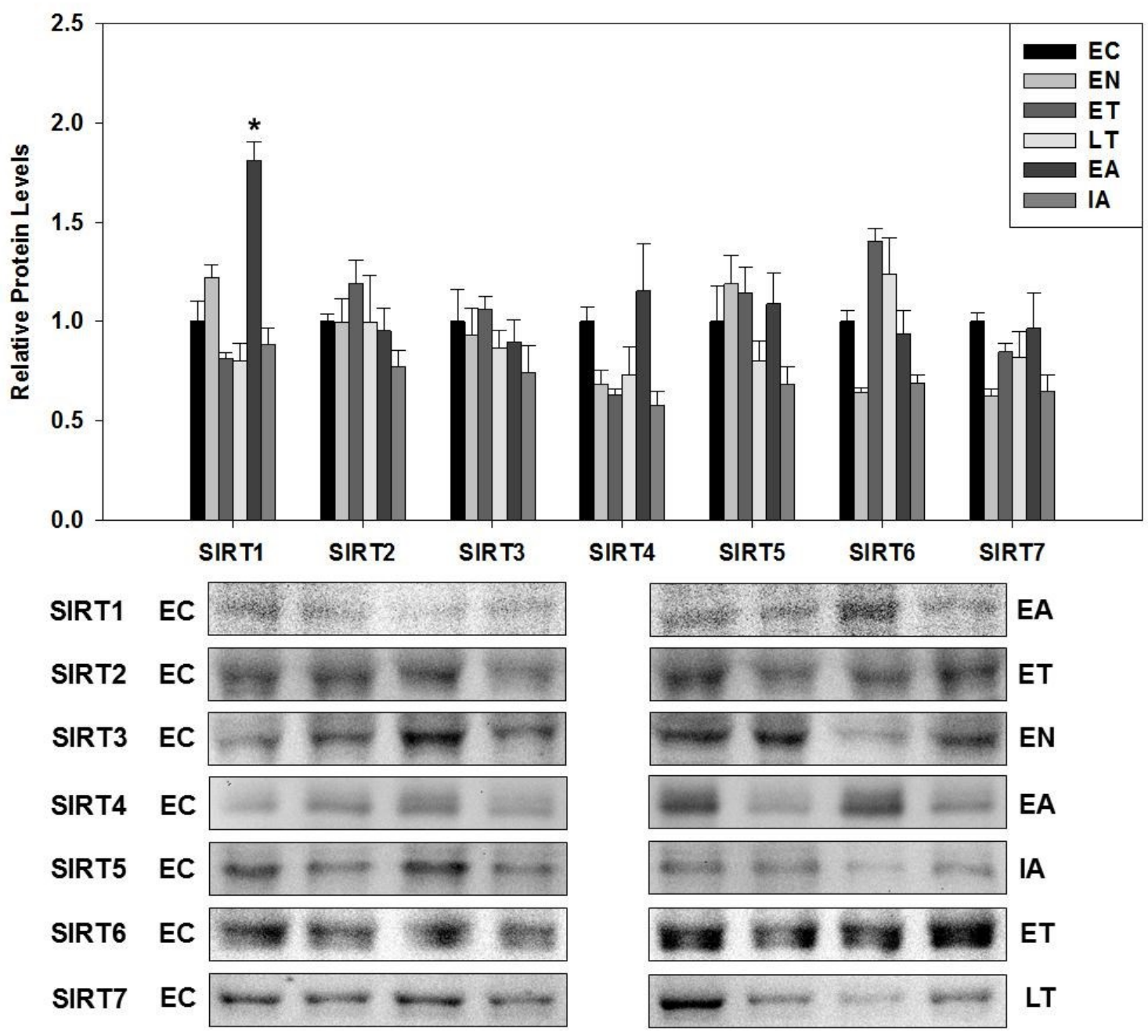

Fig. D2. Relative protein expression of SIRT1, SIRT2, SIRT3, SIRT4, SIRT5, SIRT6 and SIRT7 in BAT of I. tridecemlineatus over the torpor-arousal cycle. All other information as in Fig. D1. 


\section{Appendix E: Loading Controls for Western Blotting}

While the use of house-keeping genes is an established and necessary way to standardize protein expression signals in many types of experiments, our unique system allows us to employ a different form of loading control. Instead of standardizing our western blot signals to the corresponding band intensity of a given house-keeping gene (e.g. tubulin), we standardize our measurements to the combined intensity of a group of Coomassiestained protein bands from the same sample lane, chosen based on their lack of variation between experimental conditions and location far from the protein band of interest (as described in Chapter 2). We are able to use this method because previous studies have shown that the majority (95-99\%) of proteins found within hibernator tissues do not fluctuate significantly throughout the course of hibernation, so most proteins in our system could in this sense act as "house-keeping genes". Thus, by considering representative measurements of total protein (e.g. Coomassie-stained bands), we account for the possibility of uneven loading.

A representative Coomassie-stained blot is shown below (Fig. E1), which was used to standardize the relative protein levels of histone $\mathrm{H} 3$ acetylated at lysine 9 (H3K9) in skeletal muscle of I. tridecemlineatus for EC, ET and LT time points (Chapter 3 - Fig. 3.7). The bands corresponding to $\mathrm{H} 3 \mathrm{~K} 9$ are shown below their respective Coomassiestained protein lanes. 


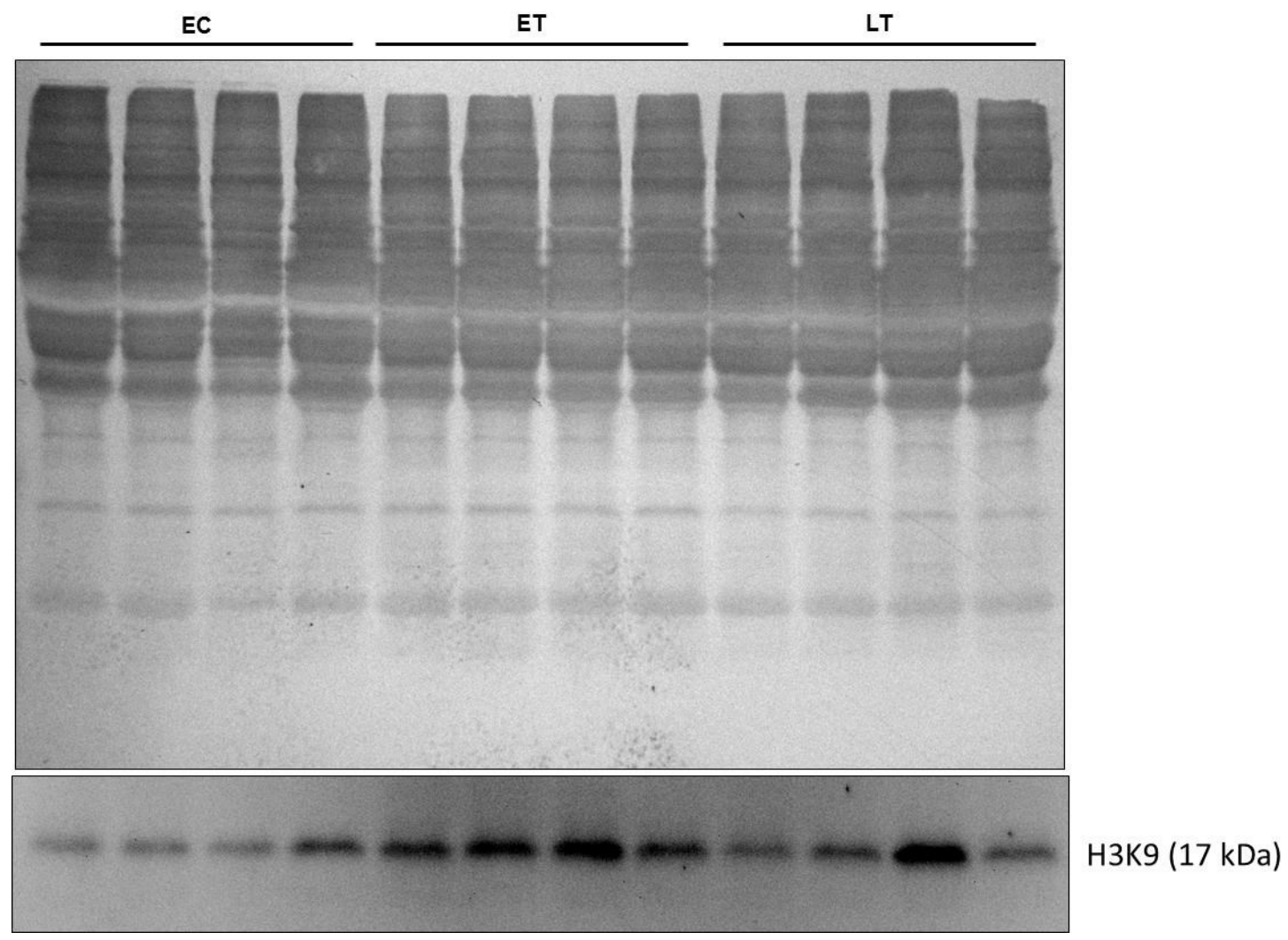

Fig. E1. Representative protein bands are shown for selected sampling points (labelled above blot) for $\mathrm{H} 3 \mathrm{~K} 9$ protein expression in skeletal muscle of I. tridecemlineatus (Chapter 3 - Fig. 3.7). Protein bands were standardized against the summed intensity of a group of Coomassie-stained protein bands from the same sample lane (Coomassie-stained blot shown above H3K9 bands). 


\section{Appendix F: Mechanistic Details for Commercial Activity Assays}

The commercial activity assays used in this thesis - Epigenase Universal SIRT Activity/Inhibition Assay Kit (CAT\#: P-4036-96) and EpiQuick Hat Activity/Inhibition Assay Kit (CAT\#: P-4003-96), both from Epigentek (Farmingdale, NY) - utilize an antibody-based method for the measurement of SIRT and KAT activities.

An outline of the Epigenase Universal SIRT Activity/Inhibition Assay Kit (CAT\#: P4036-96) mechanism is displayed below (Fig. F1). An acetylated SIRT-targeted histone peptide is stably coated to the inside of the wells of a 96-well microplate, in which protein extracts (or purified enzymes) containing SIRT activity are added. The SIRTactive samples deacetylate the histone peptide, which is then specifically recognized by a primary antibody (i.e. an antibody with specificity only for the deacetylated peptide). A secondary antibody conjugated to horse-radish peroxidase (HRP) then recognizes the primary antibody; oxidation of the chromogenic substrate TMB $(3,3$ ',5,5'-

Tetramethylbenzidine) by HRP produces a blue color, the intensity of which can be quantified by a spectrophotometer $(\lambda=650 \mathrm{~nm})$. The oxidation reaction is stopped by the addition of sulphuric acid, which changes the solution to a yellow color (absorbance read at $\lambda=450 \mathrm{~nm}$ ). The change in absorbance compared to a blank well is then directly proportional to the SIRT activity.
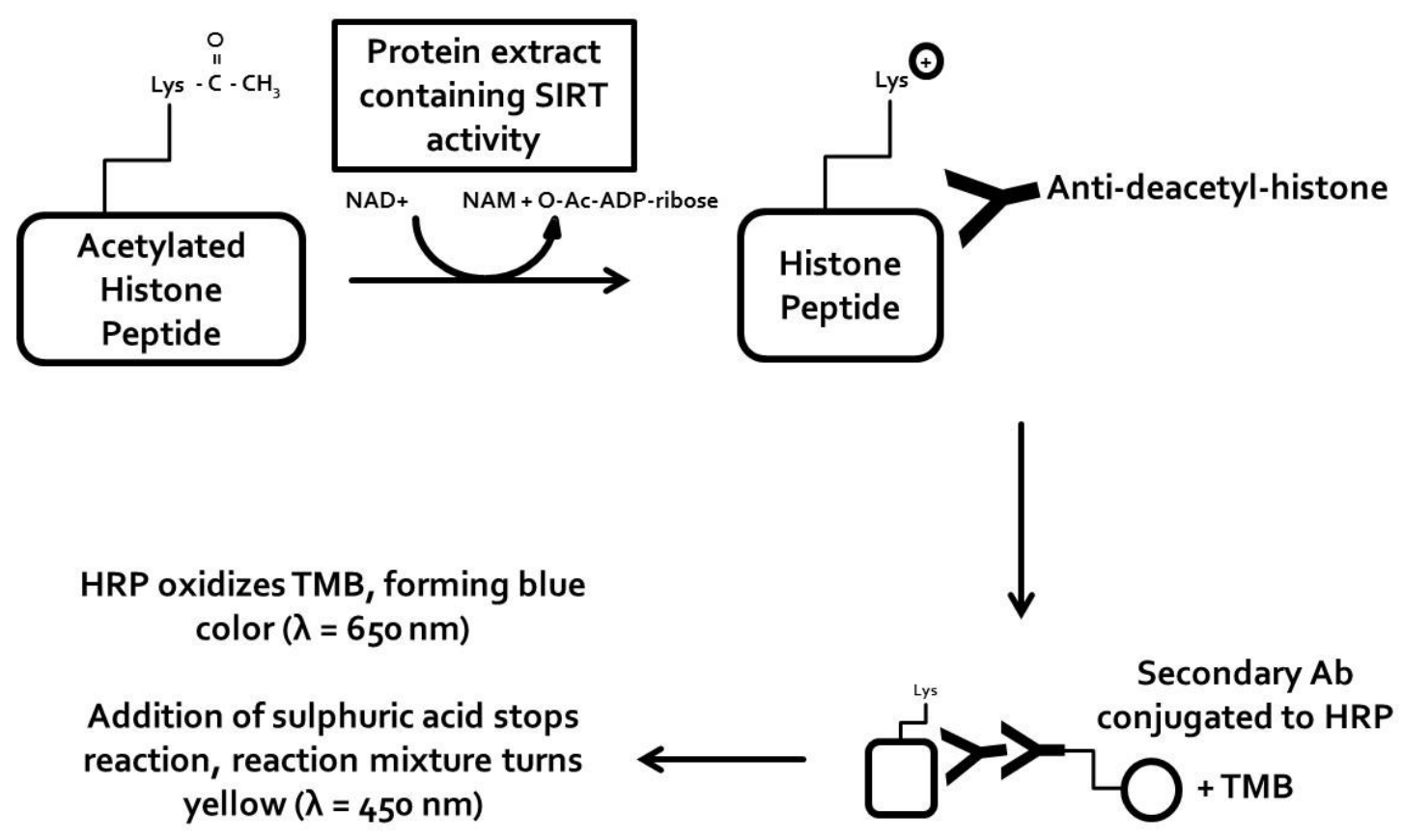

Fig. F1. Mechanism of function of the Epigenase Universal SIRT Activity/Inhibition Assay Kit (CAT\#: P-4036-96).

The same principle is used in the EpiQuick Hat Activity/Inhibition Assay Kit (CAT\#: P4003-96), only the initial peptide is not acetylated, and the primary antibody is specific for the acetylated peptide. 
Further information can be found on the manufacturer's website.

Epigenase Universal SIRT Activity/Inhibition Assay Kit (CAT\#: P-4036-96):

http://www.epigentek.com/catalog/epigenase-universal-sirt-activityinhibition-assay-kitcolorimetric-p-2882.html

EpiQuick Hat Activity/Inhibition Assay Kit (CAT\#: P-4003-96):

http://www.epigentek.com/catalog/epiquik-hat-activityinhibition-assay-kit-p-951.html 


\section{Appendix G: Justification of Tissue and Target Choices}

This thesis focused on the characterization of several specific SIRT and KAT protein targets in the context of four different tissues of the 13-lined ground squirrel ( $I$. tridecemlineatus) over the course of hibernation. These tissues were chosen due to their important roles in maintaining the torpor-arousal cycle. The protein targets were chosen based on their relevance to pathways which are implicated in the regulation of hibernation.

\section{Tissues (reference: Carey et al., 2003)}

Liver - the liver of the mammalian hibernator is essential to the regulation of the energy balance that must be maintained during torpor. Specifically, the liver plays an integral role in the mobilization of fat stores, aiding in the transition to a lipid-based energy economy that is required during hibernation. Understanding the mechanisms that promote such a drastic shift in the energy dynamics of the body is of great potential interest to researchers studying diseases of metabolic degeneracy (e.g. obesity, diabetes).

Skeletal Muscle - skeletal muscle is particularly important for the hibernator during arousal, when it contributes to the rewarming process via shivering thermogenesis. Skeletal muscle is also an interesting topic of study due to its ability to avoid significant atrophy during the prolonged periods of inactivity that characterize hibernation. Understanding the molecular basis of this ability is of interest for practical reasons, as such mechanisms may be applicable to the treatment of human diseases/conditions that involve muscle wasting.

Brown Adipose Tissue (BAT) - brown adipose tissue is essential to the rewarming that occurs during arousal from torpor. Specialized mitochondria in BAT are capable of uncoupling ATP production from the electron transport chain, such that the energy of the system is instead dissipated as heat. Understanding the molecular mechanisms that lead to the rapid activation of BAT thermogenesis is of great interest to obesity research, as the ability to turn cellular energy into heat is a potentially ideal way to quickly decrease fat stores.

White Adipose Tissue (WAT) - white adipose tissue is ultimately responsible for sustaining the energy requirements of the hibernator throughout the hibernation season. Accumulated fat deposits are stored in WAT during the months leading up to hibernation; during winter, WAT is responsible for mobilizing those fat stores to fuel the energy requirements of the torpid animal. Without this stored energy, the hibernator would not be able to survive the winter months. The molecular regulation of the significant fatmobilization and lipolysis that occurs in hibernator WAT is also of interest to obesity research. 


\section{Protein Targets}

Table G1 outlines some of the known functions of the SIRT and KAT protein targets characterized in this thesis which are potentially relevant to the hibernator system, and which are thus the reasons these factors were chosen for study.

Table G1. SIRT and KAT targets studied in this thesis, and their hibernation-relevant functions

\begin{tabular}{|c|c|c|}
\hline$\frac{\text { Chosen }}{\text { Target(s) }}$ & Hibernation-Relevant Functions & $\underline{\text { References }}$ \\
\hline $\begin{array}{l}\text { SIRTs } \\
(\text { SIRT1-7) }\end{array}$ & $\begin{array}{ll}\text { - } & \text { Promote oxidative stress responses } \\
\text { - } & \text { Regulate cellular protective responses (e.g. } \\
\text { anti-apoptosis, neuroprotection) } \\
\text { - } & \text { Regulation of transcription (epigenetic and } \\
& \text { targeting of transcription factors) } \\
\text { - } & \text { Regulation of thermogenesis (SIRT3) } \\
\text { - } & \text { Lipid metabolism }\end{array}$ & $\begin{array}{l}\text { Chapter } 4 \\
\text { Haigis and } \\
\text { Sinclair, } 2010 \\
\text { Li and Kazgan, } \\
2011 \\
\text { Morin and Storey, } \\
2009 \\
\text { Shi et al., } 2005\end{array}$ \\
\hline CBP & $\begin{array}{ll}\text { - } & \text { Transcriptional regulation (major } \\
& \text { transcriptional co-activator) } \\
\text { - } & \text { Histone acetylation (epigenetic regulation of } \\
& \text { transcription) } \\
- & \text { Cellular protective responses } \\
\text { - } & \text { Metabolic regulation }\end{array}$ & $\begin{array}{l}\text { Chapter } 3 \\
\text { Spange } \text { et al., } \\
2009 \\
\text { Kalkhoven, } 2004 \\
\text { Iyer } \text { et al., } 2004 \\
\text { Ghizzoni et al., } \\
2011\end{array}$ \\
\hline PCAF & $\begin{array}{ll}- & \text { Regulation of carbohydrate metabolism } \\
- & \text { Transcriptional regulation (major } \\
\text { transcriptional co-activator) } \\
\text { - }\end{array}$ & $\begin{array}{l}\text { Chapter } 3 \\
\text { Lv et al., } 2011 \\
\text { Jin et al., } 2011 \\
\text { Nagy and Tora, } \\
2007 \\
\text { Karmodiya et al., } \\
2012 \\
\text { Ghizzoni et al., } \\
2011\end{array}$ \\
\hline GCN5L2 & $\begin{array}{ll}- & \text { Transcriptional regulation (major } \\
& \text { transcriptional co-activator) } \\
- & \text { Histone acetylation (epigenetic regulation of } \\
& \text { transcription) } \\
- & \text { Lipid metabolism }\end{array}$ & $\begin{array}{l}\text { Chapter } 3 \\
\text { Dominy et al., } \\
2010 \\
\text { Jin et al., } 2011 \\
\text { Nagy and Tora, } \\
2007 \\
\text { Karmodiya et al., } \\
2012\end{array}$ \\
\hline HAT1 & $\begin{array}{ll}\text { - Histone acetylation (epigenetic regulation of } \\
\text { transcription) }\end{array}$ & $\begin{array}{l}\text { Chapter } 3 \\
\text { Nagarajan } \text { et al., } \\
2013 \\
\text { Roth } \text { et al., } 2001\end{array}$ \\
\hline
\end{tabular}




\section{Appendix H: Methods for the Measurement of Cellular Oxidative Damage}

Cellular oxidative stress can be quantified using measurements of oxidative damage to cellular macromolecules. Table H1 outlines methods for the measurement of oxidative damage to different cellular macromolecules.

Table H1. Methods for the measurement of oxidative damage to cellular macromolecules

\begin{tabular}{|c|l|}
\hline Macromolecule & \multicolumn{1}{|c|}{ Method for Measurement of Oxidative Damage } \\
\hline Lipids & $\begin{array}{l}\text { TBARS Assay - measures thiobarbituric acid reactive substances } \\
\text { (TBARS), which are products of the oxidative degradation of lipids. } \\
\text { In this assay, thiobarbituric acid reacts with malondialdehyde } \\
\text { (MDA, an end product of lipid peroxidation) to form an adduct that } \\
\text { can be measured colorimetrically at 530-540 nm or fluorometrically } \\
\text { at an excitation wavelength of 530 nm and an emission wavelength } \\
\text { of 550 nm. } \\
\text { Commercial TBARS Assay: } \\
\text { https://www.caymanchem.com/app/template/Product.vm/catalog/10 }\end{array}$ \\
$\begin{array}{l}\text { 009055 } \\
\text { Double Derivative Spectroscopy - measures conjugated dienes, } \\
\text { which are chemical intermediates of lipid peroxidation. } \\
\text { Xylenol Orange Complex Formation - measures the formation of } \\
\text { a complex between xylenol orange (an organic reagent which } \\
\text { changes color when complexed with certain ions) and Fe (III). Fe } \\
\text { (II) is oxidized to Fe (III) by lipid hydroperoxides (by-products of } \\
\text { lipid oxidation) - the xylenol orange-complexed Fe (III) can then be } \\
\text { detected colorimetrically at 550-570 nm. }\end{array}$ \\
\hline DNA & $\begin{array}{l}\text { 8-oxo-dG Assay - measures levels of 8-hydroxy-2'-deoxyguanosine } \\
\text { (8-oxo-dG), the product of guanosine hydroxylation (oxidative } \\
\text { damage to guanine residues of DNA). 8-oxo-dG can be detected } \\
\text { using an antibody with specificity for the residue, making this } \\
\text { detection method available in high-throughput formats (e.g. } \\
\text { ELISAs). }\end{array}$ \\
\hline Proteins & $\begin{array}{l}\text { Carbonyl Assay - measures protein carbonyl groups, which can } \\
\text { arise as a result of the oxidation of amino-acid side chains. } \\
\text { Carbonyls can be measured spectrophotometrically or by ELISA } \\
\text { techniques. }\end{array}$ \\
\hline
\end{tabular}

